NATIONAL LABORATORY

\title{
Making the Traffic Operations Case for Congestion Pricing: Operational Impacts of Congestion Pricing
}

\author{
July 2010
}

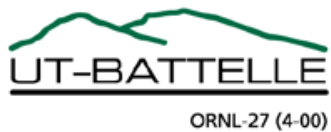




\section{DOCUMENT AVAILABILITY}

Reports produced after January 1, 1996, are generally available free via the U.S. Department of Energy (DOE) Information Bridge.

Web site http://www.osti.gov/bridge

Reports produced before January 1, 1996, may be purchased by members of the public from the following source.

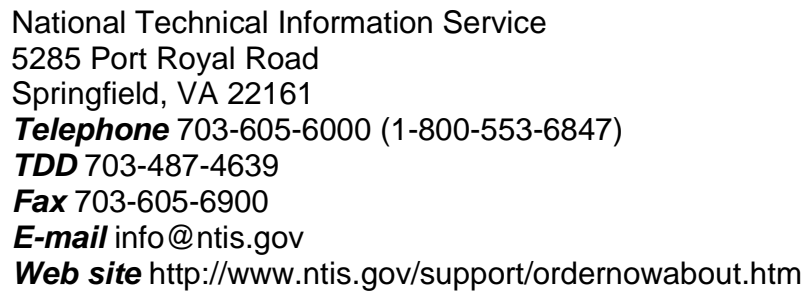

Reports are available to DOE employees, DOE contractors, Energy Technology Data Exchange (ETDE) representatives, and International Nuclear Information System (INIS) representatives from the following source.

Office of Scientific and Technical Information

P.O. Box 62

Oak Ridge, TN 37831

Telephone 865-576-8401

Fax 865-576-5728

E-mail reports@osti.gov

Web site http://www.osti.gov/contact.html

This report was prepared as an account of work sponsored by an agency of the United States Government. Neither the United States Government nor any agency thereof, nor any of their employees, makes any warranty, express or implied, or assumes any legal liability or responsibility for the accuracy, completeness, or usefulness of any information, apparatus, product, or process disclosed, or represents that its use would not infringe privately owned rights. Reference herein to any specific commercial product, process, or service by trade name, trademark, manufacturer, or otherwise, does not necessarily constitute or imply its endorsement, recommendation, or favoring by the United States Government or any agency thereof. The views and opinions of authors expressed herein do not necessarily state or reflect those of the United States Government or any agency thereof. 


\title{
Energy and Transportation Science Division
}

\section{MAKING THE TRAFFIC OPERATIONS CASE FOR CONGESTION PRICING: OPERATIONAL IMPACTS OF CONGESTION PRICING}

\author{
Patricia S. Hu \\ Shih-Miao Chin \\ Diane Davidson
}

July 2010

Prepared by

OAK RIDGE NATIONAL LABORATORY

Oak Ridge, Tennessee 37831-6283

managed by

UT-BATTELLE, LLC

for the

U.S. DEPARTMENT OF ENERGY

under contract DE-AC05-00OR22725 



\section{TABLE OF CONTENTS}

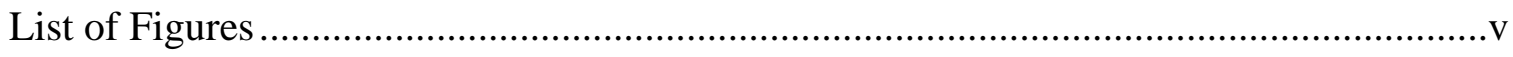

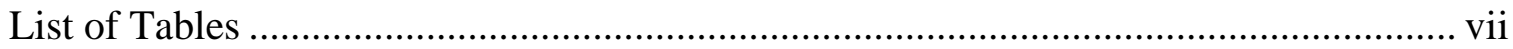

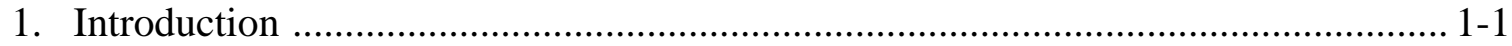

1.1 Background and Project Objectives ........................................................ 1-1

1.2 Report Organization ......................................................................... 1-5

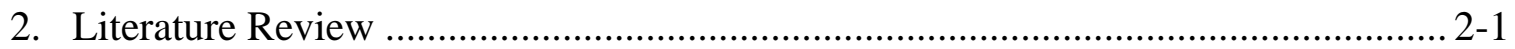

2.1 Measuring Impacts of Pricing .................................................................... 2-1

2.2 Case Studies of Performance Impacts of Pricing in U.S. ........................... 2-7

2.3 International Experience ................................................................... 2-13

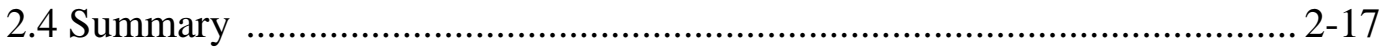

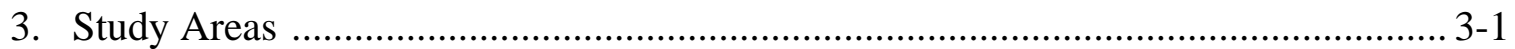

3.1 System and Network Description of MnPASS on I-394 ............................ 3-1

3.2 System and Network Description of I-95 Study Corridor ........................... 3-3

4. Estimated Impacts of HOT Express Lanes on I-394 ............................................ 4-1

4.1 Description of Simulation Model, VISSIM ................................................ 4-1

4.2 Traffic Data and Calibration ..................................................................... 4-3

4.3 Simulation Results and Estimated Impacts .............................................. 4-7

5. Impacts of Congestion Pricing on Traffic on the I-95 Corridor ..............................5-1

5.1 Description and Evaluation of Traffic Analysis and Simulation Models ...... 5-1

5.2 Traffic Data and Calibration ............................................................... 5-2

5.3 Simulation Results and Estimated Facility-Based Impacts ......................... 5-6

5.4 Impact of Congestion Pricing on Traffic Diversion .................................. 5-10

5.5 Congestion Pricing Impacts on the Study Area ....................................... 5-21

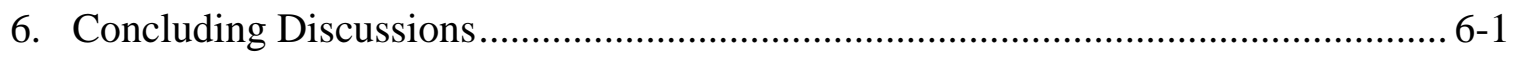

6.1 Impacts of Congestion Pricing.................................................................. 6-1

6.2 Lessons Learned and Recommended Future Activities ............................... 6-8 


\section{LIST OF FIGURES}

Figure

$\underline{\text { Page }}$

1.1 Sources of congestion .............................................................................. 1-2

3.1 MnPASS Express Lane locations on I-394 ................................................... 3-1

3.2 Schematic map of the study area on I-394 .................................................. 3-2

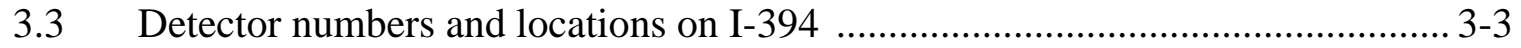

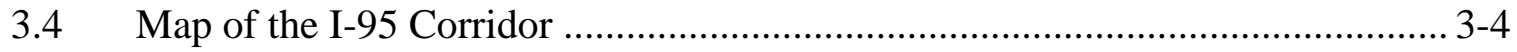

3.5 Locations of CHARTS traffic detectors ...................................................... 3-5

3.6 I-95 study corridor network representation used in DynusT ............................. 3-6

4.1 I-394 traffic detector identification numbers and locations; the simulation locations are denoted by red dots ................................................................. 4-3

4.2 Roadway geometry of I-394 study area .................................................... 4-4

4.3 Example of noticeable differences between the actual and simulated data ....... 4-5

4.4 Example of trivial differences between the actual and simulated data .............. 4-6

4.5 Speed and throughput comparisons of the general-purpose lanes at Xenia

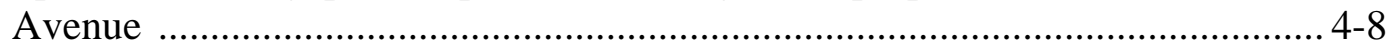

4.6 Speed and throughput comparisons of the general-purpose lanes at TH $100 \ldots . . .4$ 4-9

4.7 Speed and throughput comparisons of ramp to TH 100 ............................... 4-10

5.1 Questionable throughput data ................................................................. 5-4

5.2 Representation of the I-95 Study area as represented in DynusT ...................... 5-5

5.3 Throughput, speed and land density of link 370 on I-95 no toll scenario .......... 5-7

5.4 Comparison of speed profiles at Cherry Hill ............................................... 5-8

5.5 Throughput comparison at Cherry Hill ............................................................ 5-9

5.6 Differences and cumulative differences in throughput due to different tolls .... 5-12

5.7 Simulated Routes of An "Unwilling/Unable to Pay” Driver, Vehicle No. 480, Comparing No Toll to 20థ Toll ................................................................. 5-14

5.8 Simulated Routes of An “Indifferent” Driver, Vehicle No. 1327, Comparing No Toll to 20థ Toll .......................................................................................... 5-15

5.9 Simulated Routes of A “Somewhat Indifferent” Driver, Vehicle No. 108, Comparing No Toll to 20 $\$$ Toll ................................................................ 5-16

5.10 Simulated Routes of A “Newcomer,” Vehicle No. 108, Comparing No Toll to $20 \notin$ Toll ................................................................................................. 5-17

5.11 Distribution of Drivers Categorized by Their Route Choice Decisions, When a 20\& Toll Is Imposed ......................................................................... 5-18

5.12 Distribution of drivers categorized by their route choice decisions when various tolls are imposed ....................................................................... 5-20

5.13 Toll-resulted differences in traffic operations on area off I-95 SB................... 5-24

5.14 Toll-Induced Differences in Traffic Operations on I-95 SB (46 Links) ............ 5-26

5.15 Impacts on the entire network when tolls are imposed on I-95 study corridor.. 5-29

5.16 Congestion pricing impacts on travel speed and total delay, on the tolled system, the adjacent network, and the entire network 
6.1 Speed profiles at the general-purpose lanes at Xenia Avenue........................... 6-3

6.2 Comparison of speed profiles at Cherry Hill on I-95 SB................................. 6-4

6.3 Differences in throughput and cumulative throughput between toll and no-toll scenarios at Cherry Hill ....

6.4 Distribution of drivers categorized by their route choice decisions, when various tolls are imposed ................................................................... 6-6

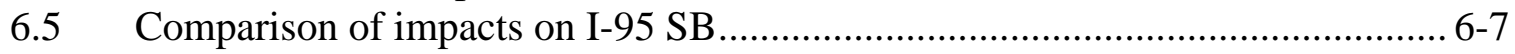

6.6 Percent difference on the entire network ................................................. 6-10 


\section{LIST OF TABLES}

Table

Page

2.1 Measuring Freeway Throughput Performance ................................................... 2-3

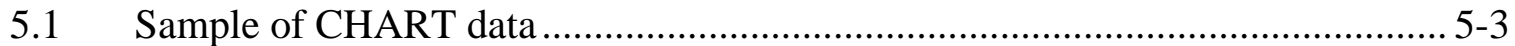

5.2 Possible Diversion Scenarios When a Toll is Imposed ................................... 5-11

5.3 Simulated Trajectories of An “Unwilling/Unable to Pay,” Vehicle No. 480, Comparing No Toll to 20\$ Toll $5-13$

5.4 Simulated Trajectories of An “Indifferent” Driver, Vehicle No. 1327, Comparing No Toll to 20థ Toll 5-15

5.5 Simulated Trajectories of A “Somewhat Indifferent” Driver, Vehicle No. 108, Comparing No Toll to 20థ Toll .............................................................. 5-16

5.6 Simulated Trajectories of A “Newcomer,” Vehicle No. 953, Comparing No Toll to 20థ Toll ................................................................................................. 5-17

5.7 Summary of Toll-Induced Traffic Diversion on I-95 Study Corridor ............... 5-19

5.8 Congestion Pricing Impacts on Area off I-95 SB ......................................... 5-23

5.9 Congestion Pricing Impacts on I-95 SB (46 Links)...................................... 5-25

5.10 Congestion Pricing Impacts on the Entire I-95 Study Network ....................... 5-28

5.11 Percent Different Due to Toll, by Toll Scenario and Location......................... 5-30

4.1 Impacts of HOT Lanes on I-394 Traffic Operations ...................................... 4-11

6.1 I-394 Bottleneck Statistics With and Without HOT Lanes ............................... 6-4 


\section{Making the Traffic Operations Case for Congestion Pricing: Operational Impacts of Congestion Pricing}

\section{INTRODUCTION}

\subsection{Background and Project Objectives}

Congestion begins when an excess of vehicles on a segment of roadway at a given time, resulting in speeds that are significantly slower than normal or "free flow" speeds. Congestion often means stop-and-go traffic. The transition occurs when vehicle density (the number of vehicles per mile in a lane) exceeds a critical level. Once traffic enters a state of congestion, recovery or time to return to a free-flow state is lengthy; and during the recovery process, delay continues to accumulate. The breakdown in speed and flow greatly impedes the efficient operation of the freeway system, resulting in economic, mobility, environmental and safety problems.

Freeways are designed to function as access-controlled highways characterized by uninterrupted traffic flow so references to freeway performance relate primarily to the quality of traffic flow or traffic conditions as experienced by users of the freeway. The maximum flow or capacity of a freeway segment is reached while traffic is moving freely. As a result, freeways are most productive when they carry capacity flows at $60 \mathrm{mph}$, whereas lower speeds impose freeway delay, resulting in bottlenecks. Bottlenecks may be caused by physical disruptions, such as a reduced number of lanes, a change in grade, or an on-ramp with a short merge lane. This type of bottleneck occurs on a predictable or "recurrent" basis at the same time of day and same day of week. Recurrent congestion totals $45 \%$ of congestion and is primarily from bottlenecks $(40 \%)$ as well as inadequate signal timing (5\%). Nonrecurring bottlenecks result from crashes, work zone disruptions, adverse weather conditions, and special events that create surges in demand and that account for over $55 \%$ of experienced congestion. Figure 1.1 shows that nonrecurring congestion is composed of traffic incidents $(25 \%)$, severe weather $(15 \%)$, work zones, $(10 \%)$, and special events $(5 \%)$. 


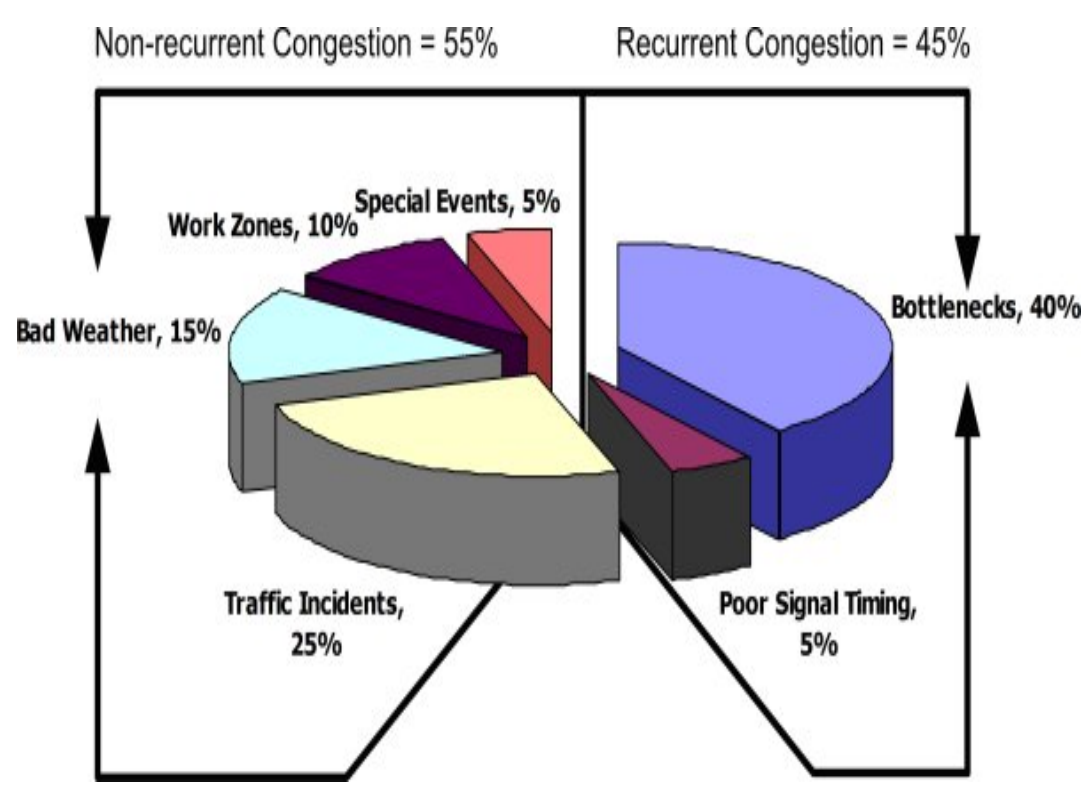

Figure 1.1 Sources of congestion. ${ }^{1}$

Between 1995 and 2005, the average percentage change in increased peak traveler delay, based on hours spent in traffic in a year, grew by $22 \%$ as the national average of hours spent in delay grew from 36 hours to 44 hours. Peak delay per traveler grew one-third in medium-size urban areas over the 10 year period. The traffic engineering community has developed an arsenal of integrated tools to mitigate the impacts of congestion on freeway throughput and performance, including pricing of capacity to manage demand for travel.

Congestion pricing is a strategy which dynamically matches demand with available capacity. A congestion price is a user fee equal to the added cost imposed on other travelers as a result of the last traveler's entry into the highway network. The concept is based on the idea that motorists should pay for the additional congestion they create when entering a congested road. The concept calls for fees to vary according to the level of congestion with the price mechanism applied to make travelers more fully aware of the congestion externality they impose on other travelers and the system itself. The operational rationales for the institution of pricing strategies are to improve the efficiency of operations in a corridor and/or to better manage congestion.

\footnotetext{
${ }^{1}$ Federal Highway Administration.
} 
As such, congestion pricing is a key component of the US DOT Congestion Initiative. At times, congestion pricing works by shifting purely discretionary rush-hour highway travel to other transportation modes or to off-peak periods, taking advantage of the fact that the majority of rush hour drivers on a typical urban highway are not commuters. Evidence suggests that by removing a fraction (even as small as 5\%) of the vehicles from a congested roadway, pricing enables the system to flow much more efficiently, allowing more cars to move through the same physical space. Similar variable charges have been successfully utilized in other industries -- for example, airline tickets, cell phone rates, and electricity rates. There is a consensus among economists that congestion pricing represents the single most viable and sustainable approach to reduce traffic congestion.

Over the next several years, congestion pricing will begin to be considered by more and more States and local agencies as they try to address their congestion problems. Many transportation professionals theorize that congestion pricing holds promise for significantly improving traffic flow and reducing levels of congestion. To date, evidence of the effectiveness of congestion pricing on improving traffic flow (i.e. throughput) and reducing traffic congestion has been based upon conjecture and the results of a very limited set of pricing project studies, such as HOT Lanes in Southern California (SR-91) and Minnesota (I-394). As States and local agencies in the United States begin to consider and possibly advance congestion pricing as a strategy to reduce traffic congestion, transportation professionals will need more technicallysound information upon which to base strategies and design, as well as to help "make the case" to decision-makers that congestion pricing will be beneficial in reducing congestion.

To this end, the objectives of this project were to:

- Better understand and quantify the impacts of congestion pricing strategies on traffic operations through the study of actual projects, and

- Better understand and quantify the impacts of congestion pricing strategies on traffic operations through the use of modeling and other analytical methods. 
Specifically, the project was to identify credible analytical procedures that FHWA can use to quantify the impacts of various congestion pricing strategies on traffic flow (throughput) and congestion.

In order to identify and evaluate existing analytical procedures and methodologies with respect to their ability to realistically simulate the impacts of congestion pricing on reduced demand and improved throughput, this project considered an array of available methods such as CORSIM, DYNASMART-P, DYNAMIT-P, AIMSUN2, PARAMICS and/or VISUM. A Dynamic Traffic Assignment approach was preferable so that diversions and route choice can be assessed.

The original work plan specified the project to focus on:

- Two congestion pricing impacts: throughput and speed,

- The facility level, and

- Three specific congestion pricing scenarios:

Scenario 1. Pricing all existing lanes of an urban interstate;

Scenario 2. Pricing one or two existing lanes of an interstate, such as for High Occupancy Toll (HOT) lanes; and

Scenario 3. Pricing one or two new lanes of an interstate, such as for express lanes.

Further into the project, it became apparent that analyses focused at the facility level are significantly less valuable than those focused at the system level. Therefore, the project was expanded to focus not only at the facility level but also at the system level. Furthermore, the congestion pricing impacts were expanded from two considerations (throughput and demand) to include speed profile and traffic diversion. The modifications on the project scope reallocated the project resources, thereby eliminating analysis of the four pricing scenarios. 


\subsection{Report Organization}

In the next chapter, results from an extensive literature review are described and summarized. The network descriptions and traffic characteristics of the two study sites MnPass on I-394 and I-95 between Baltimore (I-695) and Washington, DC (I-495) - are discussed in Chapter 3. Chapter 4 describes the simulation models and data used to quantify the impacts of congestion pricing on I-394. Simulation results on I-394 conclude Chapter 4. Chapter 5 describes steps taken for the I-95 study, and summarizes the facility-based and systemwide impacts of congestion pricing on I-95 study area. Limitations and future research needs conclude the report. 
Impacts of Congestion Pricing

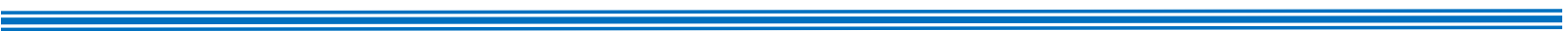

$1-6$ 


\section{LITERATURE REVIEW}

The Oak Ridge National Laboratory (ORNL) conducted a literature review of recent research on congestion pricing project in the United States and internationally, to better understand the impact of congestion pricing projects on the reliability of the performance of arterial and freeway operations. The literature on freeway performance was reviewed and case studies of deployed operational projects were reviewed for information on the location of the congestion pricing implementation; modeling studies that accompanied facility design; sources and methods of performance measurement; the results generated from the studies regarding mode choice, routing, lane selection and delay; and, a description of the applicability and limitations of the results. Operational projects which were designed and deployed for the purposes of corridor efficiency and congestion management were reviewed whereas priced projects, which were intended to solely raise revenue, were not.

\subsection{Measuring Impacts of Pricing}

Pricing is not necessarily a new concept. It was first proposed by William Vickrey, winner of the Nobel Prize for Economics, in $1952^{1}$. He later developed a bottleneck model, where all commuters wished to arrive at work at a certain time but there is a bottleneck with finite capacity that will not allow all of them to arrive at their preferred time. There are costs associated with early and late arrival, which together with the toll, are added to the cost of the trip, which commuters try to minimize by choosing their departure time. Queuing time evolves during the rush hour and this imposes a time pattern of departures. He recommended that subway fares and road fees be increased in peak times and in high-traffic sections and be lowered in others. International pricing projects use terms such a "road user charging," "road use pricing” or "congestion charging," for the levying of a fee road use. In this case, the intent is to use price as a means to influence a meaningful proportion of road users to change their travel behavior in order to manage the demand for the use of the road capacity. The aim is not to

\footnotetext{
${ }^{1}$ Arnott, Richard, William Vickrey; Contributions to Public Policy, Dept. of Economics, Boston College (http://fmwww.bc.edu/ec-p/wp387.pdf), October 1997
} 
reduce the level of access to the road network or reduce the movement of people or goods into and within the priced road network, since a pricing policy would also include complementary transport modes.

Congestion pricing has been touted as yielding significant benefits to users and non-users alike based on the reduction in delay and travel time savings, vehicle operating savings and lower stress for motorists. System performance may be impacted through the following changes that result from pricing operations:

Shift in the time of travel, from the peak traffic period to the off-peak travel period, with a consequent reduction of peak period traffic;

Mode shift from solo automobile to alternative travel modes (bus, carpool, cycling, etc.);

Route or facility shift from a tolled to an un-tolled road or lower tolled roads;

A change in travel behavior by combining or chaining activities together (trip chaining); and/or

A change in destination or origins as the pricing impacts residential and/or work locations.

A quantitative analysis of HOT lanes was cited by FHWA in "A Comparative Evaluation of Costs, Benefits, and Performance,” as support for the potential operational benefits. A logit travel-demand model was used to compare changes in travel times associated with the conversion of an existing HOV lane in a congested corridor to a general purpose lane. The study found in almost all cases, HOT lanes or toll lanes provided greater mobility benefits. The conversion to HOT from HOV lanes produced greater benefits because tolling preserved freeflow conditions on the managed facility, even if congestion worsens on the general purpose lanes. The modeling demonstrated that tolling options produced reduction benefits and confirmed speed flow analyses from actual projects. 
A survey of several state and regional agencies was conducted as part of a National Corporate Highway Research Program (NCHRP) project $^{2}$ to develop a comprehensive table of freeway performance metrics being used around the country. The project report noted that the measurement of congestion and mobility aspects of freeway performance is not yet well developed and that although performance concepts have advanced, data limitations remain to using and standardizing them. The more complex concepts, such as reliability require that data be collected nearly continuously.

\section{Vehicle Throughput}

Throughput measures the quality of service on a segment of a freeway or the corridor. Table 2.1 summarizes the throughput measures identified by the NCHRP 3-68 project. They are typically expressed as a morning, midday and evening peak periods of time or on a daily basis. The project emphasized the need to develop standardized assessments and models of the amount of throughput to be derived from these pricing measures. For example, in the case of lanes priced by time of day, the level of congestion management is somewhat undefined and is generally targeted to be simply better than the equivalent general lane.

Table 2.1 Measuring Freeway Throughput Performance

\begin{tabular}{|l|l|l|}
\hline Measure & \multicolumn{1}{|c|}{ Definition } & \multicolumn{1}{c|}{ Unit of Measurement } \\
\hline Throughput (Vehicles) & Number of vehicles traversing a freeway & Vehicles per unit time \\
\hline Throughout (Persons) & Number of persons traversing a freeway & Persons per unit time \\
\hline $\begin{array}{l}\text { Vehicle Miles of Travel } \\
\text { (VMT) }\end{array}$ & $\begin{array}{l}\text { The product of the number of vehicles } \\
\text { traveling over a length of freeway times the } \\
\text { length of the freeway }\end{array}$ & Vehicle-miles \\
\hline $\begin{array}{l}\text { Truck Vehicle Miles of } \\
\text { Travel }\end{array}$ & $\begin{array}{l}\text { The product of the number of trucks } \\
\text { traveling over a length of freeway times the } \\
\text { length of the freeway }\end{array}$ & Vehicle-miles \\
\hline Lost Highway Productivity & $\begin{array}{l}\text { Lost capacity due to flow breakdown - the } \\
\text { difference between measured volumes on a } \\
\text { freeway segment under congested flow } \\
\text { versus the maximum capacity for that } \\
\text { segment }\end{array}$ & Vehicles per hour \\
\hline
\end{tabular}

\footnotetext{
2 Margiotta, Richard, Cambridge Systematics, Research Results Digest 312: Guide to Effective Freeway Performance 03/19/2007, page 1. http://onlinepubs.trb.org/onlinepubs/nchrp/nchrp_rrd_312.pdf
} 


\section{Modeling Throughput}

In general, planners and engineers measure what they can, given the availability of data and model. With the availability of data, the traditional four step model process can be used to generate system level estimates of the implementation of pricing alternatives but still lack the detail to model throughput by lane where complex integrated strategies are being deployed. Through the Travel Model Improvement Program (TMIP), Federal Highway Administration (FHWA) funded the development and dissemination of advanced models and forecast techniques. Examples of facility specific simulation TMIP funded software include NETSIM, ROADSIM and FRESIM. These simulation models have limited application when it comes to generalized networks with ATIS implementations.

For instance, the 2006 Washington State study ${ }^{3}$ of toll used the best available traffic analysis "within the timeframe and resources". The Puget Sound Regional Council (PSRC) regional travel demand model was used. The model allows for changes when people travel in response to congestion and pricing and elasticity of demand to toll prices, time of travel, and mode shifts. It was updated to distinguish regional changes in vehicle miles and vehicle hours of travel. Even so, it could not effectively analyze highway features that cause bottlenecks; i.e., non-recurring bottlenecks at interchanges, ramps, lane drops, and other particular highway features. While a microsimulation procedure was more desirable, it was deemed to be too time consuming and costly, and infeasible for the study.

Other models exist and have been used to demonstrate the impacts of pricing on traffic operations. In the analysis of alternative pricing policy scenarios for effects of HOT lanes and Fair Lanes in the Alemeda Corridor on speeds, volumes, travel times and toll revenues the ECONorthwest's Toll Optimization Model $\left(\mathrm{TOM}^{\complement}\right)$ was used. TOM is a model designed to determine equilibrium toll levels and lane volumes in the presence of HOT lane type tolling ${ }^{4}$. Also, De-Corla Souza demonstrated the usefulness of several modified macroscopic quick-

3 Washington State Transportation Commission. Washington State Comprehensive Tolling Study, Volume 2 Background Papers, p. 142

4 Parsons Brinckerhoff Quade \& Douglas, Inc.for the Alameda County Congestion Management Agency. HOT Credit Lanes Feasibility Study, August 2005, pp 28-46. 
response models to estimate the high-level traffic impacts of several potential pricing alternatives, such as the Sketch Planning Analysis Spreadsheet (SPASM), and Spreadsheet Model for Induced Travel Estimation (SMITE) .

In addition to the aforementioned models, a new generation of traffic micro-simulation models has been developed for ITS applications such as AUTOS, METROPOLIS, PARAMICS, VISSIM, DYNASMART, DYNAMIT, INTEGRATION, THOREAU, and AIMSUN2. Boxill and $\mathrm{Yu}^{6}$ conducted a two-step evaluation study of simulation models: initial screening and indepth evaluation. They concluded that out of the nine models assessed in terms of ITS features, PARAMICS and VISSIM are the leading models for real time simulation of hundreds of vehicles.

However, in recognition of a growing need for more robust models to guide the planning design and operation of complex managed lane projects, the U.S. Department of Transportation (USDOT) launched an Analysis, Modeling and Simulation (AMS) initiative to use a combined modeling approach (macro, meso and micro) to a test corridor in the San Francisco area (I-880). Mobility, reliability of travel time, safety and cost will be the primary performance measures associated with this effort ${ }^{7}$.

\section{Modeling Reliability}

Measuring the impacts of pricing has expanded to the concept of reliability. The concept of "reliability" is growing in importance as a measure of system performance because of the growing recognition in the profession that not only does congestion occur on "typical" or "average" days, but it is the variability that occurs day to day that is important. Therefore, freeway performance must include the notion of reliability to be useful to both operators and

\footnotetext{
${ }^{5}$ DeCorla-Souza, Evaluation of Toll Options Using Quick-Response Analysis Tools: A Case Study of the Capital Beltway, Federal Highway Administration, November 16, 2002. p, 2.

${ }^{6}$ Boxill, S. A., and Yu, L. “An Evaluation of Traffic Simulation Models for Supporting ITS Development”. Center for Transportation Training and Research, Texas Southern University, October 2000.

7 US DOT, Spotlight on the USDOT’s ICM Initiative: Analysis, Modeling, and Simulation”, Integrated Corridor Management Quarterly Newsletter, page 9.
} 
planners. The variability of congestion is why differential pricing strategies are effective and necessary.

While there is a growing understanding of the impact of facility characteristics on performance, in general, there remains a gap between what we know needs to be modeled, acquisition of data to run the model, and reliable before and after data to calibrate models of alternatives for complex integrated corridors. Some of the recent work that FHWA have advanced include:

Next Generation Simulation (NGSIM) Program. This effort entailed the collection of detailed, high-quality vehicle trajectory datasets on freeways and arterials to develop freeway lane selection algorithms. FHWA also plans to develop additional algorithms for arterial lane selection, arterial gap acceptance, cooperative/forced freeway merging, and oversaturated freeway conditions.

Traffic Analysis Toolbox. The Toolbox has been updated to include guidance on how to select and apply traffic simulation tools to project analyses.

Furthermore, there is growing recognition within the FHWA, academic and traffic community of the need to develop robust models, for which data is available, and that are within the means for state and regional planners to acquire, understand and use ${ }^{8}$. Some of the issues that remain in the area of modeling enhancements for complex integrated corridors include:

Modeling of oversaturated conditions.

Modeling of traffic flow in various non-recurring conditions of congestion; i.e. adverse weather conditions; work zones; and surrounding traffic incidents.

Modeling of fully integrated multi-modal corridors.

Modeling of driver response to advanced traveler information.

\footnotetext{
${ }^{8}$ Federal Highway Administration. FHWA/UTC Workshop on Urban/Suburban Mobility and Congestion Mitigation
} Research, June 7, 2006. 


\subsection{Case Studies of Performance Impacts of Pricing in U.S.}

The earliest operational deployment of pricing as a congestion management strategy occurred began in the 1970's with the Singapore cordon charge scheme. The following is a list of both U.S. and international deployments:

1970s Singapore cordon charge,

1986 Bergen, Norway, toll ring

1990-2003 Oslo, Trondheim \& other Norwegian cities adopt toll rings

1995 Orange County, CA State Route 91 Express Lanes;

1996 San Diego, CA; I-15 FasTrak

1996 Singapore full electronic road pricing

$2000 \quad$ Congestion pricing of NY bridges

2002-2004 Swiss, Austrian truck tolls

$2003 \quad$ London cordon charge

2005 Germany tolls autobahn trucks

$2006 \quad$ Stockholm congestion charge

One of the very first American congestion management projects began in the mid-1990s in California as High Occupant Vehicle Lanes (HOT) lanes were operated alongside general purpose lanes. We did not find examples of operational congestion pricing cases where free lanes had been transformed into toll lanes. All the reviewed projects are either transformations of underutilized HOV lanes into HOT lanes or toll reductions during off-peak periods when tolls were already in existence. The HOT lane operation is enabled by ITS services such as electronic toll booths, dynamic message signs and technology that ties the amount of the toll to the level of traffic in "real-time".

\section{New Jersey Turnpike}

The New Jersey Turnpike Authority operates a 148-mile facility that carries an average of 500,000 trips a day. In 2000, a variable toll pricing program put higher tolls into operation 
during the peak period using electronic toll collection. Data shows that traffic has shifted out of the peak period so that although total facility traffic has increased by around seven percent, the morning peak traffic has grown by six percent and the afternoon peak traffic is up by only four percent. Very minor morning and afternoon peak period decreases were cited of less than 0.3 percent ${ }^{9}$.

\section{Port of New Jersey/New York (PANYNJ) - Time of Day Pricing}

PANYNJ programs emphasize value pricing by providing offpeak discount toll prices. A major element of these programs is E-ZPass, an electronic toll-collection technology used at most toll facilities in metropolitan New York and along I-95 in the Northeast Corridor where EZPass users are eligible for toll discounts. Time of day pricing was initiated using E-Z Pass in March 2001. Analyses based on the traffic data routinely collected at all toll lanes by PANYNJ confirmed significant shift towards pre-peaks -- both in the mornings (5:00 - 6:00 am) and afternoons (3:00 -4:00 pm). Data indicated the following mode and behavior changes by users:

- Decreased travel by car in conjunction with an increased use of transit (2.6\%);

- Increased use of transit in conjunction with an increase or initiation of carpooling (1.8\%);

- Decreased number of trips taken during the peak and increased the number of trips taken during the off-peak period (1.5\%);

- Decreased the number of total trips taken during both peak and off peak (1.3\%); and,

- Increased the use of public transportation and switched to E-ZPass (1.2\%).

A Port Authority comparison of one typical day in May 2001 with a typical day in May 2000 found that seven percent fewer drivers used the agency's bridges and tunnels during the morning peak hour period and that 4 percent fewer were traveling the crossings during the afternoon peak hours. These declines amount to 5,150 fewer vehicles in the morning's most congested hours and 2,500 fewer during the early evening rush.

\footnotetext{
${ }^{9}$ California Center for Innovative Transportation, UC Berkeley Institute of Transportation Studies, and the California Department of Transportation; ITS Decision Web site, http://www.calccit.org/itsdecision/serv_and_tech/Congestion_pricing/congestion_pricing_report.htm\#results
} 
Weekday truck traffic percent share showed statistically significant shift to morning prepeak (5:00 - 6:00 am) and afternoon post-peak hours $(7: 00-8: 00 \mathrm{pm})^{10}$. However, weekend car and truck traffic percent share did not have statistically significant change in peak-shoulder hours (11:00 am -12:00 pm and 8:00 - 9:00 pm). In addition, weekday and weekend peak-period car percent share experienced statistically significant decrease only at George Washington Bridge (lower and upper levels). Unlike car traffic, truck traffic decreased for all peak-periods on both weekdays and weekends at all crossings after the time-of-day pricing, though the decrease in peak traffic was statistically significant only on weekdays. These findings indicated that PANYNJ time-of-day pricing initiative was successful in spreading weekday peak period traffic to the hours just before or after the peak toll rates are in effect, for both cars and trucks.

\section{SR-91 in Orange County, CA}

California’s first value pricing project opened in 1995 on SR-91 in Orange County. Now in its third expansion phase, the facility has logged more than 64 million vehicle trips and saved more than 32 million hours of commuting time. Each variably priced lane in the median of State Route 91 reportedly carried twice as many vehicles per lane as the free lanes during the hour with heaviest traffic, which has allowed twice as many vehicles to be served per lane at three to four times the speed on the free lanes ${ }^{11}$. Studies discussed later also showed HOT lanes increased the number of passengers per car to 1.6, compared to the average of 1.2. During the height of the peak period, the 91X lanes accommodate 1,400-1,600 vehicles per hour per lane, about the same as the adjacent freeway and more than the freeway had previously accommodated when jammed with severe congestion before the $91 \mathrm{X}$ lanes existed.

The upgrading of two free lanes to toll managed lanes is like creating a virtual whole new lane of freeway, at much less cost. DeCorla-Suza cited SR-91 as an example of tolling that achieved congestion reduction, citing that during periods of heavy traffic, express lanes accommodate 40 percent of traffic even though they comprise only 33 percent of the facility

\footnotetext{
10 Ozbay, Yanmaz-Tuzel, Holguin-Veras, “The Impacts of Time-of-day Pricing Initiative at NY/NJ Port Authority Facilities Car and Truck Movements”, Transportation Research Board’s 85th Annual Meeting, Washington, D.C., 2006, pp. 12-14

${ }^{11}$ U.S. Department of Transportation, Federal Highway Administration, A Congestion Pricing Primer, December 2006, Publication Number: FHWA-HOP-07-074, page 3.
} 
capacity $^{12}$. The presence of the value-priced by-pass lanes resulted in an equilibrium under which the overall facility operates better than before.

\section{Katy Freeway in Houston, TX}

The Katy Freeway requires that all users be part of a carpool. Carpools with three or more persons ride for free, while carpools of two persons pay $\$ 2$ to use the facility. SOVs are not allowed. On the Katy Freeway, about 8-10 percent of the 2-person trip carpools switched from traveling in the shoulder time period into the peak period. Value pricing increased the usage of the Katy Freeway lanes, but only by a small fraction of the available capacity ${ }^{13}$.

Vehicle occupancy changes were also notable on the Katy Freeway with more than half of users switching from single-occupancy vehicles into carpools to use the HOV lane. About one quarter of the 2-person carpools moved from the main lanes to the HOV lane during peak hours, and the number of 3+ carpool trips increased by 6.1 percent in the evening. About 18 percent of the morning QuickRide trips diverted from higher occupancy modes, but only 1 percent in the evening. Transit ridership did show a slight decrease after QuickRide was implemented, but the absolute number of riders was miniscule.

A study conducted on the Katy Freeway by Hickman, Brown and Miranda and reported by Ward, calculated a travel time savings by dividing the length of the lane by the average travel speeds recorded by day. The estimate found the average daily time savings to be 20 minutes, valued at $\$ 6.00 / \mathrm{hr}$.

\section{E-470 in Denver, CO}

E-470 is a 47-mile orbital toll road running along the eastern perimeter of the Denver metropolitan area -- from State Highway C-470 at I-25 in Douglas County south of Denver to the east and north through Aurora and then passes along the western edge of Denver International

\footnotetext{
${ }^{12}$ DeCorla-Souza, Evaluation of Toll Options Using Quick-Response Analysis Tools: A Case Study of the Capital Beltway, Federal Highway Administration, November 16, 2002. page 2.

13 Ward, Jennifer. Value Pricing: A Synthesis of Lessons Learned Hubert H. Humphrey Institute of Public Affairs University of Minnesota.
} 
Airport, finally turning back towards the west and terminating at I-25 near 157th Avenue north of Denver in Thornton. The project was built in four separate phases between 1989 and 2003.

\section{I-25 HOT Lane, Denver, CO}

This is an HOV conversion that opened in 2006 which received a full funding grant agreement from the Federal Transit Administration (FTA) which specifies that net revenues must go to transit and that bus travel times take precedence over all others using the facility, meaning that the addition of SOV traffic should not impact bus operations.

\section{I-394 MnPass in Minneapolis}

The Minnesota Legislature enacted High-Occupancy Toll Lane Legislation (160.93, Sec.7) in 2003, authorizing the Minnesota Department of Transportation (Mn/DOT) to implement user fees on existing HOV lanes. A dynamic High Occupancy Toll application was deployed on I-394 in the Minneapolis/St. Paul region in May 2005. The I-394 corridor is located on the western side of the Minneapolis-St. Paul Metropolitan area, connecting downtown Minneapolis with the western suburbs. This corridor is one of the two cases studied in this study.

\section{Lee Highway in Lee County Florida}

Electronic toll equipment was deployed in 1998 to price the Cape Coral Bridge and the Midpoint Bridge, which are two of four bridges that connect Cape Coral and Fort Meyers. A variable pricing tolling structure was used to induce patrons who usually travel during peak periods to change their time of travel by offering a 50\% discount during the shoulder periods just before and after the peak traffic period (6:30 to 7:00 am, 9:00 to 11:00 am, 2:00 to 4:00 pm, and 6:30 to 7:00 pm). The variable toll discount encouraged patrons to change their time of travel without making the peak periods trips more expensive. Ward's analysis of the project showed the following travel behavior changes ${ }^{12}$ : 
- An estimated 300 trips per day were diverted from peak period travel to discounted shoulder periods.

- $\quad$ Eligible users were making an additional 151 trips per day.

- A total of $25.9 \%$ of eligible users increased their trip frequency in the first few months of variable pricing.

- No significant change in travel mode or vehicle occupancy.

\section{I-15 FasTrak in San Diego, CA}

The FasTrak system is an eight-mile-long, two-lane separated roadway in the median of I-15 called Express Lanes. The Interstate 15 Value Pricing project began as a three-year demonstration project, implemented in two phases. The Phase 1 ExpressPass program, which allowed single occupancy drivers to buy-in to the HOV lane with a monthly pass, operated from December 2, 1996 to March 30, 1998. An AVI transponder system was in place in March 1998, at which time Phase 2 FasTrak program became operational. The HOT lanes are priced on a real time basis and run parallel to free lanes. FasTrak allows solo drivers to use the HOT facility for a fee that is dynamically adjusted to assure level of service (LOS) C on the facility at any time. It is in its ninth year of operation.

The 2003 State of the Commute Report, produced by the San Diego Council of Governments (SANDAG), reported that 21\% more people moved between the hours of 3:00 pm and 5:00 pm on the I-15 managed lanes ${ }^{14}$. On San Diego's I-15 HOT lanes, revenues generated by toll-payers financed transit improvements that contributed to a 25 percent increase in bus ridership ${ }^{15}$.

\section{I-15 Express Lanes in Salt Lake City}

In September 2006, the Utah Department of Transportation converted 38 miles of existing HOV Lanes in Salt Lake and Utah counties to Express Lanes. The lanes include 16

\footnotetext{
${ }^{14}$ SANDAG, The 2005 State of the Commute Report, Keep San Diego Moving, p.2.

15 U.S. Department of Transportation, Federal Highway Administration, A Congestion Pricing Primer, December 2006, Publication Number: FHWA-HOP-07-074, page 5.
} 
access points marked by a white dotted line, while the rest of the corridor is marked with a double-white solid line. Each point is 3,000 feet long, giving plenty of room for users to enter and exit the lanes. All vehicles with two or more occupants, motorcycles, emergency vehicles, buses, and clean-fuel vehicles can use the Express Lanes free of charge.

\subsection{International Experience}

Cities such as London, Stockhom and Singapore have successful implementations and plan expansions. The international experience has a larger focus on cordon pricing to impact traffic in center cities whereas the United States is gaining more experience with corridor pricing. In a cordon toll scheme, travelers who want to drive into the charged area have to pay a toll that is levied at specific points of the road network located on the cordon. In all of these cases, the conditions for using the lanes can differ in terms of: the types of vehicles permitted (cars, trucks), the parameters defining the toll (time of day, traffic volume, travel distance, frequency of travel, type of vehicle), and the payment options available (electronic deduction, cash). The most common approach is to have rates that vary with time of day.

The earliest operational deployment of pricing as a congestion management strategy occurred began in the 1970's with the Singapore cordon charge scheme. Key experience is summarized here.

\section{Singapore Electronic Road Pricing - Cordon Pricing}

There were two manual road pricing schemes used in Singapore, namely the Area Licensing Scheme (ALS) and the Road Pricing Scheme (RPS). The ALS was in place for 23 years before being replaced by an electronic version called the Electronic Road Pricing System (ERP), while the RPS was implemented progressively on expressways from 1995 (and also subsequently replaced by the ERP in 1998). The Singapore Area License Scheme, limited access to the central business district during the morning peak hours to cars with a valid permit. This relatively compact city with a population of four million was the first city to implement a cordon-based congestion system based on time of day pricing. The ALS covered the more 
congested parts of the Central Business District (CBD), designated as the Restricted Zone (RZ). The scheme integrated the charging system with rail and road investments. All vehicles, except emergency vehicles, are charged. The charging area is divided into central business districts and outer ring roads. The initial drop in traffic entering the RZ was $44 \%$, but it crept up to a $31 \%$ drop by 1988. This was despite the growth by a third in employment in the city and by $77 \%$ in vehicle population during the same period ${ }^{16}$.

An ERP system introduced in 1998 which has variable charges for different roads at different times automatically as vehicle passes under gantries. The charge has been successful in reducing the number of solo drivers and shifting trips from peak to non-peak times. There has been a reduction of 24,700 vehicles during the peak period, accompanied by a $22 \%$ increase in traffic speeds. Traffic volume into the CBD had reduced by about $10-15 \%$ during the ERP operation hours. The ERP influenced the travel behavior of those who previously made multiple trips into the $\mathrm{CBD}$, which amount to almost one-quarter of trips that entered the CBD during the ALS days. Many of these multiple trip-makers cut down their number of trips, e.g. office workers no longer use their cars to attend mid-day meetings or lunches - more relied on the public transport system instead. Prices are adjusted quarterly to maintain speeds of 45-65 kph on expressways and 20-30 kph on arterial roads.

\section{Durham Congestion Charging}

A Transport Act of 2000 provided for cities across England to impose road user charges for the purpose of reducing congestion as part of an integrated local transport strategy with the requirement that all proceeds be put into real improvements in local transport. The scheme is not designed purely to raise revenue but make real contributions to congestion reduction and integrated transport. The cities of Durham and London were first to implement under the act. ${ }^{17}$. Durham is a small town with a historic center and a main shopping area along a narrow street

\footnotetext{
16 Keong, Chin Dr., Land Transport Authority Singapore, “Road Pricing, Singapore’s Experience”, IMPRINT EURPOE, Effective Use of Research on Pricing in Europe, 2004, page 5.

${ }^{17}$ Goodwin, Michael. Department of Transport, Urban Pricing Initiatives in the UK, Managing Transport Demand through User Charges: Experience to Date, International Conference hosted by Transport for London, London, January 2004, page 6.
} 
that goes through a medieval center. The center had 17,000 pedestrians per day and up to 2,000 vehicles per day, of which many were considered as “nonessential movement.' A £2 charge introduced in October 2002 to be applied weekdays and Saturday during the period of peak pedestrian flows (1,000 -1,600). The payment was due on exit and enforced by a rising bollard control. An "utilized" bus service was extended to link the rail station and "park \& ride" to the city center. The Durham results have been amazing with vehicle counts at Saddler Street in the city center dropping from 3,600 vehicles per day (vpd) in December 1992 to 547 in December 2002 and a low of 239 vpd in 2003. The modest two pound (three Euros) fee was effective in support a frequent bus service and reducing vehicular traffic by 85 percent.

\section{London Congestion Charging Scheme (CCS)}

Central London employs one million workers and has the worst traffic congestion in the UK with an average traffic speeds of $15 \mathrm{~km} / \mathrm{hr}$. Vehicles typically spent half their time in queues. The charge is enforced by observing vehicle registration numbers with both fixed and mobile cameras linked to automatic number plate recognition technology. If there is no record of payment by midnight, a $£ 80$ penalty charge sent to registered vehicle keeper. Repeat violators and persistent evaders are towed.

At the first year mark, Button reported that first year results indicated that congestion fell by $30 \%$ within the central zone, that traffic levels remained down by $18 \%$, and that bus patronage was up by nearly 30,000 passengers during the morning peak ${ }^{18}$. The increase in transit was attributed to decreased wait time at bus stops, which was down $20 \%$ both across London and by within the charging zone. Bus delays in central London reduced by $50 \%$ after the pricing scheme was introduced. There was a seven percent increase in bus riders ${ }^{19}$.

\footnotetext{
${ }^{18}$ Button, Kenneth, Final Report, Road Pricing, For the Center for Transportation Policy, Operations and Logistics, March 2004.

19 U.S. Department of Transportation, Federal Highway Administration, A Congestion Pricing Primer, December 2006, Publication Number: FHWA-HOP-07-074, page 5.
} 


\section{Stockholm - Cordon Pricing}

About $70 \%$ of the 1.3 million Stockholm residents use private automobiles. The City initiated a pilot congestion pricing project for seven months between January and July 2006. The charge was heavily contested at its outset, but public opinion gradually veered in its favor. The issue was put before voters in a referendum, and the pricing was reinstated in July 2007.

The project was measured in a comprehensive manner under the direction of the Congestion Charge Secretariat of the City of Stockholm whose task was to plan, coordinate, inform of and evaluate the trial. Gunnar Soderholm, the key government official who implemented the system, reported in January 2007 that the project had cut traffic to and from the inner city by $15 \%$ and had reduced congestion delay in and near the inner city by $30-50 \%{ }^{20}$. Traffic in the cordon area fell by 23\%. Outer approach road and outer approach street traffic fell by five 5\%. Access improved and travel times fell as a result of the reduction in motor traffic. The decrease in traffic across the cordon was largest during the morning and afternoon rush hours. The largest reduction occurred in the afternoon.

The pricing project is integrated with transit enhancements, including 197 new buses, 16 new bus lines and more trains at peak periods. Travel by public transport was about 6 percent higher in spring 2006 than in spring 2005. The congestion tax seems to have caused in increase in travel by public transport by approximately 4.5\%, while higher gasoline prices and other global events probably account for the rest of the increase (about $1.5 \%$ ). Of the $22 \%$ decrease in car travel across the charge zone, only $0.1 \%$ at the most could have been caused by the expanded bus services.

\footnotetext{
20 Söderholm, Gunnar, The Politics and Success of the Stockholm Congestion Trials, Environmental Defense and the Humphrey Institute, January 2007, page 21.
} 


\subsection{Summary}

This literature review found that congestion pricing improves traffic operations.

- London, cordon pricing reduced congestion by $30 \%$ and reduced the volume of traffic entering the priced zone by $18 \%$. Bus delays in central London dropped by $50 \%$ after the pricing scheme was introduced and there was a 7\% increase in bus rider.

- Hudson River crossing tolls in New York reduced peak period traffic volumes by 7\%.

- SR-91 Express Lanes saved more than 32 million hours of commuting time and reduced typical travel time on the remaining free lanes from 30-40 minutes to 12 minutes.

- In San Diego and Texas, HOT lane and congestion pricing projects reduced trip times during peak travel periods by 12 to 20 minutes and spread the peak period.

- Singapore’s cordon pricing reduced private car travel by $73 \%$ for work trips. Carpooling increased by $30 \%$ and transit commuters doubled.

- Trondheim's ring of cordon pricing around the central business district has reduced peak period traffic by $10 \%$ and off-peak traffic by $8 \%$.

- In Stockholm, 200 new buses were put into service in August 2005, several months in advance of the pricing trial, which began in January 2006. After the pricing scheme was implemented, daily public transportation use compared to the same month in 2005 was up by 40,000 riders daily.

- California’s SR 91 priced express lanes resulted in an increase of $40 \%$ in the number of vehicles with more than three passengers.

- On San Diego's I-15 high-occupancy toll lanes, revenues generated by toll-payers financed transit improvements that contributed to a 25\% increase in bus ridership. 
Impacts of Congestion Pricing

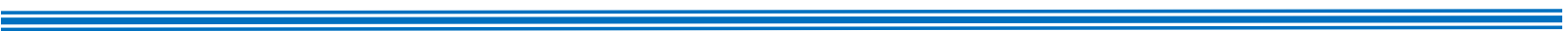

$2-18$ 


\section{STUDY AREAS}

Two areas were used to analyze the impacts of congestion pricing: (1) MnPASS on I-394 and (2) I-95 corridor from I-695 (Baltimore) to I-495 (Washington DC).

\subsection{System and Network Description of MnPASS on I-394}

MnPASS is the Minnesota Department of Transportation's electronic toll collection system (Figure 3.1). Drivers who participate in MnPASS lease a small electronic transponder that is attached to their windshield behind the rear view mirror. The toll is automatically deducted from their pre-paid MnPASS account by toll-recording equipment located on the road. Fees vary in amount, depending on the level of traffic congestion in the MnPASS lanes. MnPASS was selected as one of the study areas because of its comprehenseive archive of the traffic condition data and the maturity of its pricing program.

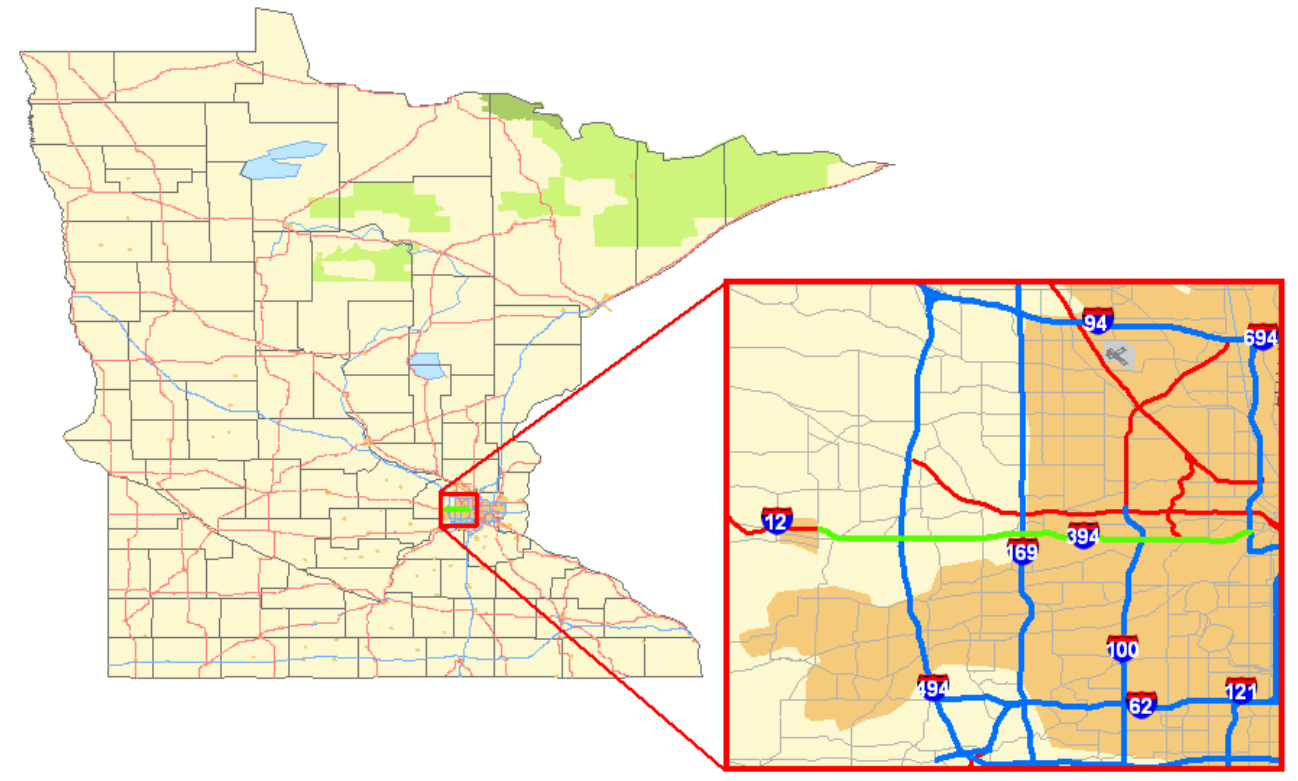

Figure 3.1 MnPass Express Lane locations on I-394.

In 2005, the HOV lanes were converted to high occupancy toll (HOT) lanes. These lanes are also known as the MnPASS Express Lanes. The goal is to maximize capacity in the I-394 corridor and to make better use of the capacity in the high occupancy vehicle lane. Transit buses, carpools and motorcycles can use the MnPASS Express Lanes for free. Vehicles with a 
single driver can use the HOT lane by paying an electronic toll. Speeds at or near the posted limits are maintained by "dynamic" pricing that varies with demand and use of the lanes - fees range from $\$ 0.25$ to $\$ 8.00$. The collection of fees is automated without any toll booth.

The I-394 MnPass Express Lanes start east from the CR 101 South junction to the I-94 interchange. There are 2 HOT lanes (reversible and barrier-separated) - east of Trunk Highway 100 and one concurrent HOT lane in each direction west of Truck Highway 100. The MnPass Express Lanes are operated Monday through Friday from 6 a.m. to 10 a.m. and from 2 p.m. to 7 p.m. The lanes are open to the general traffic for the rest of each week day and on weekends.

The analysis concentrated on the part of I-394 in the Minneapolis/St. Paul area between downtown Minneapolis, the I-494 beltway, and the western suburbs (Figure 3.2). There are two HOT sections:

- Two reversible, barrier-separated high-occupancy vehicle (HOV)/high occupancy toll (HOT) lanes located in the center median between I-94 and Trunk Highway (TH) 100, and

- A single, non-barrier-separated HOV lane in each direction west of Trunk Highway 100 which as originally designed and constructed as a High Occupancy Vehicle (HOV) lane.

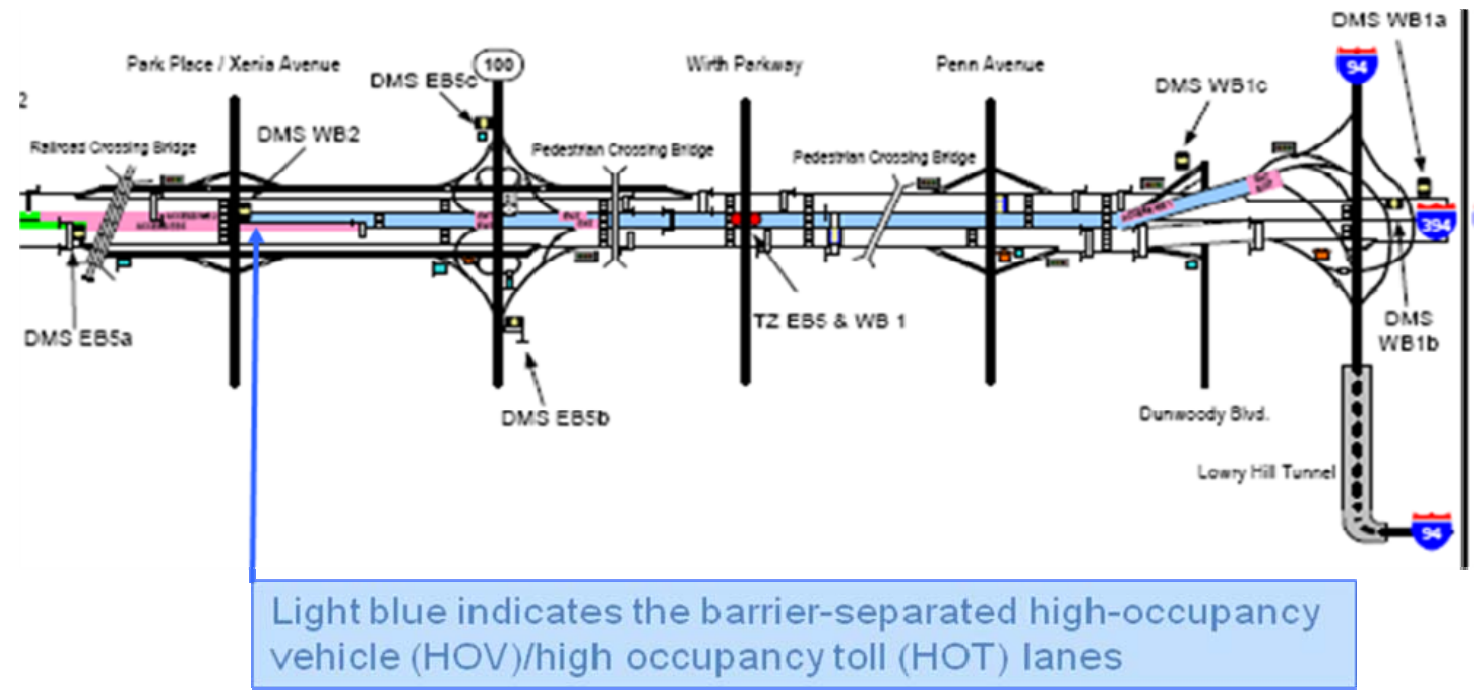

Figure 3.2 Schematic map of the study area on I-394. 
Traffic data collected by the detectors are web-accessible, and were used to calibrate the traffic simulation model and to conduct the "before-and-after" analysis. Specifically, the traffic data from the detectors identified in Figure 3.3 were used.

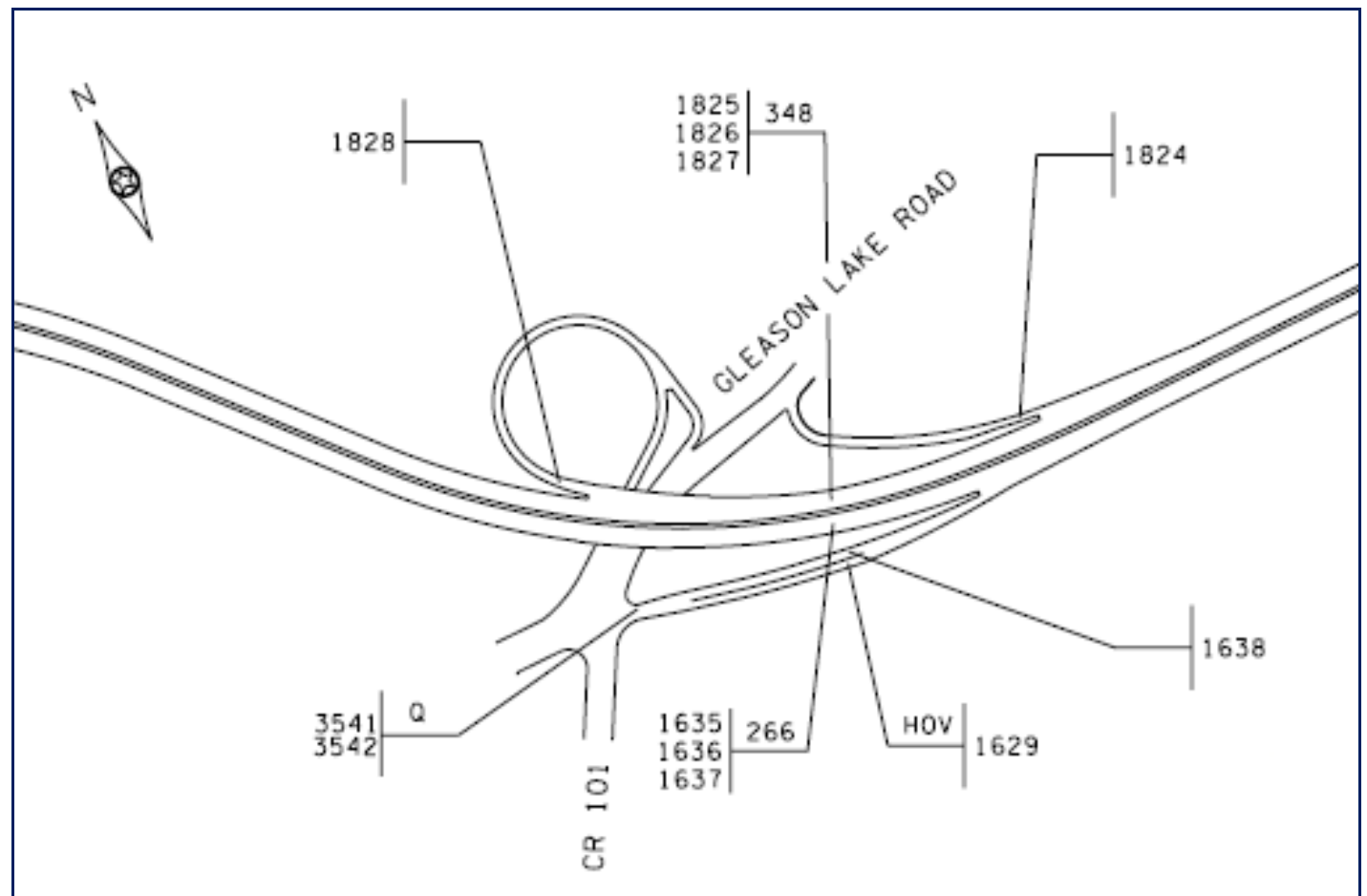

Figure 3.3 Detector numbers and locations on I-394.

\subsection{System and Network Description of I-95 Study Corridor}

The second case study focused on the I-95 corridor between Baltimore, MD and Washington, DC (Figure 3.4). The corridor starts from I-695 (south of Baltimore) to I-495 (north of Washington, DC). The network includes freeways I-95, US 29, US 1 and SR 295 in the north and south directions, and the corridor includes SR 166, SR 100, SR 32 and SR 198 in the east and west directions. This corridor was selected for this project due to:

its traffic gridlock,

a network that was already geocoded, and

I. OD flow data that were already compiled. 
The I-95 study corridor consists of 46 links and covers 18 miles. However, the entire study area expands beyond the I-95 corridor and consists of 23,567 links and is categorized into 111 origin and destination zones. This study area was used to estimate the system-wide impacts of congestion pricing.

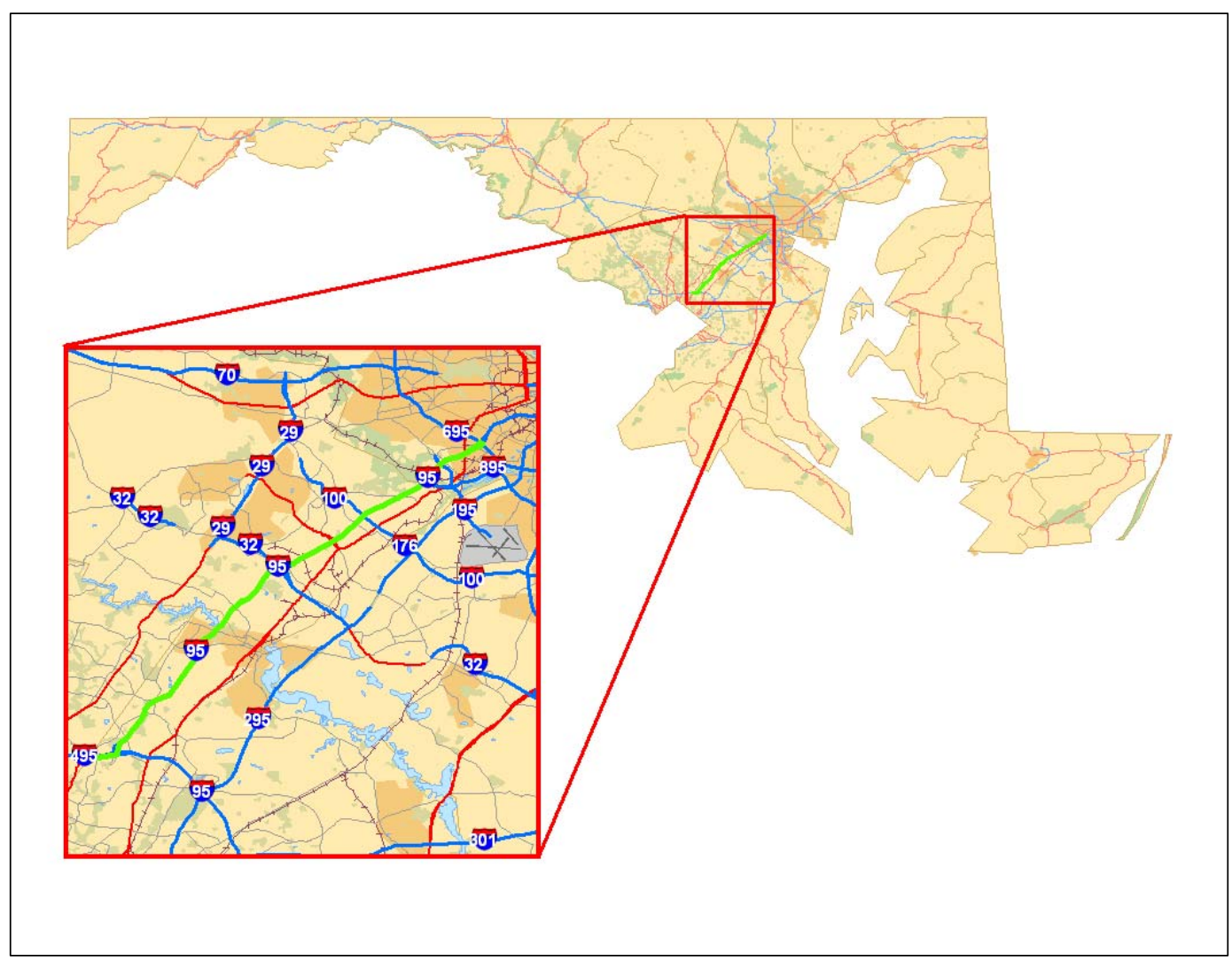

Figure 3.4 Map of the I-95 corridor.

The geocoded version of the I-95 network was originally developed by the University of Maryland which used a variety of data sources, including a GIS (geographic information system) file, maps, and field visits. The University of Maryland modified and fine-tuned the GIS file using information from field visits and internet maps (e.g., from the Mapquest website). In addition to geographic information, zoning and signal information ${ }^{1}$ were added to the network

\footnotetext{
1 The signal locations and signal timing plans were provided by the State Highway Administration (SHA).
} 
development. The characteristics of the zones were defined consistent with the traffic analysis zones $^{2}$ (TAZs).

Traffic conditions on this study corridor are monitored by seven detectors on I-95 and two on I-495, as denoted by pushpins in Figure 3.5. Unfortunately, data were aggregated where no land-specific traffic data was available, speed was averaged and volumes were totaled across all lanes. This study focused on the east-bound traffic.

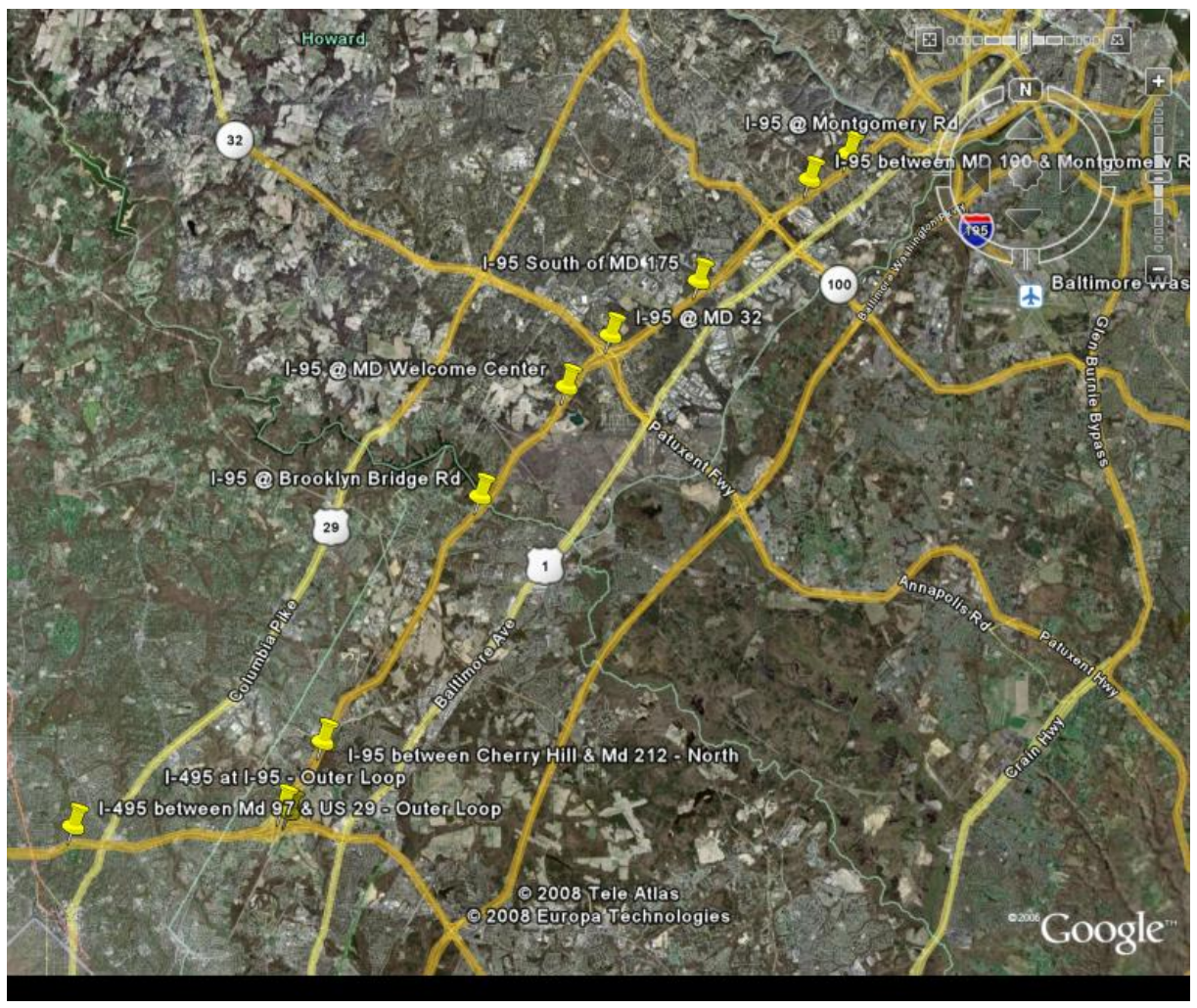

Figure 3.5 Locations of $\mathrm{CHART}^{3}$ traffic detectors.

\footnotetext{
${ }^{2}$ TAZ information was provided by the Maryland Department of Transportation (MDOT).

${ }^{3}$ Coordinated Highways Action Response Team (CHART) is to improve "real-time" operations of Maryland's highway system. http://www.chart.state.md.us/
} 
Figure 3.6 depicts the network representation of I-95 study corridor in the simulation model, DynusT. This network has 2,182 nodes, 3,387 links, and 111 zones. The simulation data were calibrated to the 2008 traffic volume and operating speed information from CHART.

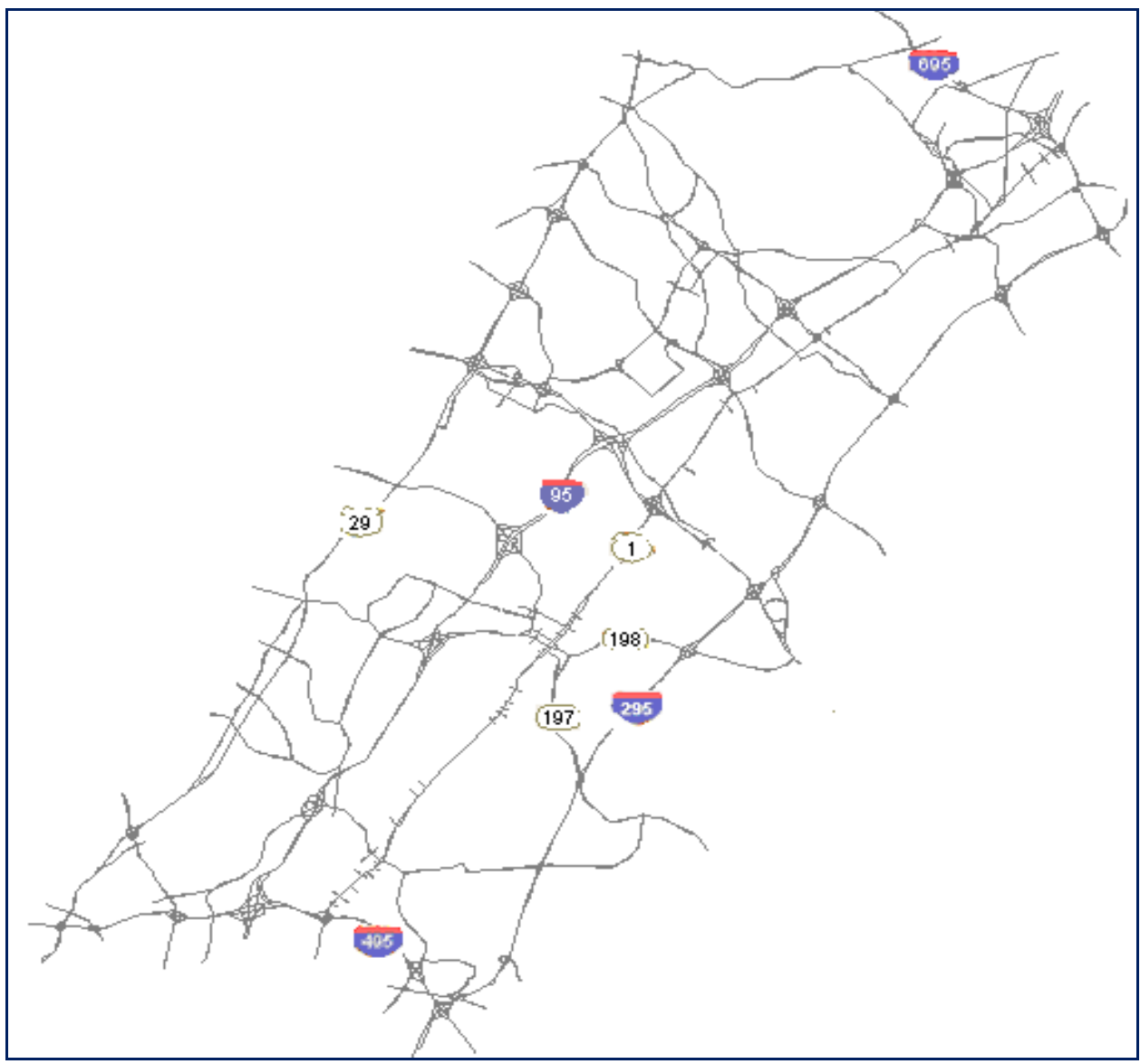

Figure 3.6 I-95 Study corridor network representation used in DynusT. 


\section{ESTIMATED IMPACTS OF HOT EXPRESS LANES ON I-394}

This chapter describes the simulation model that was used and summarizes the estimated impacts of HOT express lanes on I-394. The simulation model was used to simulate traffic conditions in the absence of the HOT lanes (i.e., the "before" scenarios). The simulated results were then compared to the actual observations of the traffic conditions to estimate the impacts. Note that the analysis on I-394 was facility-based but not system-based.

\subsection{Description of Simulation Model, VISSIM}

Since one of the project objectives is to identify credible analytical procedures that FHWA can use to quantify the impacts of various congestion pricing strategies, VISSIM was selected due to its widespread user base. VISSIM is a microscopic, time-step, and behaviorbased simulation model developed to model urban traffic and public transit operations. It can analyze traffic and transit operations under constraints such as lane configuration, traffic composition, traffic signals, transit stops, etc., making it a useful tool to evaluate the effectiveness of various operations strategies. For example, it was used to evaluate the effectiveness of preferential treatment solutions for buses (e.g. queue jumps, curb extensions, bus-only lanes) and the impacts of variable message signs.

The VISSIM consists of two different parts. The simulation generates an online visualization of traffic operations and offline output files of statistical data such as travel times and queue lengths. The traffic simulator is a microscopic traffic flow simulation model that includes car-following and lane-change logic. The signal state generator is signal control software that polls detector information from the traffic simulator on a discrete time step basis (e.g., down to $1 / 10$ of a second). It then determines the signal status for the following time step and returns this information to the traffic simulator.

The accuracy of a traffic simulation model largely depends on the quality of the traffic data that are used for calibration purpose, and the quality of the vehicle traffic modeling, e.g. the methodology for moving vehicles through the network. In contrast to less complex models using constant speeds and deterministic car-following logic, VISSIM uses the psycho-physical driver 
behavior model developed by Rainer Wiedemann in 1974 at Karlsruhe University. The basic concept of VISSIM is that the driver of a faster moving vehicle starts to decelerate as he/she reaches his/her individual perception threshold to a slower moving vehicle. Since he/she can't precisely determine the speed of that other vehicle, his/her speed will fall below that vehicle's speed until he/she starts to accelerate again after reaching another perception threshold. As such, VISSIM uses an iterative process of acceleration and deceleration. VISSIM's traffic simulator allows drivers on multiple lane roadways to react to preceding vehicles ( 2 vehicles by default) and neighboring vehicles on the adjacent travel lanes.

VISSIM simulates traffic flow by moving “driver-vehicle units” through a network. Every driver with his/her specific behavior characteristics is supposedly assigned to a specific vehicle $^{1}$. Attributes characterizing each driver-vehicle unit are categorized into three categories:

1. Technical specifications of a vehicle, e.g.,

- Length,

- Maximum speed,

- Potential acceleration,

- Actual position in the network, and

- Actual speed and acceleration

2. Behavior of driver-vehicle units, e.g.,

- Psycho-physical sensitivity thresholds of the driver (ability to estimate, aggressiveness),

- Memory of a driver, and

- Acceleration based on current speed and driver's desired speed

3. Interdependence of driver-vehicle units, e.g.,

- Reference to leading and following vehicles on the unit's own and adjacent travel lanes,

- Reference to current link and next intersection, and

- Reference to next traffic signal.

\footnotetext{
${ }^{1}$ VISSIM 5.10 User Manual by PTV (Planning Transport Verkehr) America. More information about VISSIM and
} PTV America can be found at http://www.ptvamerica.com/ 


\subsection{Traffic Data and Calibration}

The Minnesota Department of Transportation collects traffic data on the freeway system throughout the Twin Cities Metro area. This data are accessible via XML files. Data from each traffic detector, along with the detector identification number and location, are published. An example of the detector locations and identification numbers used for this project is illustrated in Figure 4.1. The Mn/DOT Data Extraction Tool was used to acquire traffic data, in 15-minute intervals, on I-394 eastbound from 6:00 am and 12:00 am on May, 18, 2008. These data were used to calibrate the VISSIM model. The 15-minute interval traffic volume on the entrance ramp (i.e., the ramp metering site) was used as the primary input. The mid-link traffic volume was adjusted to the observed traffic volume based on traffic volume on the down-stream off-ramps. The connectivity of links and nodes of the study network was “coded” in VISSIM by tracing the roadway geometry using Google Earth (Figure 4.2).

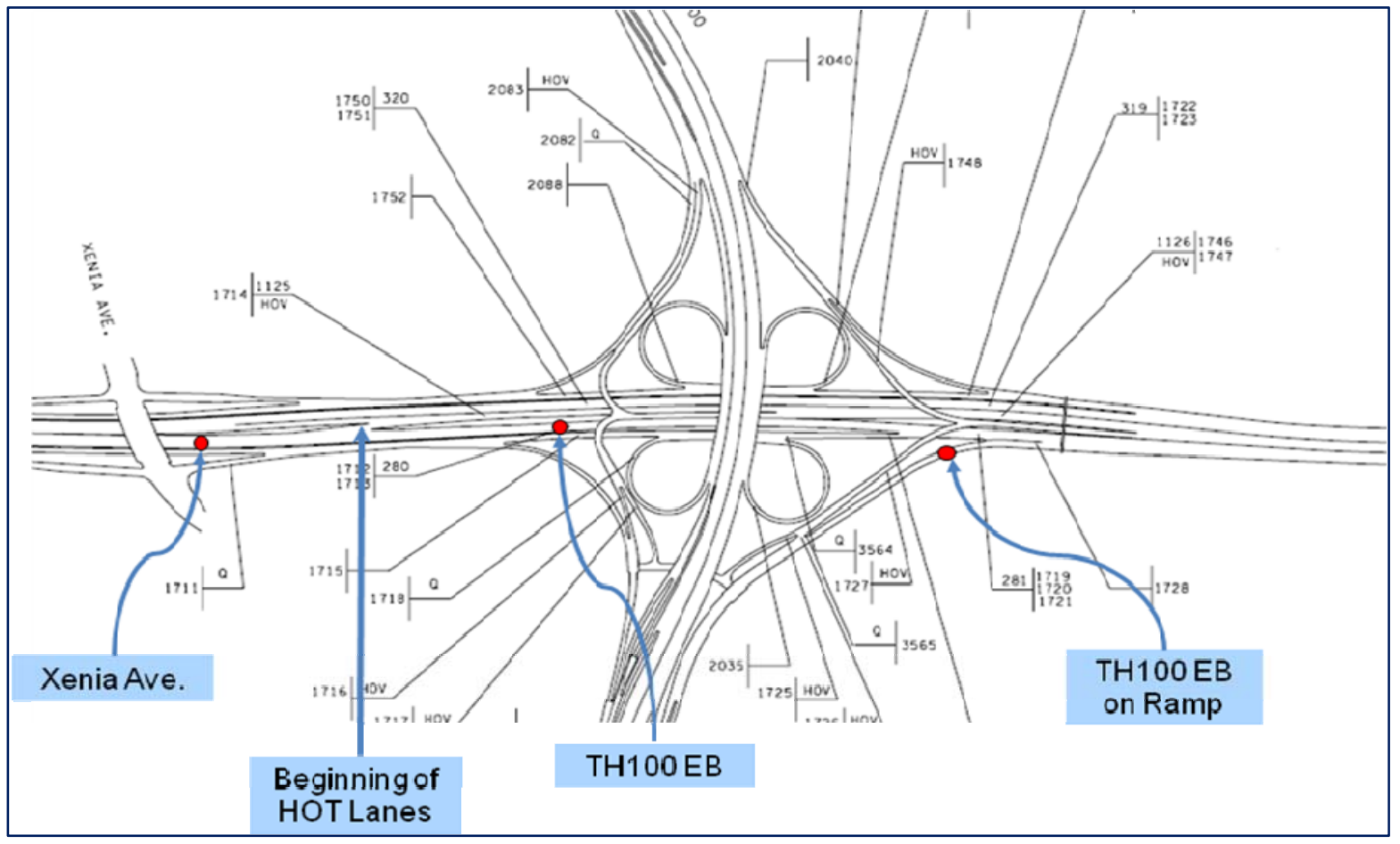

Figure 4.1 I-394 traffic detector identification numbers and locations; the simulation locations are denoted by red dots. 
In the I-394 study case, the simulation model was used to simulate the "before" scenario. That is, what would the traffic conditions be if the HOT lanes were not instituted? Before this question can be answered, it is critically important to confirm that the simulation model is adequately calibrated and that it is able to reasonably simulate the current traffic conditions (with the HOT lanes).

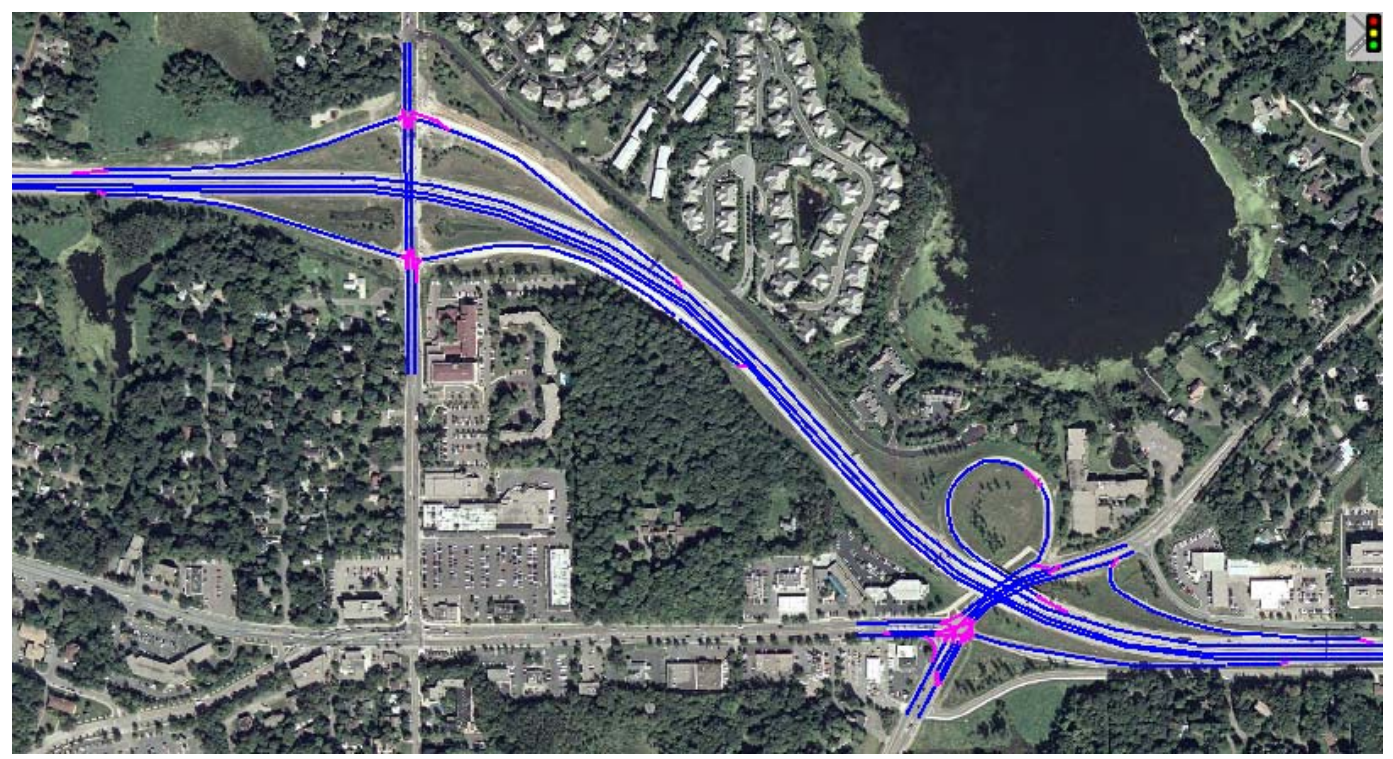

Figure 4.2 Roadway Geometry of I-394 Study Area.

(Image from 2009 Google Earth)

Results of the comparisons between the simulated and the actual traffic conditions were somewhat mixed. The differences between the simulated and the actual data were trivial at some locations while the differences were significant at other locations. Figure 4.3 illustrates examples of some not-so-closely simulated results, while Figure 4.4 illustrates examples of closely simulated results. That said, VISSIM was able to track the overall patterns of the traffic conditions (i.e., throughput and speed) with reasonable accuracy. 


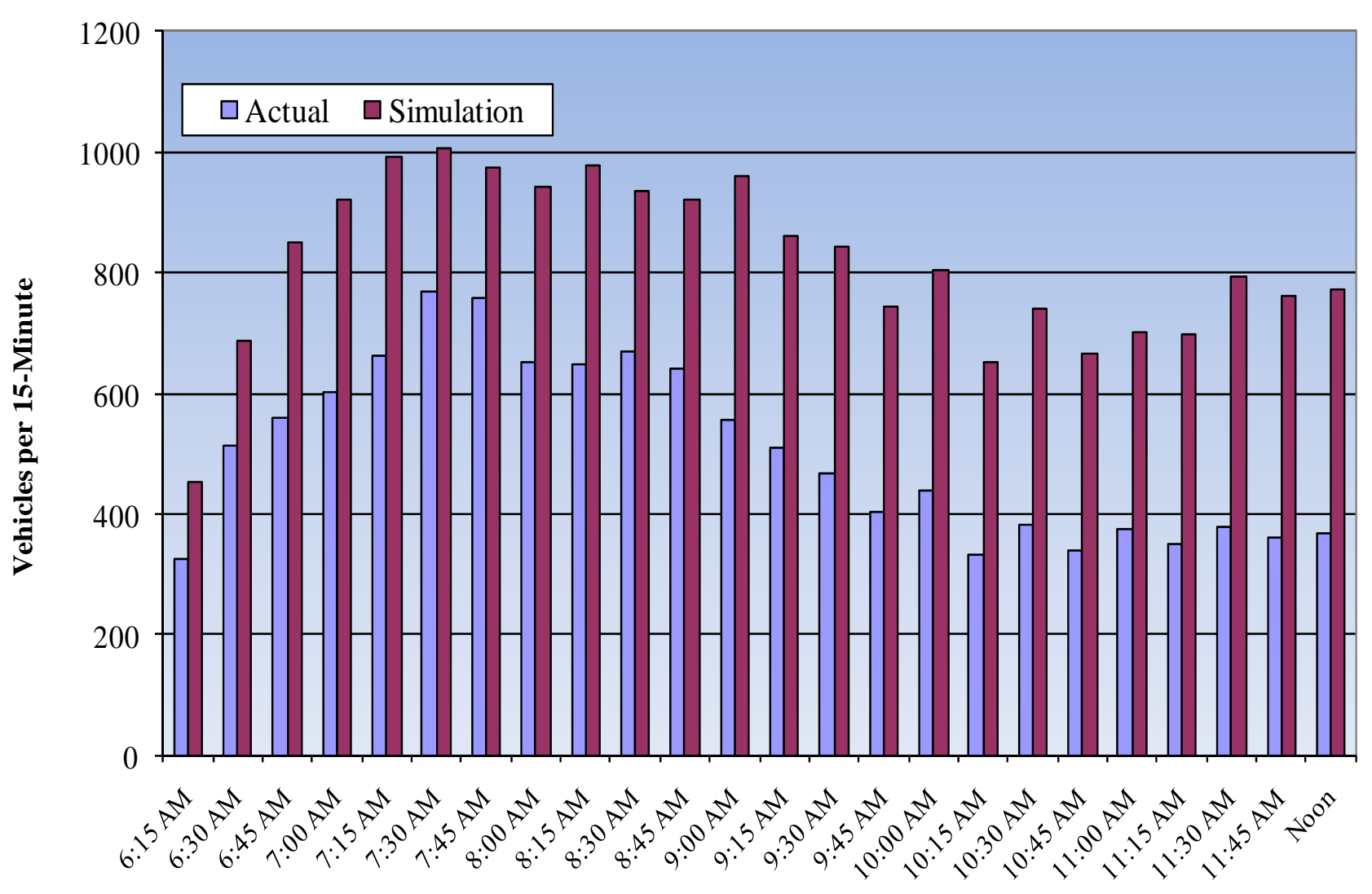

Time

Figure 4.3 Example of noticeable differences between the actual and simulated data. 

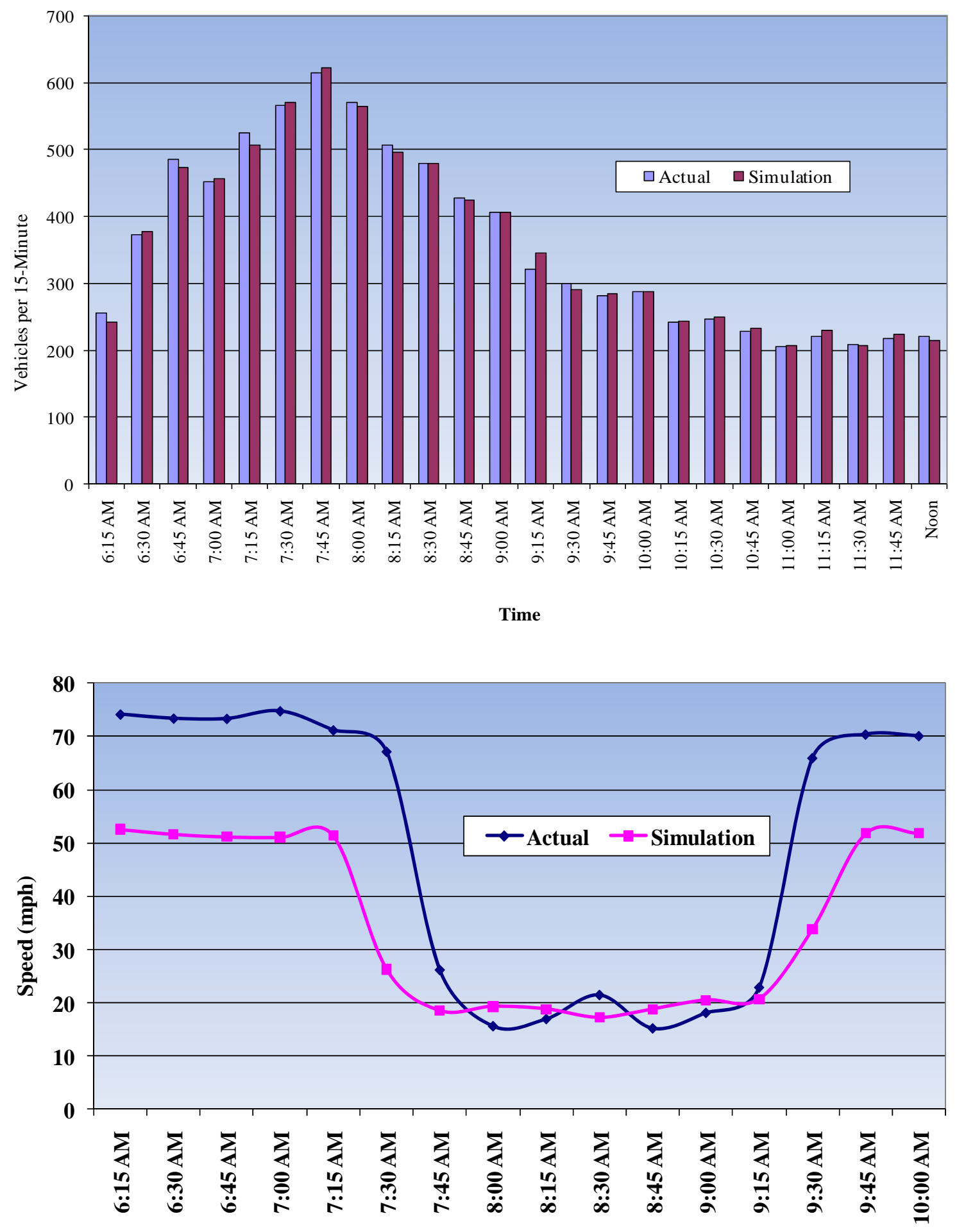

Time

Figure 4.4 Examples of trivial differences between the actual and simulated data.

$$
4-6
$$




\subsection{Simulation Results and Estimated Impacts}

Traffic conditions were simulated for the "no HOT lanes" scenario. It was found that $38 \%$ of the vehicles using the HOT lanes were single occupancy vehicles and the remaining $62 \%$ were high occupancy vehicles ${ }^{2}$. Therefore, if there were no HOT lanes, then $38 \%$ of the HOT lanes traffic should have been travelled on the general-purpose lanes. This assumption was used to simulate the traffic conditions before the HOT lands were added (i.e., the "before" scenario).

Three facilities along I-394 were identified to further understand the impacts of congestion pricing (Figure 4.1):

(1) Eastbound on Xenia Avenue. This facility is located right before the HOT lanes begin.

(2) Eastbound on Trunk Highway (TH) 100, and

(3) The entrance ramp onto TH 100.

From the perspective of speed, the benefits of the HOT lanes were obvious. Without the HOT lands, the conditions in the general purpose lanes started to "collapse” at Xenia Avenue at 6:45 am and only began to recover around 10:30 am (Figure 4.5). With the HOT lanes, speed was maintained above $50 \mathrm{mph}$ until a half-hour later at 7:15 am and began to recover almost an entire hour earlier than when there were no HOT lanes. Even during the slowdown in speed (i.e., between 7:45 am and 9:15 am), the existence of the HOT lanes helped move the flows on the general-purpose lanes at a higher speed than when there were no HOT lanes. Although the impacts of congestion pricing vary from one facility to the next, the trends are indicative in that HOT lanes facilitate moving traffic at a higher speed (Figures 4.5 through 4.7).

\footnotetext{
2 Table 5.3. “I-394 MnPASS Technical Evaluation: Final Report.” Cambridge Systematics, Inc. November 2006.
} 


\section{Impacts of Congestion Pricing}
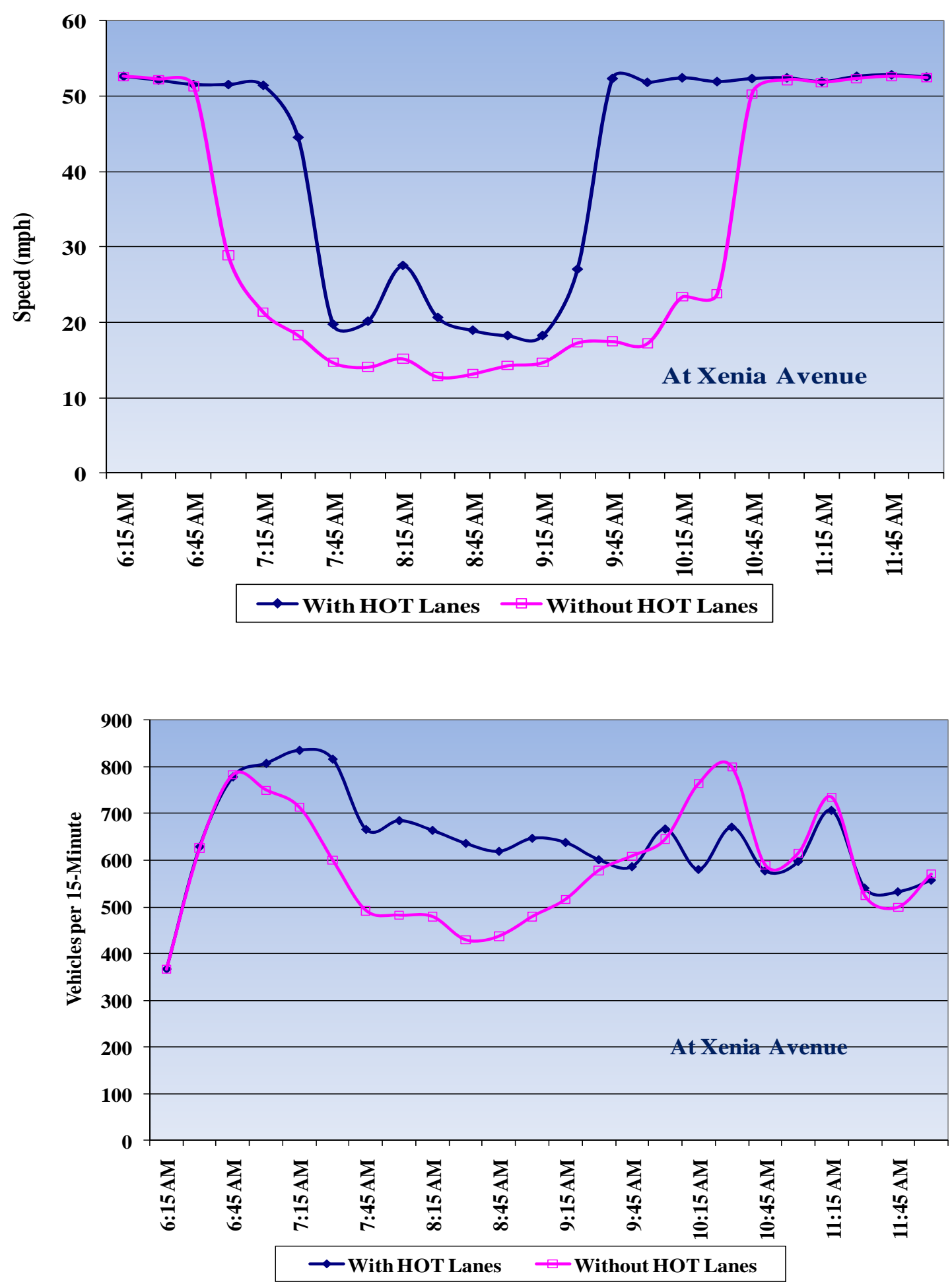

Figure 4.5 Speed and throughput comparisons of the general-purpose lanes at Xenia Avenue. 

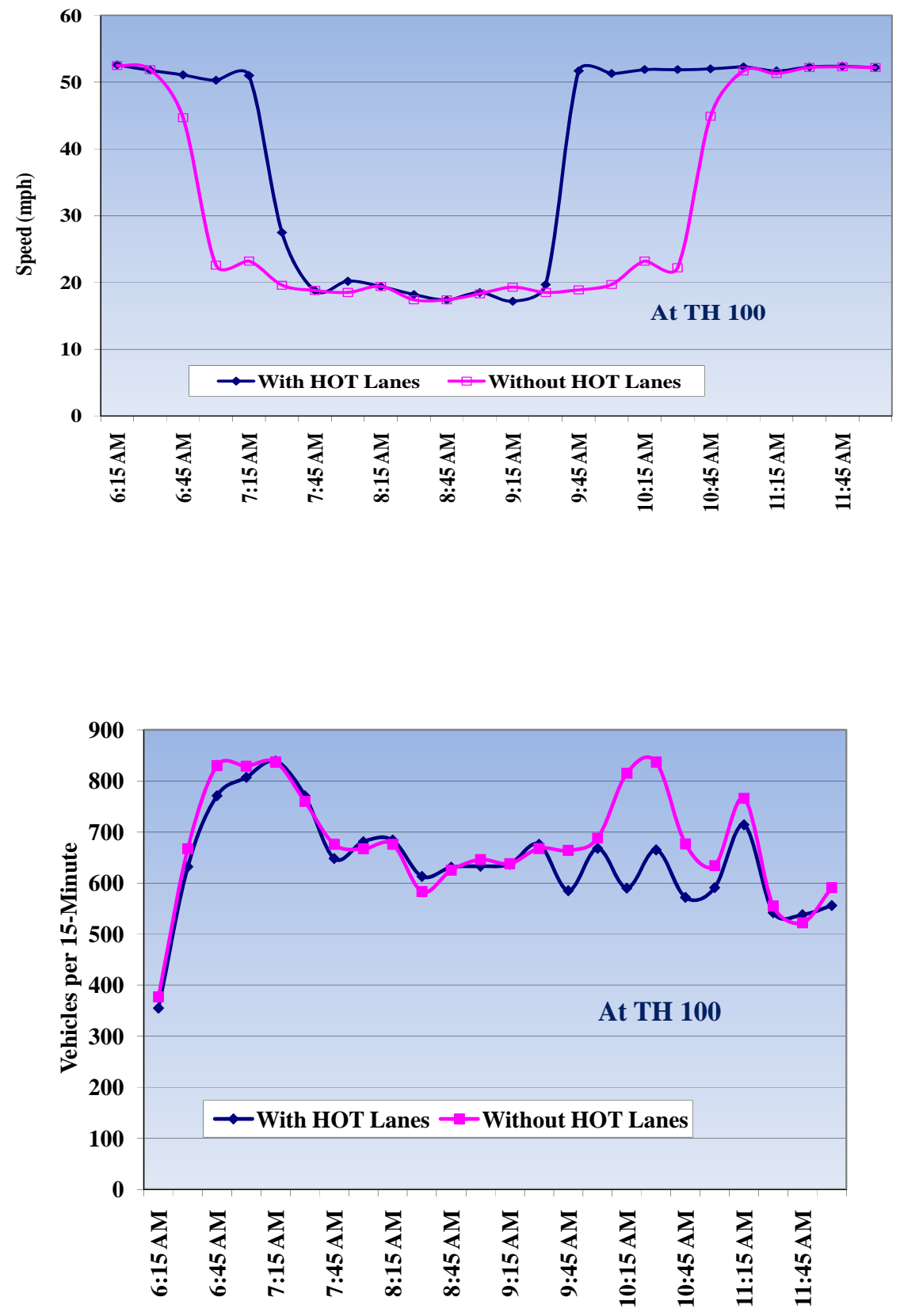

Figure 4.6 Speed and throughput comparisons of the general-purpose lanes at TH 100 . 

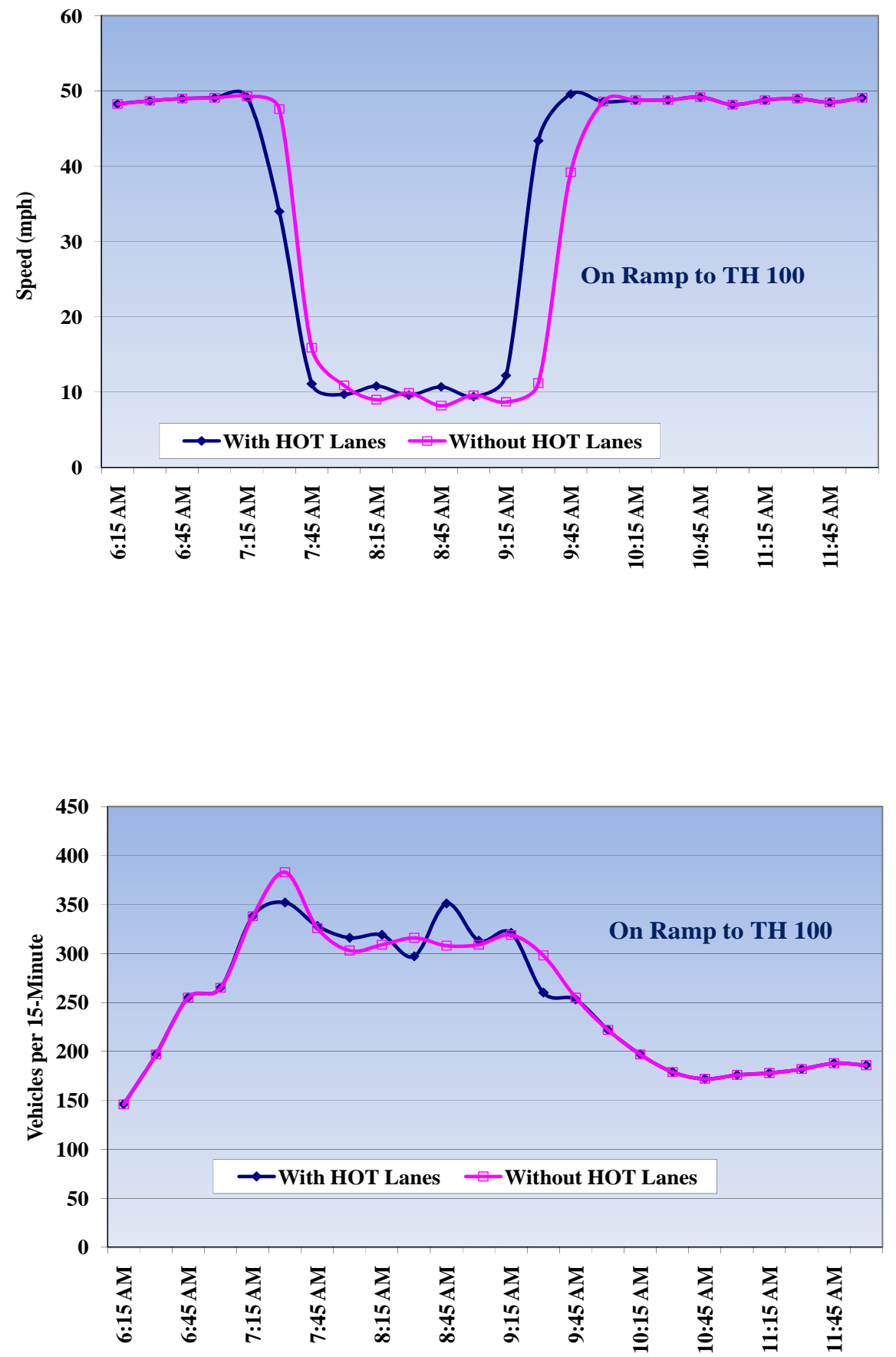

Figure 4.7 Speed and throughput comparisons on ramp to TH 100.

$$
4-10
$$


Impacts of the HOT lanes were simulated for the segment from Xenia Avenue to westbound of Wirth Parkway, which includes the on-ramp to TH 100. Overall, the HOT lanes improve the speed of traffic flow by more than $22 \%$ and reduce total delay by $40 \%$. The difference in the overall VMT is negligible.

Table 4.1 Impacts of HOT Lanes on I-394 Traffic Operations

From Xenia Avenue to Wirth Parkway during the Study Period

\begin{tabular}{|c|c|c|c|}
\hline & $\begin{array}{c}\text { Before } \\
\text { (without HOT Lanes) }\end{array}$ & $\begin{array}{c}\text { After } \\
\text { (with HOT Lanes) }\end{array}$ & \% Change \\
\hline Throughput & 20,088 & 21,396 & $6.51 \%$ \\
\hline VMT & 32,442 & 32,514 & $0.22 \%$ \\
\hline Total Delay (hour) & 772 & 461 & $-40.37 \%$ \\
\hline Average Speed (MPH) & 30.9 & 23.9 & $-22.65 \%$ \\
\hline
\end{tabular}


Impacts of Congestion Pricing

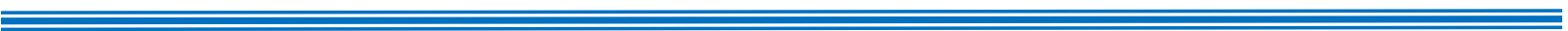

$4-12$ 


\section{IMPACTS OF CONGESTION PRICING ON TRAFFIC ON THE I-95 CORRIDOR}

This chapter first summarizes the evaluation results of two different simulation models: VISSIM and DynusT. Then, impacts of mocked-up pricing scenarios on the I-95 corridor between from I-695 (Baltimore) and I-495 (Washington, DC) are estimated. The chapter concludes by discussing lessons from this corridor study. Unlike the case study on I-394, no congesting pricing was actually implemented on the I-95 study corridor at the time of the analysis. Thus, the simulation model(s) were used to simulate traffic conditions in the presence of congestion pricing strategies (i.e., the "after" scenarios). The simulated results were then compared to the actual observations of traffic conditions to estimate the impacts. The analysis on I-95 focuses not only on speed and throughput changes at individual facilities but also on traffic diversion due to various pricing strategies. Finally, the system-wide impacts of the congestion pricing conclude this chapter.

\subsection{Description and Evaluation of Traffic Analysis and Simulation Models}

Again, since one of the project objectives is to identify and evaluate existing analytical procedures and methods with respect to their ability to realistically simulate the impacts of congestion pricing, only existing methods were considered by this project. Both VISSIM and the Dynamic Urban Systems for Transportation (DynusT) model were considered. VISSIM was selected due to its relative ease of use and its ability to simulate traffic conditions in the I-394 case study with reasonable accuracy. DynusT was selected because: (1) it has been tested using the I-95 data ${ }^{1}$, and (2) it was one of the affordable models that is capable of simulating congestion pricing and traffic diversion. VISSIM was subsequently eliminated from consideration after extensive testing. Results from the tests suggest that VISSIM assigns a small number of vehicles in toll lanes even when the toll is as high as $\$ 100$.

DynusT is a variation of the DYNASMART-P and is among the latest dynamic traffic simulation and assignment tools for regional operational planning analysis. It was developed to assist transportation agencies and practitioners in modeling and decision-making. Another

\footnotetext{
${ }^{1}$ http://www.trb-freewayops.org/5.\%20Value\%20Pricing\%20with\%20DynusT\%20TRB08.pdf
} 
motivation of developing DynusT is to create an open-source model to allow analysts, practitioners, and academia to further develop dynamic traffic assignment research.

Unlike VISSIM, DynusT is based on a mesoscopic modeling concept called the Anisotropic Mesoscopic Simulation (AMS) ${ }^{2}, 3,4$ which is a departure from the typical link-based, queue-server model. The underlining concept of the AMS model is that at any time a vehicle's prevailing speed is affected only by vehicles in front/ahead of it, including those in the (immediate) adjacent lanes. In other words, for any vehicle $i$, only those leading vehicles (in the same lane or in the adjacent lanes) present in vehicle $i$ 's immediate downstream and within a certain distance are considered to be influential to vehicle $i$ 's speed response. This is a similar concept to stimulus-response type of car-following models with the difference that the stimulus of a vehicle's speed response is represented in a macroscopic form.

In DynusT, congestion pricing impacts are modeled based on the assumptions that a driver makes his/her route choice decisions by taking into account both travel time and toll rates. Drivers with a higher value of time will perceive the toll as having less impact on their trips when comparing to those with a lower value of time. In other words, if it is perceived that travel time is shorter in the HOT lanes, then drivers with a higher value of time are more likely to use the toll facilities. DynusT estimates the traffic and revenue for different HOT/HOV scenarios by equilibrating the generalized cost consisting of actual travel time and the equivalent travel time based on toll rates and value of time.

\subsection{Traffic Data and Calibration}

The input data set for the I-95 corridor simulation is calibrated to the traffic information collected by the Coordinated Highways Action Response Team (CHART) ${ }^{5}$. Traffic data are collected by 7 detectors on I-95 and two on I-495 (Figure 3.5). The instantaneous speed

2 Y.-C. Chiu and L. Zhou, “An Anisotropic Mesoscopic Traffic Simulation Model: Basic Properties and Numerical Analysis,” presented at the 85th Annual Meeting of Transportation Research Board, Washington, D. C., 2006.

3 Y.-C. Chiu and H. Song, "The Development and Calibration of the Anisotropic Mesoscopic Simulation Model on Uninterrupted Flow Facilities,” presented at the 86th Annual Meeting of TRB, Washington, D.C., 2007.

4 Y.-C. Chiu, “An Anisotropic Mesoscopic Traffic Simulation Model for Uninterrupted Flow Facilities: Part I: Basic Properties and Numerical Analysis,” Transportation Research Part B (under review), 2008.

5 http://www.chart.state.md.us/ 
information is refreshed every 5-minutes and can be access from the web $^{5}$. A sample of the CHART speed data is illustrated in Table 5.1. Unfortunately, the volume data cannot be obtained directly from the CHART web site. A copy of the speed and volume data for every 15minute interval was, however, provided by the University of Maryland ${ }^{6}$. Speed recorded as “over $65 \mathrm{mph}$ ” was given a numeric value of $65 \mathrm{mph}$ in the analysis. Specifically, speed and volume data on May, 11, 2008 were used for the DynusT model calibration.

Table 5.1 Sample of CHART data

\begin{tabular}{|l|l|l|}
\hline I-95 @ Brooklyn Bridge Rd North & $55.5 \mathrm{MPH}$ & $2 / 23 / 2010$ 9:18:32 AM \\
\hline I-95 @ MD Welcome Center North & Over 65 MPH & $2 / 23 / 2010$ 9:15:36 AM \\
I-95 @ Montgomery Road North & Over 65 MPH & $2 / 23 / 2010$ 9:14:36 AM \\
\hline I-95 between Cherry Hill and MD 212 North & Over 65 MPH & $2 / 23 / 2010$ 9:17:42 AM \\
I-95 between Cherry Hill and MD 212 South & $40 \mathrm{MPH}$ & $2 / 23 / 2010$ 9:13:47 AM \\
I-95 south of MD 175 South & $62.5 \mathrm{MPH}$ & $2 / 23 / 2010$ 9:14:14 AM \\
I-95 south of MD 175 North & $62.7 \mathrm{MPH}$ & $2 / 23 / 2010$ 9:16:00 AM \\
\hline I-95 South of Montgomery Road South & $55.9 \mathrm{MPH}$ & $2 / 23 / 2010$ 9:14:23 AM \\
\hline
\end{tabular}

The quality of the CHART data was carefully examined before they were used for model calibration. When examined in the context of traffic flow, CHART data at certain locations appeared to be unreasonable. One such example is the very-low throughput recorded at I-95 @ MD 32 and at Maryland Welcome Center on May 7, 2008 (Figure 5.1). When examined at the individual detector level, the throughput at the 15-minute interval seems to follow a reasonable pattern. However, when compared with the throughput profiles at the adjacent locations, it became apparent that the throughput data at I-95@ MD 32 and at Maryland Welcome Center were erroneous. In this case, the erroneous data recorded at I-95 @ MD 32 and at Maryland Welcome Center were deleted from subsequent analysis.

\footnotetext{
${ }^{6}$ With the assistance of Mr. Pack, Director of the Center for Advanced Transportation Technology Laboratory at the
} University of Maryland in College Park. 
Impacts of Congestion Pricing

\#3. S of MD175 - Volume
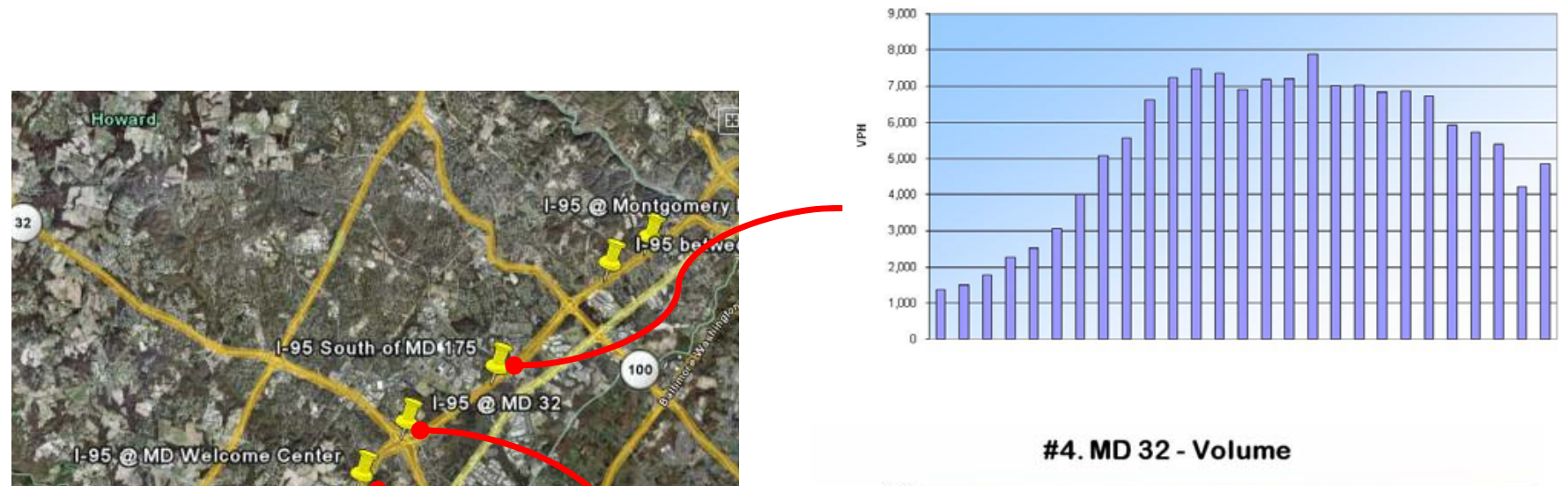

\#4. MD 32 - Volume
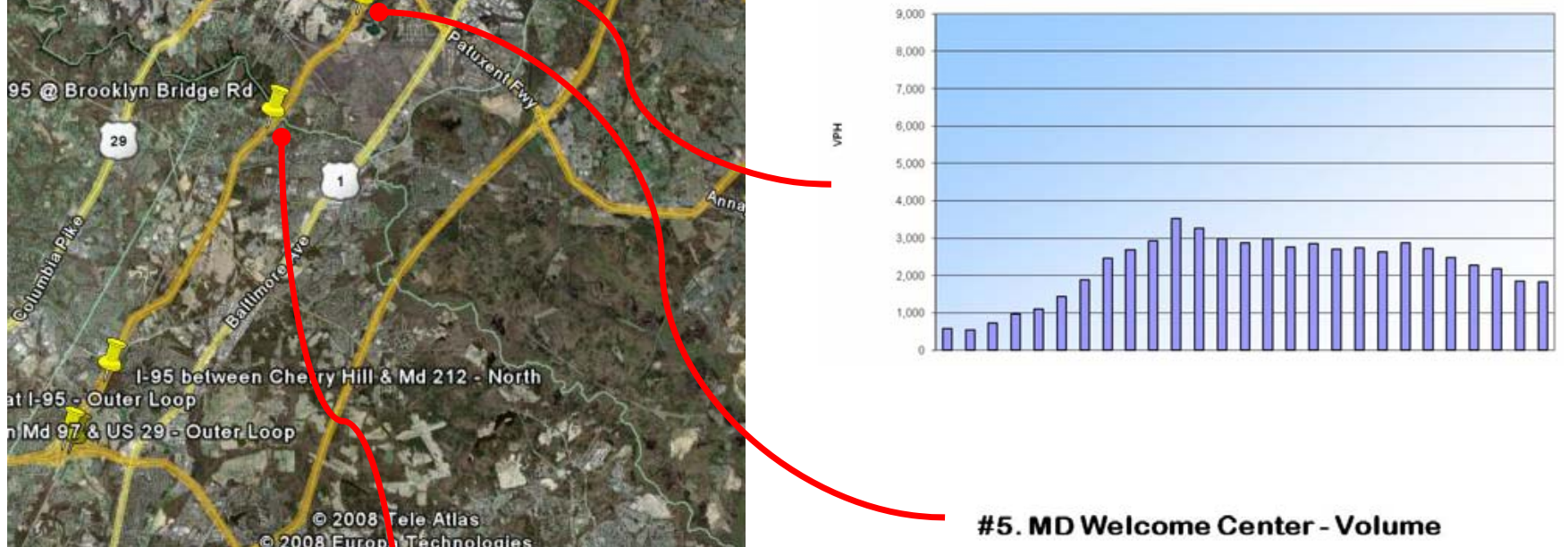

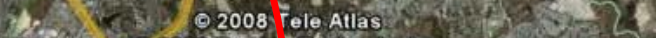
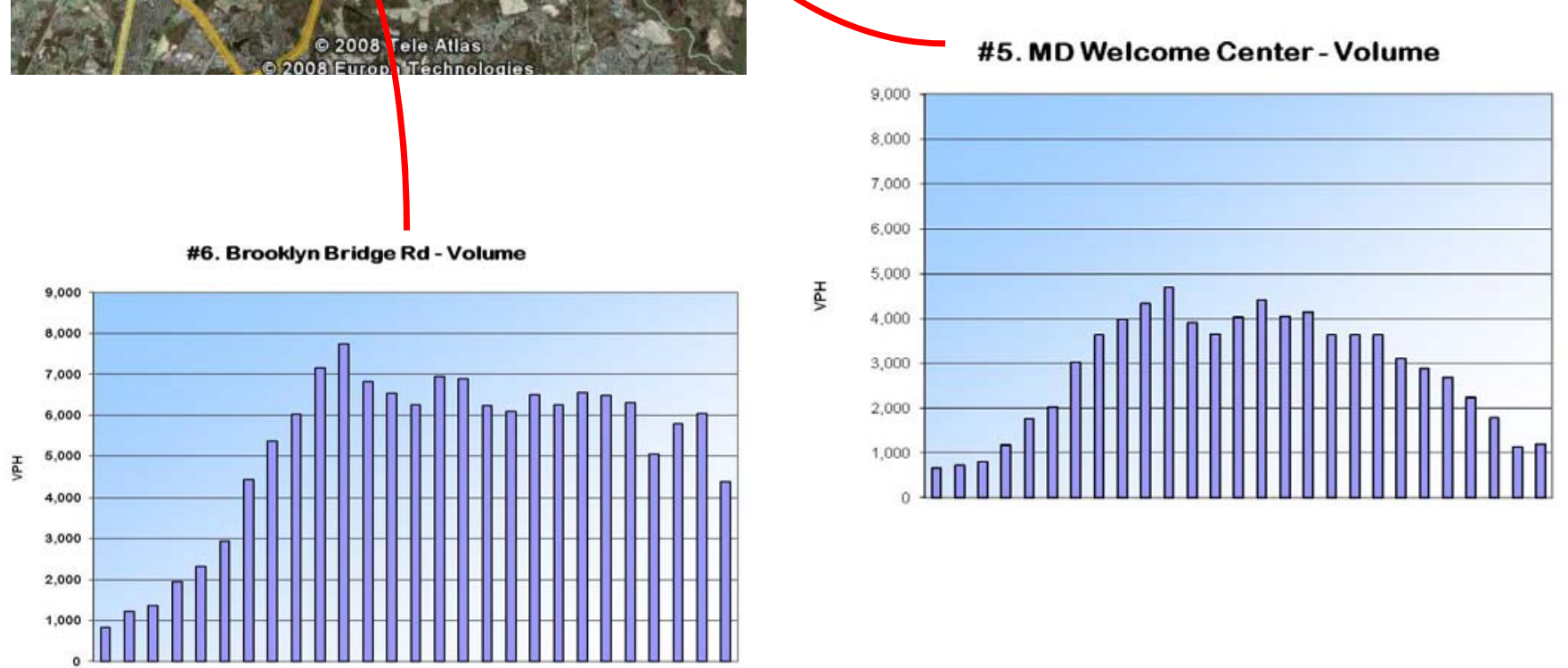

Figure 5.1 Questionable throughput data. 
Once the erroneous CHART data were deleted, DynusT was calibrated to the remaining CHART data. The study area has 2,182 nodes, 3,387 links, and 111 origin and destination zones. Figure 5.2 depicts the I-95 study area in DynusT. Traffic was simulated from 4:00 am to 10:40 am. It is important to note that the simulated impacts of congestion pricing -- the throughput, trip length, speed, travel time, or hours of delay -- are only pertinent to travel on the links that are within the study area. Thus, if one is to travel from an origin north of Baltimore which is outside the study area to a destination south of Washington, DC which is also outside the study area, then only the portion of his/her trip that is within the study area will be included in the impact analysis. This feature makes the interpretation of system-wide impacts more challenging. One such example would be the estimated trip length. If the estimated trip length is 10 miles when there is no toll and the estimated trip length is 10.5 miles when a $20 \mathbb{4}$ toll is imposed, then the impact of congestion pricing is estimated to be such that a $20 \pitchfork$ toll makes traversing the study area 5\% longer in length.

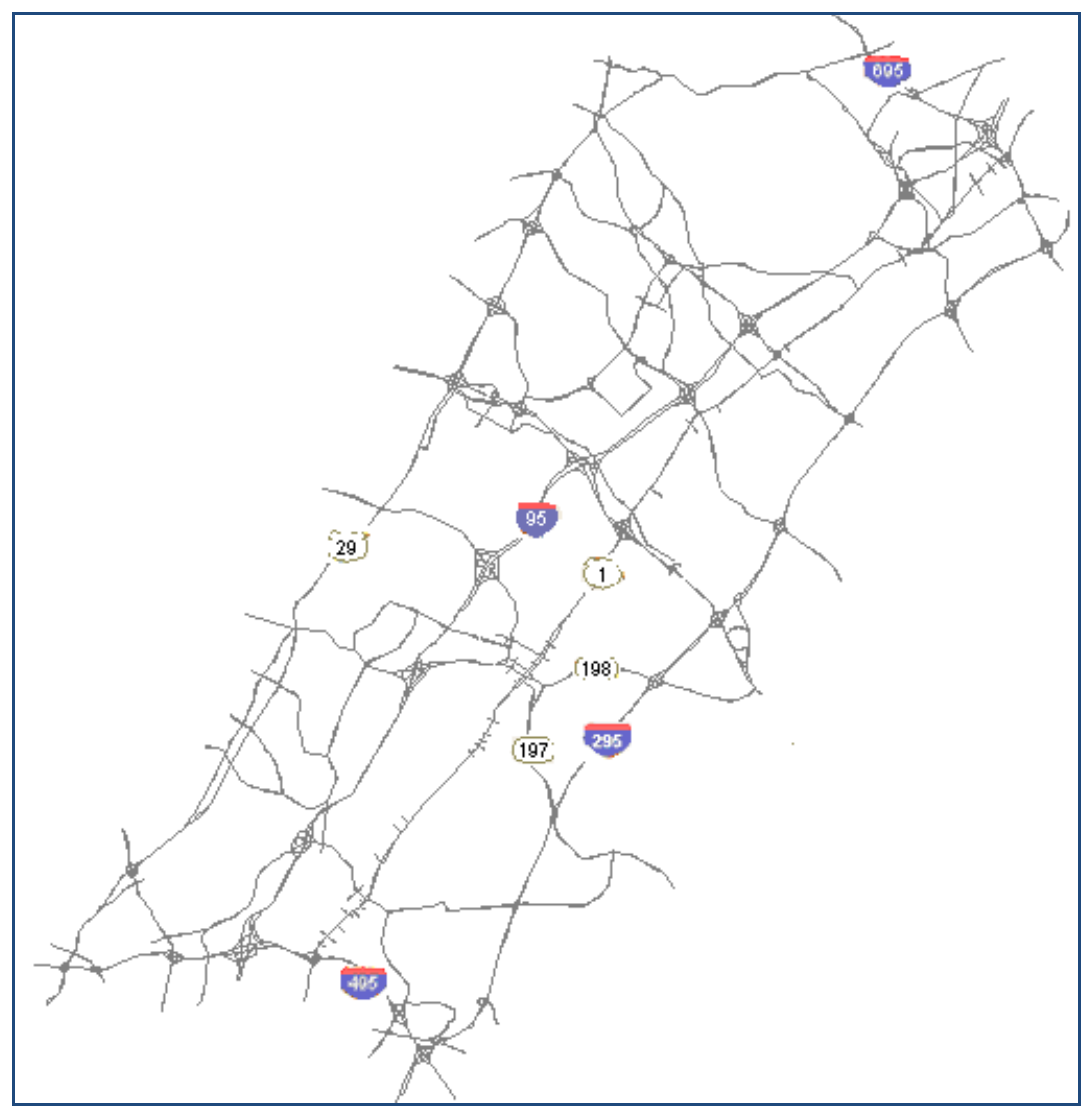

Figure 5.2 Representation of the I-95 study area as represented in DynusT. 
Results from the initial model calibration (Figure 5.3) led to extensive diagnostics of the model's validity. For example, although the relationship between speed and lane density on Link 370 is reasonable, the relationship between speed and throughput is questionable (Figure 5.3). Steps taken and findings from the diagnostics are summarized in Appendix 1. The diagnostics led to a change in DynusT where only one traffic model was applied to all links on I-95 study corridor. Prior to the change, one link could be using a traffic model which is different from the ones used on the adjacent links. After the change, DynusT was recalibrated to the 2008 CHART data.

\subsection{Simulation Results and Estimated Facility-Based Impacts}

Impact analysis was based on the following specifications:

- Traffic was simulated for peak hours, from 4:00 am to 10:30 am;

- Simulation was calibrated to 2008 CHART traffic volume;

- Tolls were imposed at each of the entrance ramps on I-95 southbound;

- Impacts focused on throughput, speed, and traffic diversion;

- Toll scenarios used were: 20థ, 80థ, \$1.00, \$2.00, and \$7.00; and

- Vehicle trajectory was simulated for each of the 351,688 vehicles travelling on the study network.

The toll scenarios were set at incremental intervals so to test the sensitivity of different pricing levels on the pricing impacts. 

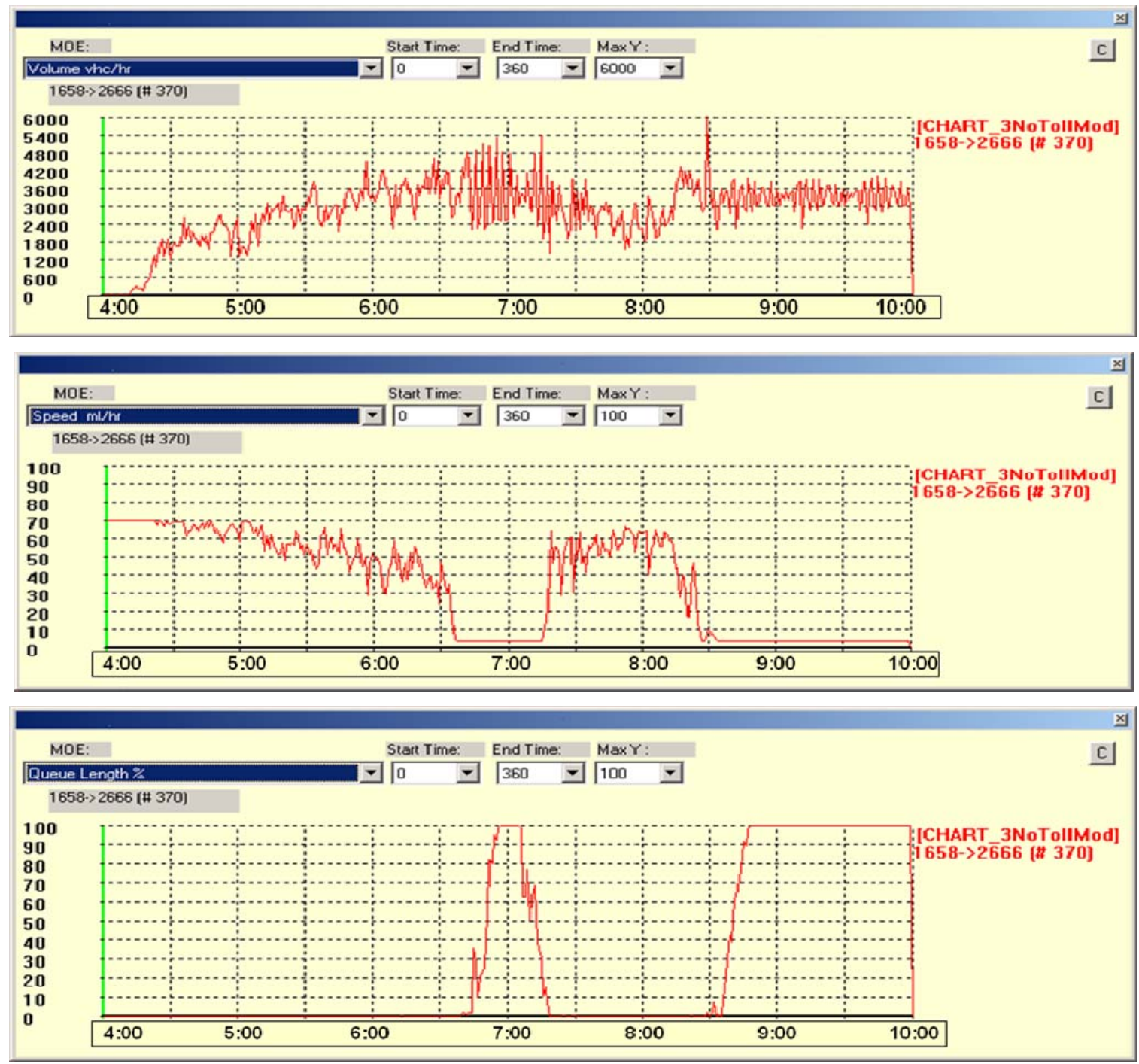

Figure 5.3 Throughput, speed and lane density of link 370 on I-95 no toll scenario.

$$
5-7
$$


Similar to the findings on I-394, pricing seems to improve the speed of traffic flow (Figure 5.4). Figure 5.4 compares speed data collected from CHART, the speed profile simulated by DynusT when no toll is imposed, and the simulated speed when a toll is imposed. The traffic volume comparisons among three scenarios are in Figure 5.5. Also in Figure 5.5 is the cumulative difference between the no-toll and the 20\$ toll. The cumulative difference in throughput during the study period (4:15 am to 10:30 am) can be used to gauge the net gain in throughput as a result of the toll.

The differences in throughput between the "no toll" and the "20ष toll” scenarios range widely, from fewer than 1,000 vehicles to more than 1,000 vehicles for a 15-minute interval (Figure 5.5). The fluctuation makes it difficult to gauge the overall impacts of pricing on throughput. Alternatively, the differences at 15-minuate intervals were accumulated over the entire study period. It is estimated that a 204 toll will increase the total number of vehicles travelling through Cherry Hill by 4,000 vehicles (Figure 5.5), or roughly one-fifth of the typical hourly throughput at Cherry Hill when no toll is imposed.

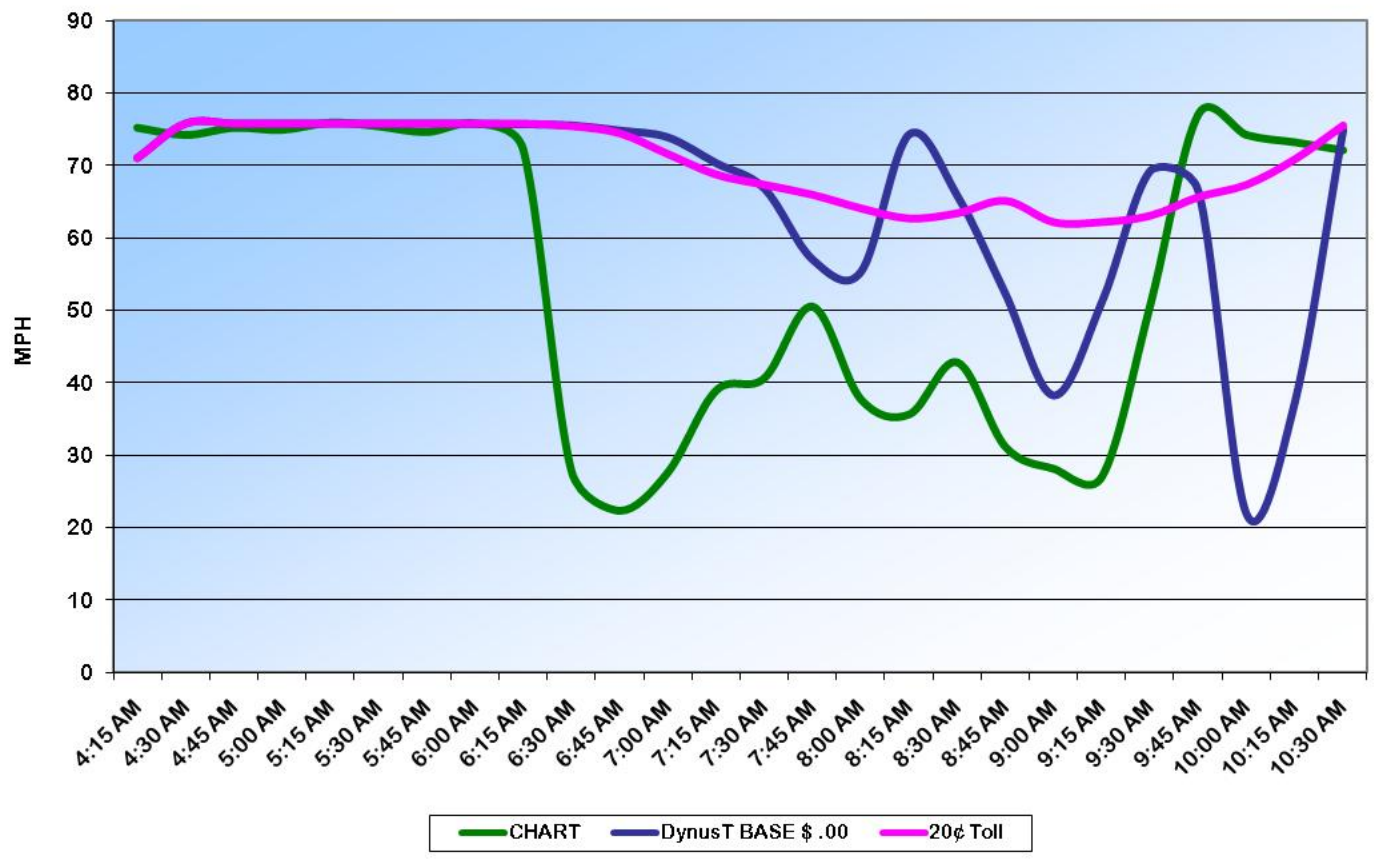

Figure 5.4 Comparison of speed profiles at Cherry Hill. 

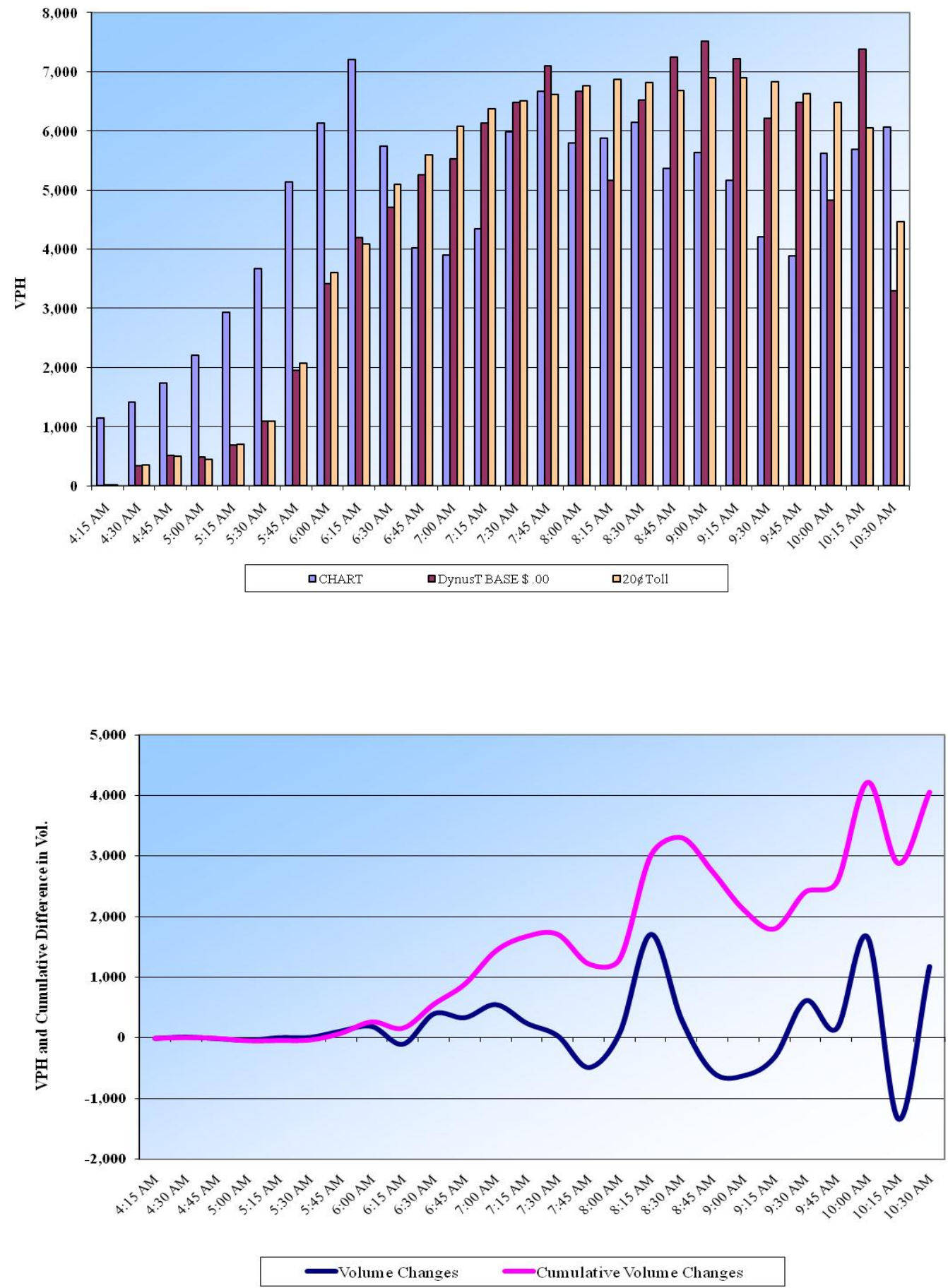

Figure 5.5 Throughput comparison at Cherry Hill. 
While a $20 \$$ toll improves throughput at Cherry Hill during the study period, this improvement diminishes with increasing tolls. The simulated results suggest that increases in toll could eventually level or reduce the impacts of pricing at a given facility, primarily due to the fact the traffic will begin to divert away from the facility when the toll increases to a certain level. When the toll increases from $20 \$$ to $80 \AA$, more than 6,000 vehicles are diverted from Cherry Hill to other links during the study period as a result of the $80 \AA$ toll (Figure 5.6). As expected, the extent of diversion increases as the toll increases. This finding confirms that the impacts of congestion pricing should be analyzed at the system level to fully consider the effects of diversion to other links, instead of at the facility/link level. Also, more research will be necessary to understand drivers' decisions to divert, and to estimate the impacts of pricing based on more realistic pricing strategies.

\subsection{Impact of Congestion Pricing on Traffic Diversion}

The impact of congestion pricing on traffic diversion on I-95 southbound (SB) was analyzed based on the following three specifications:

- Consideration of traffic that is diverted from, or diverted to, all or part of the 46 links in the I-95 study area,

- Comparison of the "no toll" to a toll scenario, and

- Simulated vehicle trajectory for each of the 351,688 vehicles traveled on the study network.

A separate simulation was conducted for each of the pricing scenarios.

When a toll is imposed, a driver will make one of the four traffic-diversion decisions (Table 5.2) and the driver can be categorized into one of the following groups:

1 Indifferent to the toll. Drivers who continue to travel on I-95 SB without any route changes.

2 Somewhat indifferent to the toll. Drivers who continue to travel on I-95 SB but with some route changes away from I-95 SB. 
Table 5.2 Possible Diversion Scenarios When a Toll is Imposed

\begin{tabular}{|c|c|c|c|}
\hline \multirow{2}{*}{\multicolumn{2}{|c|}{$\begin{array}{l}\text { Diversion } \\
\text { Scenarios }\end{array}$}} & \multicolumn{2}{|l|}{ No Toll } \\
\hline & & Use & Not Use \\
\hline \multirow{2}{*}{ 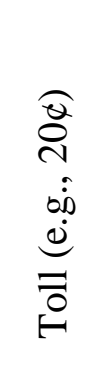 } & Use & 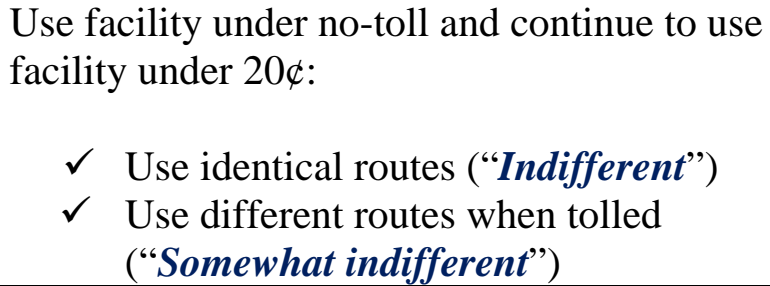 & $\begin{array}{l}\text { Do not facility under } \\
\text { no-toll but use } \\
\text { facility under } 20 \notin \text { toll } \\
\text { ("Newcomer") }\end{array}$ \\
\hline & Not Use & $\begin{array}{l}\text { Use facility under no-toll but bypass facility } \\
\text { under } 20 \$ \text { toll ("Unwilling/unable to pay") }\end{array}$ & \\
\hline
\end{tabular}

3 Unwilling and/or unable to pay. Drivers who used to travel on, but who completely bypass, I-95 SB when a toll is imposed.

4 Eager to pay. Newcomers who never travel on I-95 SB when there is no toll, but who begin to travel on I-95 SB when a toll is imposed. 

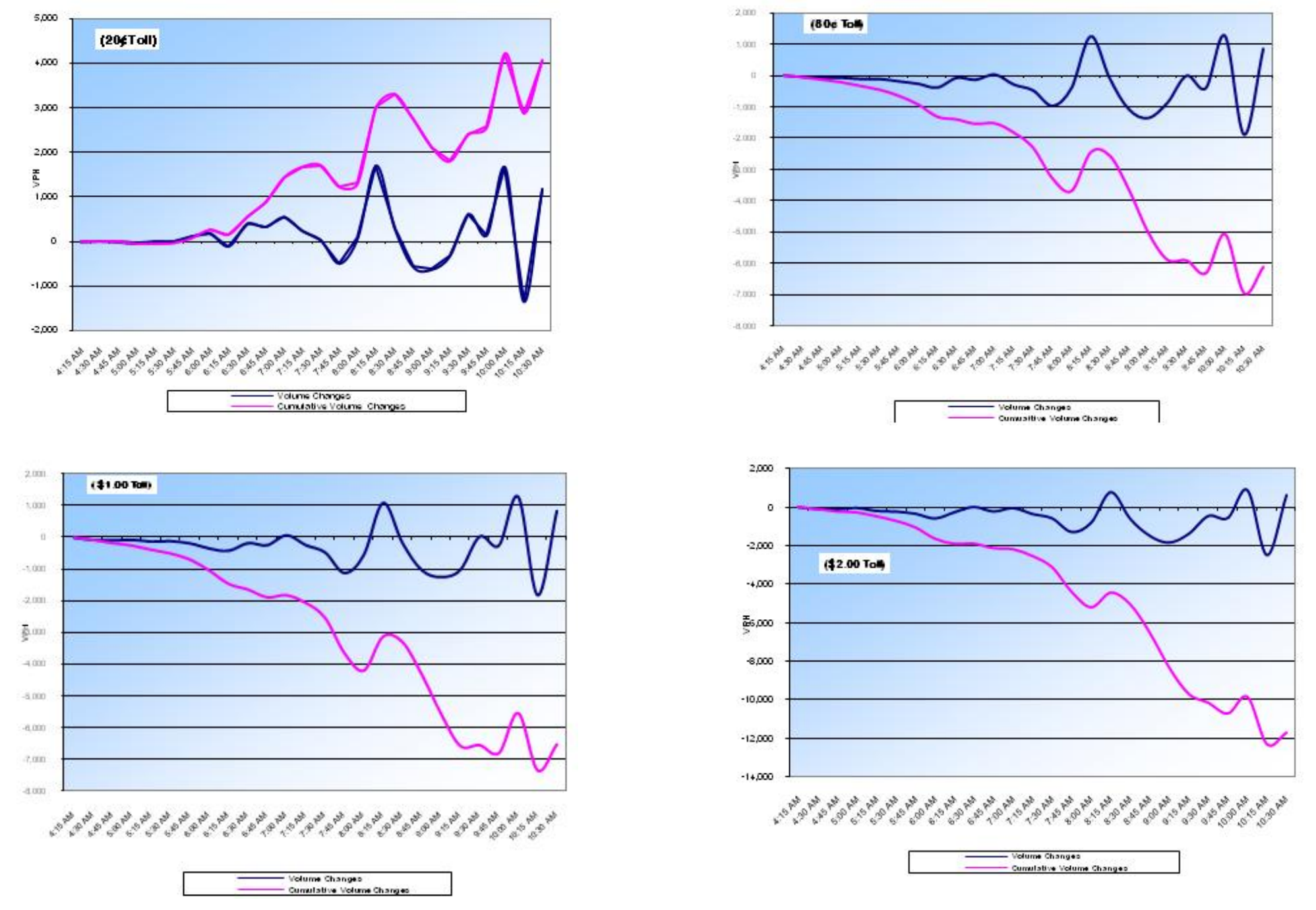

Figure 5.6 Differences and cumulative differences in throughput due to different tolls. 
Using DynusT, vehicle trajectories were simulated for each one of the 351,688 vehicles that traveled on the study network for each of the pricing scenarios. For example, Table 5.3 lists the individual nodes traveled by vehicle No. 480. By comparing the trajectories between the notoll and the $20 \$$ toll scenario, it was determined that vehicle No. 480 is an example of the "unwilling and/or unable to pay" because it used to travel on, but then bypassed, I-95 SB when a $20 \nsubseteq$ toll was imposed. Its simulated routes are illustrated in Figure 5.7.

Table 5.3 Simulated Trajectories of An "Unwilling/Unable to Pay" Vehicle No. 480, Comparing No Toll to 20๕ Toll

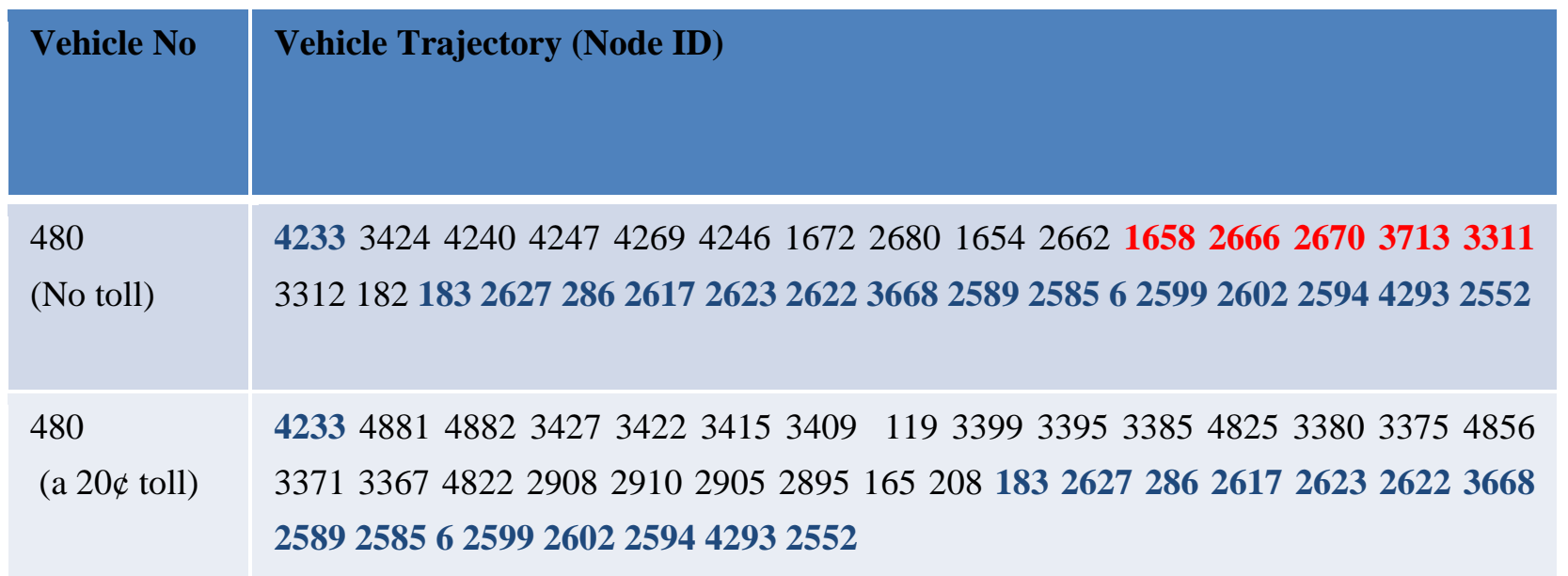

Color Code: Blue - Identical nodes between the no-toll and toll scenarios Red - Nodes on I-95 SB

Black - Different nodes between the no-toll and toll scenarios 


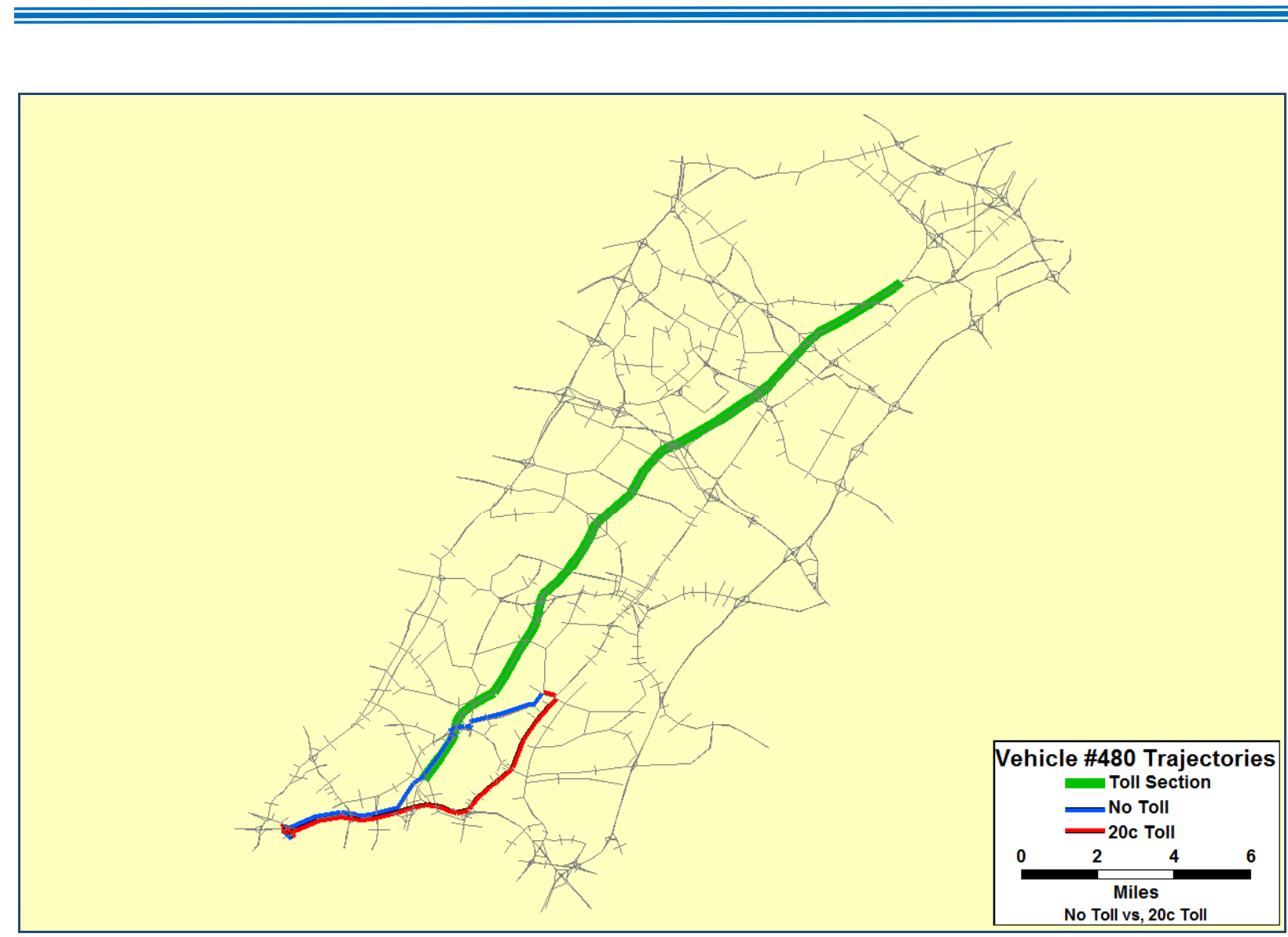

Figure 5.7 Simulated Routes of An "Unwilling/Unable to Pay” Driver Vehicle No. 480, Comparing No Toll to 20๕ Toll.

Table 5.4 and Figure 5.8 illustrate the simulated trajectories of an indifferent driver who adhered to his/her original trajectories on I-95 SB even when a 20థ toll was imposed. Table 5.5 and Figure 5.9 illustrate similar information on a somewhat-indifferent driver who continued to travel on I-95 but altered his/her route slightly when a 20\$ toll was imposed. Table 5.6 and Figure 5.10 illustrate similar information for a newcomer who was eager to pay the toll to travel on I-95. 
Table 5.4 Simulated Trajectories of An "Indifferent" Driver Vehicle No. 1327, Comparing No Toll to 20థ Toll

\begin{tabular}{|c|c|}
\hline Vehicle No & Vehicle Trajectory (Node ID) \\
\hline $\begin{array}{l}1327 \\
\text { (No toll) }\end{array}$ & $\begin{array}{l}43414342306651133883388130604850306530563052305116113461 \\
3894311253331113107310434583459743346034532301229922912311 \\
22964171\end{array}$ \\
\hline $\begin{array}{l}1327 \\
\text { (20థ toll) }\end{array}$ & $\begin{array}{l}43414342306651133883388130604850306530563052305116113461 \\
3894311253331113107310434583459743346034532301229922912311 \\
22964171\end{array}$ \\
\hline
\end{tabular}

Color Code: Blue - Identical nodes between the no-toll and toll scenarios Red - Nodes on I-95 SB

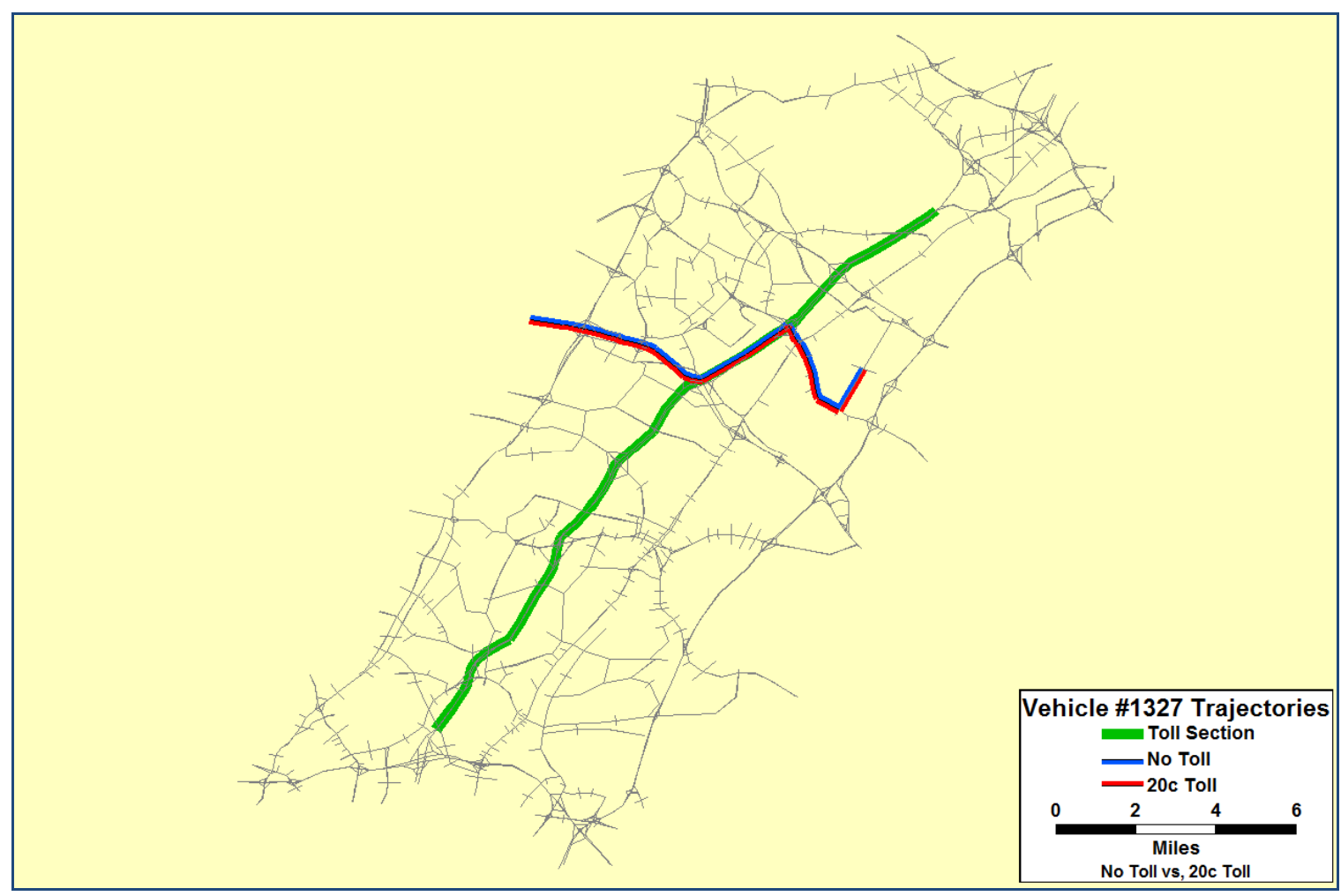

Figure 5.8 Simulated Routes of An “Indifferent” Driver Vehicle No. 1327, Comparing No Toll to 20屯 Toll. 
Table 5.5 Simulated Trajectories of A “Somewhat Indifferent” Driver Vehicle No. 108, Comparing No Toll to 20థ Toll

\begin{tabular}{|l|l|l|}
\hline Vehicle No & Vehicle Trajectory (Node ID) \\
\hline 108 & 15691776177517781103382138223824352435261590409619641969 \\
(No toll) & 3268382638283831383215932994332333243325598349334913486 \\
& 62170734965147 \\
\hline 108 & 15691776177517781103382138223824352435261590409619641969 \\
\hline $20 \notin$ toll) & 32683826382838313832159329943323332433273508350735183512 \\
& 3506395370734965147 \\
\hline
\end{tabular}

Color Code: Blue - Identical nodes between the no-toll and toll scenarios Red - Nodes on I-95 SB

Black - Different nodes between the no-toll and toll scenarios

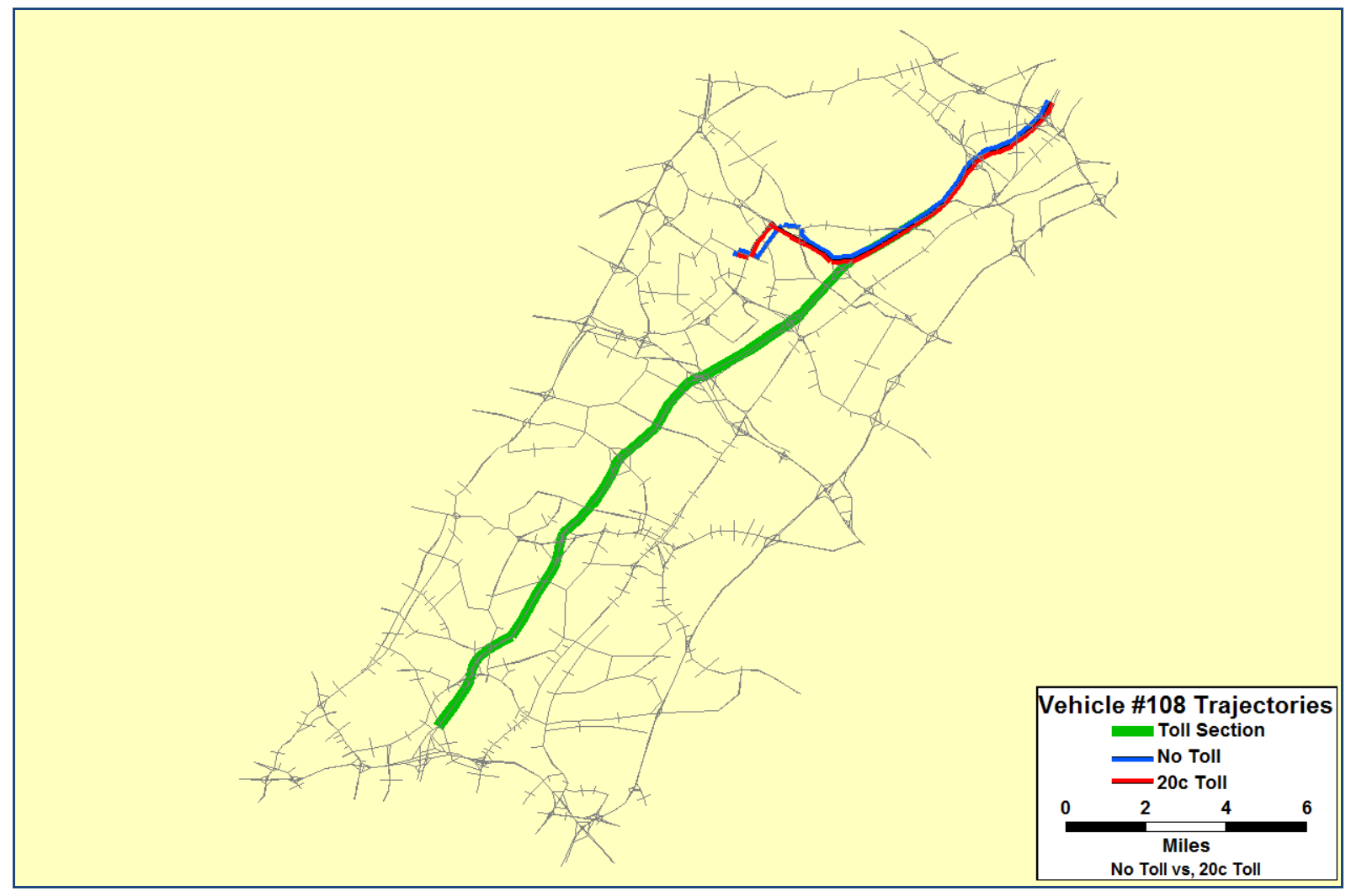

Figure 5.9 Simulated Routes of A “Somewhat Indifferent” Driver Vehicle No. 108, Comparing No Toll to 20థ Toll. 
Table 5.6 Simulated Trajectories of A "Newcomer"

Vehicle No. 953, Comparing No Toll to 20థ Toll

\begin{tabular}{|c|c|}
\hline Vehicle No & Vehicle Trajectory (Node ID) \\
\hline $\begin{array}{l}953 \\
\text { (No toll) }\end{array}$ & $\begin{array}{l}356640931921192611371939485217121942485419731981326038593861 \\
386368938653866386938723875387051675163598349334913486621 \\
707349651465103394239415099216821742182215815434175\end{array}$ \\
\hline $\begin{array}{l}953 \\
\text { (20® toll) }\end{array}$ & $\begin{array}{l}356640931921192611371939115411561929157935281577352615904096 \\
19641969326838263828383138321593160030063879160473351833050 \\
30463042652303130323946394451033942394150992168217421822158 \\
15434175\end{array}$ \\
\hline
\end{tabular}

Color Code: Blue - Identical nodes between the no-toll and toll scenarios

Red - Nodes on I-95 SB

Black - Different nodes between the no-toll and toll scenarios

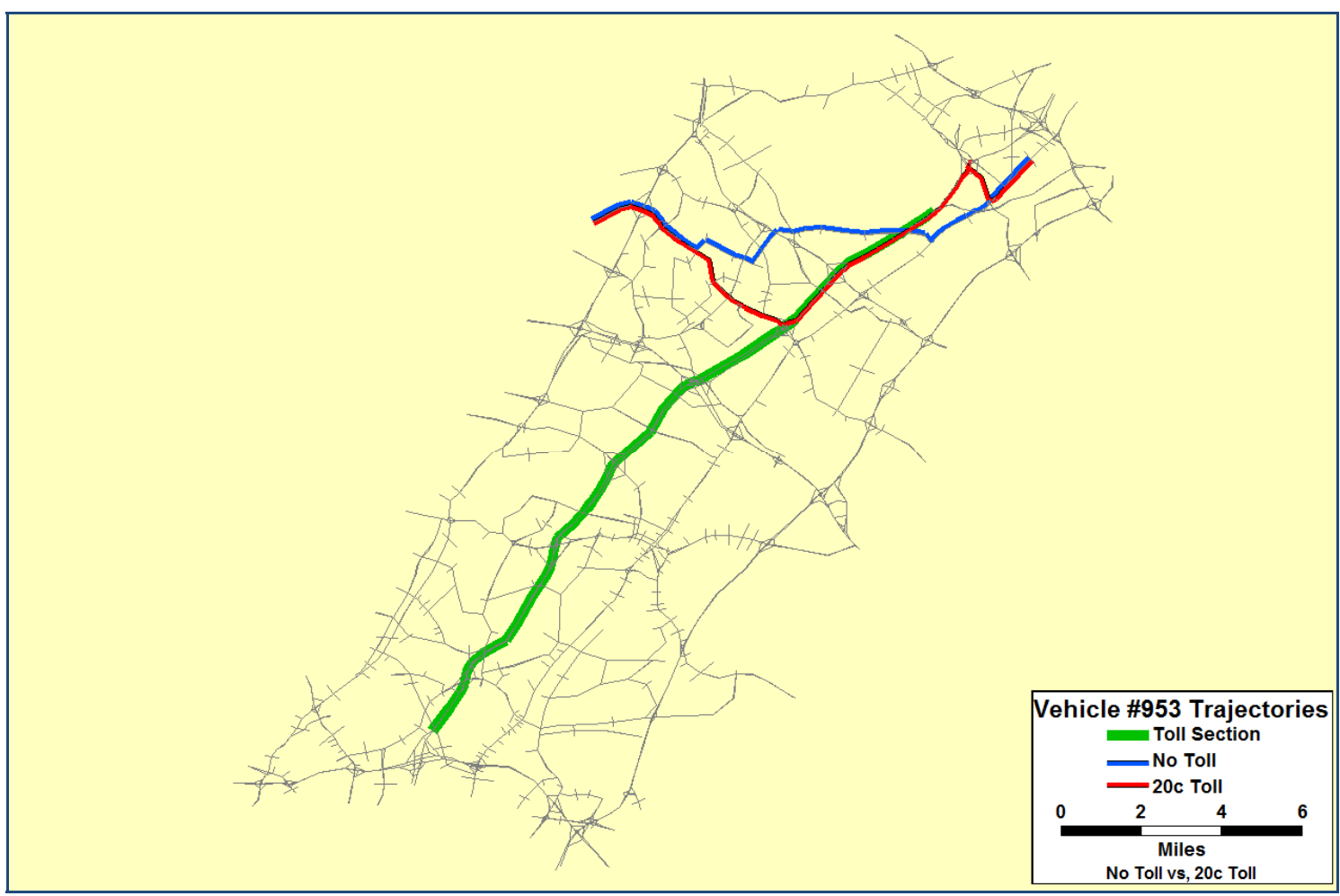

Figure 5.10 Simulated Routes of A "Newcomer"

Vehicle No. 108, Comparing No Toll to 20๔ Toll. 
By comparing the trajectories of each of the 351,688 vehicles that travelled on the study network, the impacts of congestion pricing on traffic diversion were quantified. Of the 351,688 vehicles, 51,179 vehicles travelled on all or some of the 46 links on the I-95 SB study corridor when no toll was imposed. When a $20 \$$ toll is imposed, 9,938 vehicles/drivers $(19.4 \%$ of the 51,179 vehicles) were unwilling and/or unable to pay, and bypassed I-95 SB. Thirty-two percent (16,427 out of 51,179 vehicles) adhered to their original routes and $48.5 \%$ (24,814 out of 51,179 vehicles) continued to travel on I-95 but altered their routes slightly when a $20 \$$ toll was imposed (Figure 5.11). With the perception that a $20 \$$ toll would improve traveling speed on the I-95 study corridor, 8,397 vehicles began to travel on all or some of the 46 links on I-95. Even with the "newcomers," the $20 \$$ toll was not enough to offset the traffic diverted away from I-95.

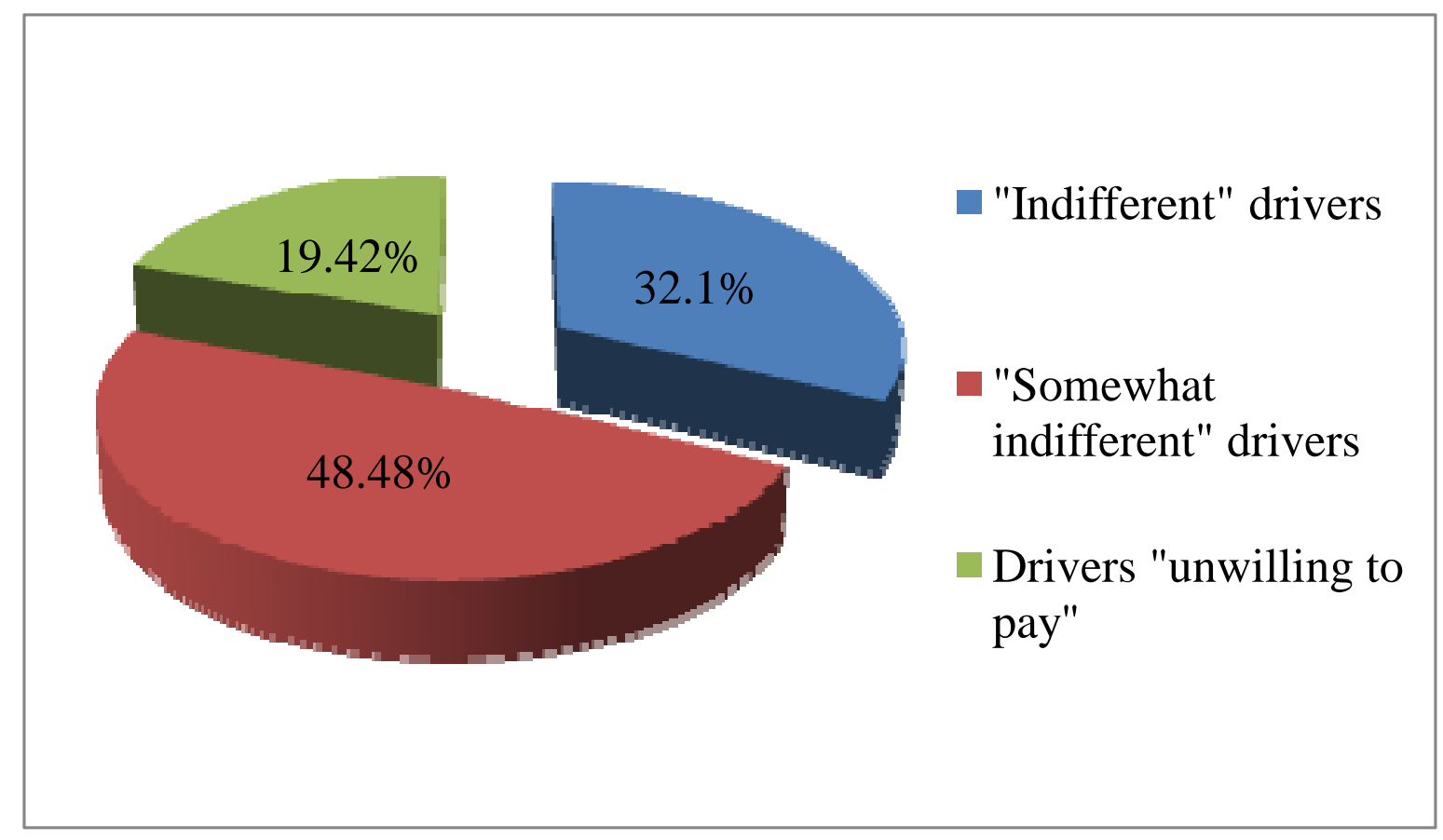

Figure 5.11 Distribution of drivers categorized by their route choice decisions, when a $20 \pitchfork$ toll is imposed. 
Repeating this process for each of the five pricing scenarios, Table 5.7 summarizes the traffic diversion by individual pricing scenario. The percentage of drivers who bypassed the I-95 study corridor increases from $19.4 \%$ when a $20 \$$ toll is imposed to $30.3 \%$ when there is a $\$ 7.00$ toll (Figure 5.12). Interestingly, the percentages of "somewhat indifferent" drivers remain relatively constant regardless of the amount of the toll. Since a "somewhat-indifferent" driver was defined in this study as one who continued to travel on I-95 but altered a portion of his/her route, more analysis would be useful to assess the extent and nature of route alternation (e.g., $20 \%$ of the original route altered vs. $90 \%$ of the original route altered). More research is needed to estimate the impacts based on reasonable pricing scenarios.

Table 5.7 Summary of Toll-Induced Traffic Diversion on I-95 Study Corridor 4:00 am - 10:00 am, Wednesday, May 7, 2008

\begin{tabular}{|c|c|c|c|c|c|c|c|}
\hline Toll & $\begin{array}{c}\text { Total vehicles } \\
\text { when no toll } \\
\text { is imposed }\end{array}$ & $\begin{array}{c}\text { "Indifferent" } \\
\text { drivers }\end{array}$ & $\begin{array}{c}\text { "Somewhat } \\
\text { indifferent" } \\
\text { drivers }\end{array}$ & $\begin{array}{l}\text { Drivers } \\
\text { "unwilling } \\
\text { to pay" }\end{array}$ & $\begin{array}{c}\text { New } \\
\text { comers }\end{array}$ & $\begin{array}{c}\text { Total } \\
\text { vehicles } \\
\text { when a toll is } \\
\text { imposed }\end{array}$ & $\begin{array}{c}\% \\
\text { Difference } \\
\text { due to toll } \\
\end{array}$ \\
\hline $20 \pitchfork$ & 51,179 & $\begin{array}{c}16,427 \\
(32.1 \%)\end{array}$ & $\begin{array}{c}24,814 \\
(48.5 \%)\end{array}$ & $\begin{array}{c}9,938 \\
(19.4 \%)\end{array}$ & 8,397 & 49,638 & $-3.0 \%$ \\
\hline $80 \pitchfork$ & 51,179 & $\begin{array}{c}13,711 \\
(26.8 \%)\end{array}$ & $\begin{array}{c}25,275 \\
(49.4 \%) \\
\end{array}$ & $\begin{array}{c}12,193 \\
(23.8 \%)\end{array}$ & 6,797 & 45,783 & $-10.5 \%$ \\
\hline$\$ 1.00$ & 51,179 & $\begin{array}{c}13,252 \\
(25.9 \%)\end{array}$ & $\begin{array}{c}25,261 \\
(49.4 \%) \\
\end{array}$ & $\begin{array}{c}12,666 \\
(24.7 \%)\end{array}$ & 6,511 & 45,024 & $-12.0 \%$ \\
\hline$\$ 2.00$ & 51,179 & $\begin{array}{c}11,595 \\
(22.7 \%) \\
\end{array}$ & $\begin{array}{c}25,744 \\
(50.3 \%) \\
\end{array}$ & $\begin{array}{c}13,840 \\
(27.0 \%)\end{array}$ & 6,177 & 43,516 & $-15.0 \%$ \\
\hline$\$ 7.00$ & 51,179 & $\begin{array}{c}9,375 \\
(18.3 \%)\end{array}$ & $\begin{array}{c}26,301 \\
(51.4 \%)\end{array}$ & $\begin{array}{c}15,503 \\
(30.3 \%)\end{array}$ & 6,596 & 42,272 & $-17.4 \%$ \\
\hline
\end{tabular}




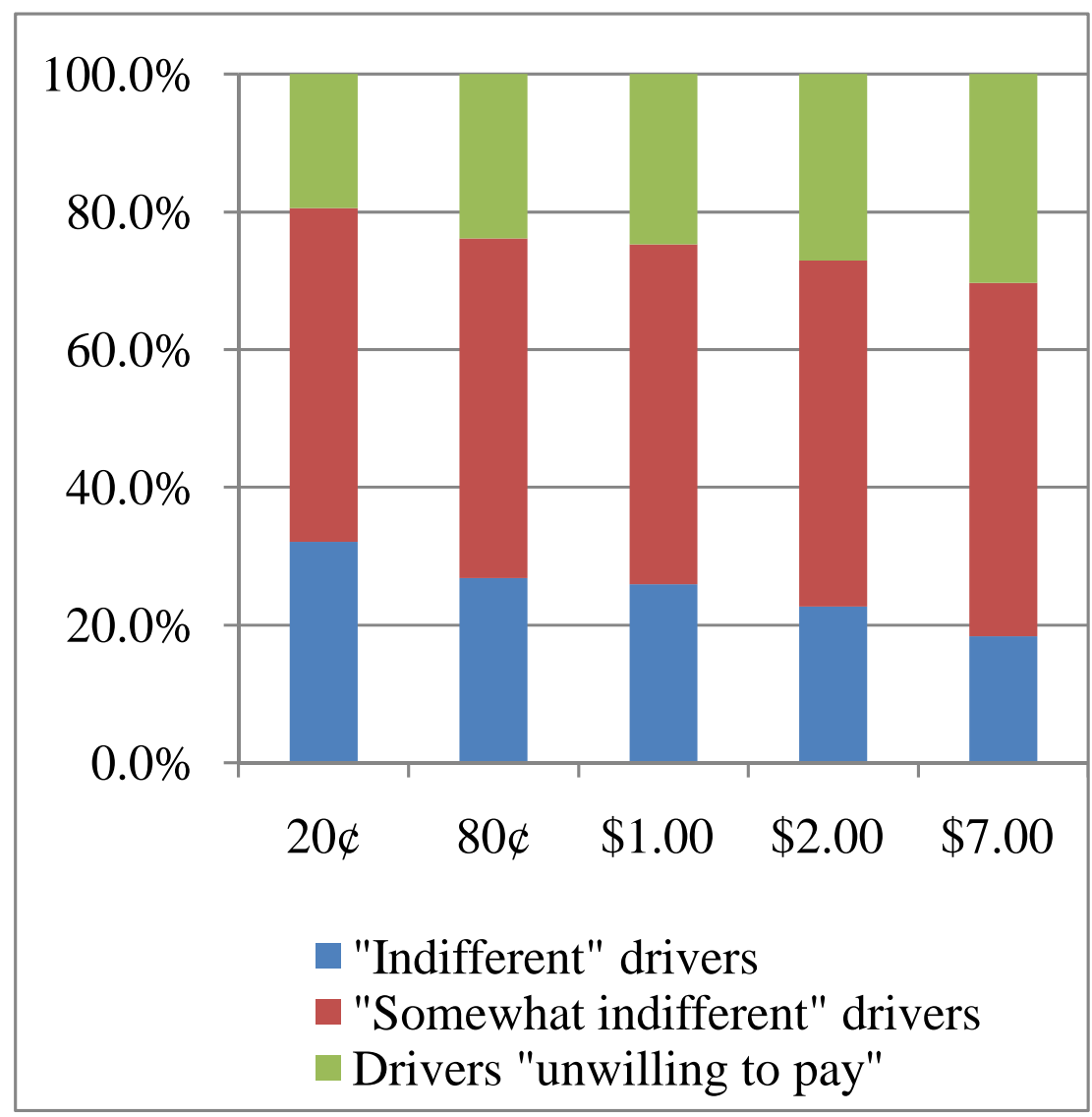

Figure 5.12 Distribution of drivers categorized by their route choice decisions when various tolls are imposed. 4:00 am - 10:00 am, Wednesday, May 7, 2008 


\subsection{Congestion Pricing Impacts on the Study Area}

To estimate the system wide impacts, links that were impacted by the toll were identified. There were a total of 23,567 links in the study area - of which 46 were on the I-95 study corridor. Based on the simulated vehicle trajectories for each of 351,688 vehicles, links that are impacted by congestion pricing were identified. Two types of impacted links were defined:

Links to which traffic from I-95 SB was diverted as a result of a toll.

For example, the links that were not used by any of the 51,799 vehicles that travelled on I-95 SB when no toll was imposed, but became part of these vehicles' trajectories when a $20 \$$ toll was imposed. The link between node No. 3327 and node No. 3508 in Table 5.5 is the example of this group.

Links from which traffic was diverted away as a result of a toll.

For example, the links that were part of the trajectory of vehicles that used to travel on I-95 SB but bypassed I-95 SB when a 20థ toll was imposed. The link between node No. 1658 and node No. 2666 belongs to this group.

For example, the link between node No. 117 and node No. 1669 was an impacted link because 1,189 vehicles were diverted away from it and 1,365 vehicles were diverted to it when a $20 \notin$ toll was imposed. Links that were not impacted by the toll were eliminated from the subsequent analysis.

The impacts of congestion pricing were first estimated for the links off the I-95 SB, and then for the 46 links on I-95 SB. Finally, impacts were quantified for the entire I-95 study area/network. When a 20 toll is imposed, 2,525 links off the I-95 study corridor were impacted, meaning there was traffic diverted to or from one or more of the 2,525 links when a toll is imposed. A total of 345,437 vehicles or trips traveled on these 2,525 links when a 204 toll is imposed and 345,486 vehicles/trips traveled on the identical 2,525 links when no toll is imposed (Table 5.8). 
Congestion pricing improves the speed of traffic flow in areas outside the I-95 study corridor by 7 to $9 \%$, and decreases the average travel time by 6 to $9 \%$. The greatest benefit of congestion pricing is the large reduction in the total number of hours delayed, which ranged from as much as a $54 \%$ reduction with a $20 \$$ toll to a $40 \%$ reduction with a $\$ 7$ toll (Figure 5.13). 
Table 5.8 Congestion Pricing Impacts on Area off I-95 SB

4:00 am - 10:00 am, Wednesday, May 7, 2008

\begin{tabular}{|c|c|c|c|c|c|c|c|}
\hline Toll Scenario & Throughput & $\begin{array}{l}\text { Average Trip } \\
\text { Length (mile) }\end{array}$ & VMT & $\begin{array}{l}\text { Total Delay } \\
\text { (hour) }\end{array}$ & $\begin{array}{l}\text { Weighted } \\
\text { Speed }\end{array}$ & $\begin{array}{l}\text { Average Travel } \\
\text { Time/Vehicle } \\
\text { (minute) }\end{array}$ & $\begin{array}{c}\text { Number of Links } \\
\text { Off I-95 Impacted } \\
\text { by Toll }\end{array}$ \\
\hline 204 & 345,437 & 8.35 & $2,888,102$ & 9,557 & 45 & 15.60 & \multirow{3}{*}{2,525} \\
\hline No toll & 345,486 & 8.34 & $2,882,776$ & 20,830 & 41 & 17.13 & \\
\hline \% Impacted & $-0.01 \%$ & $0.12 \%$ & $0.18 \%$ & $-54.12 \%$ & $9.76 \%$ & $-8.93 \%$ & \\
\hline 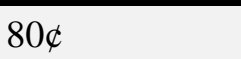 & 345,556 & 8.43 & $2,914,463$ & 9,580 & 45 & 15.64 & \multirow{2}{*}{2,522} \\
\hline \% Impacted & $-0.02 \%$ & $0.96 \%$ & $1.02 \%$ & $-54.05 \%$ & $9.76 \%$ & $-8.64 \%$ & \\
\hline$\$ 1.00$ & 345,514 & 8.36 & $2,889,808$ & 9,525 & 45 & 15.45 & \multirow{3}{*}{2,484} \\
\hline No toll & 345,501 & 8.26 & $2,854,701$ & 20,663 & 41 & 16.89 & \\
\hline \% Impacted & $0.00 \%$ & $1.21 \%$ & $1.23 \%$ & $-53.90 \%$ & $9.76 \%$ & $-8.53 \%$ & \\
\hline$\$ 2.00$ & 345,598 & 8.52 & $2,945,811$ & 10,422 & 44 & 15.78 & 2,526 \\
\hline No toll & 345,534 & 8.34 & $2,881,599$ & 20,875 & 41 & 17.26 & \multirow[t]{2}{*}{2,540} \\
\hline \% Impacted & $-89.99 \%$ & $4.80 \%$ & $4.92 \%$ & $-41.96 \%$ & $7.32 \%$ & $-6.03 \%$ & \\
\hline
\end{tabular}




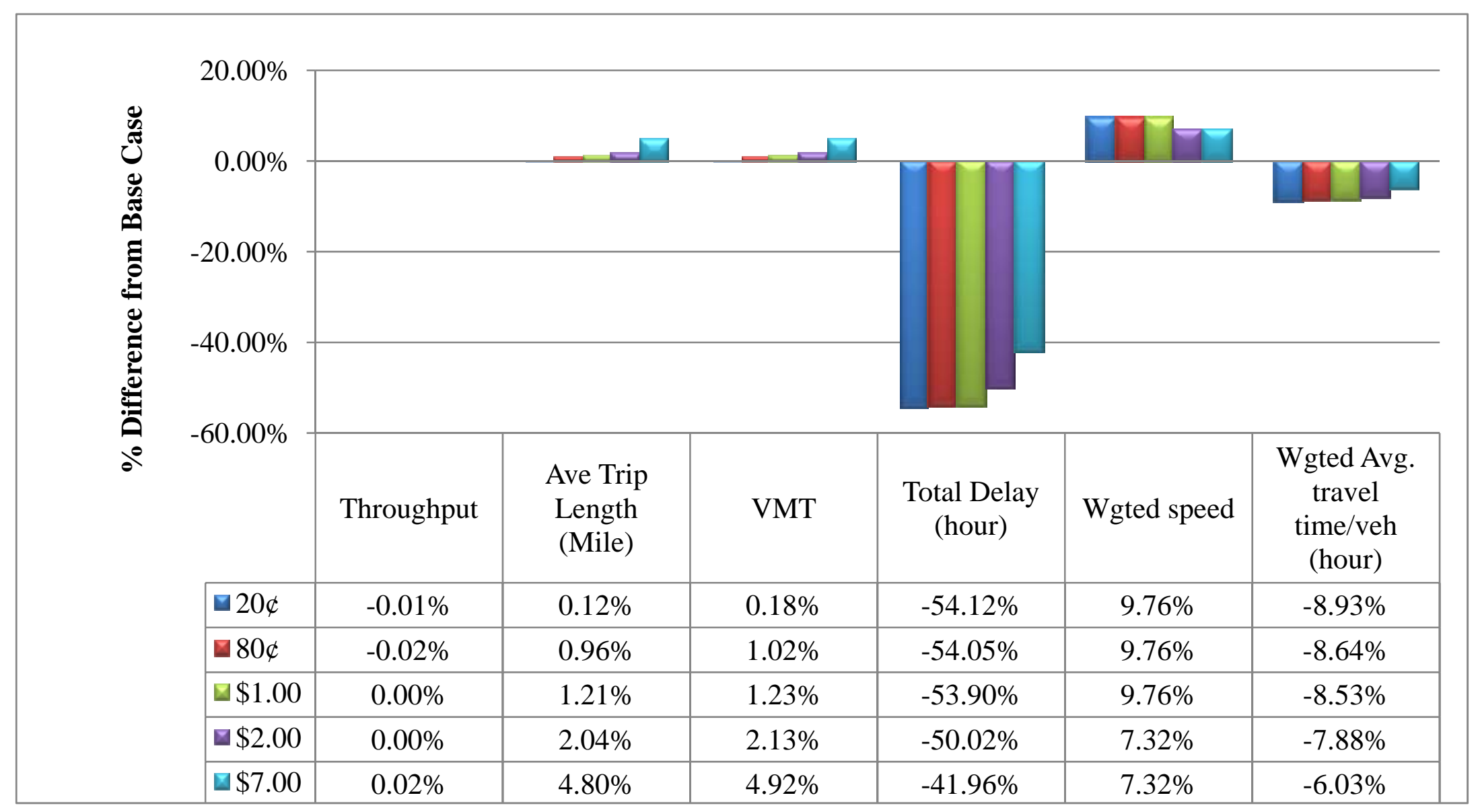

Figure 5.13 Toll-resulted differences in traffic operations on area off I-95 SB 4:00 am - 10:00 am, Wednesday, May 7, 2008 
Table 5.9 summarizes the impacts of five congestion pricing scenarios on the 46 links on I-95 SB. With a $20 \$$ toll, the throughput on these links dropped by $1.8 \%$. The sensitivity to the amount of the toll became apparent when the toll reached $80 \$$ where the throughput on I-95 SB dropped by almost $10 \%$, resulting in an increase of $12 \%$ in average travel speed (Figure 5.14). These operational improvements on I-95 SB could be attributed to traffic diversion. Almost onequarter of the traffic on I-95 SB diverted as a result of an $80 \$$ toll (Table 5.7).

Table 5.9 Congestion Pricing Impacts on I-95 SB (46 Links) 4:00 am - 10:00 am, Wednesday, May 7, 2008

\begin{tabular}{|c|c|c|c|c|c|c|}
\hline 4:00-10:00 am, 2008 & Base Case & $20 \pitchfork$ & $80 \pitchfork$ & $\$ 1.00$ & $\$ 2.00$ & $\$ 7.00$ \\
\hline Throughput & 50,307 & 49,401 & 45,630 & 44,706 & 43,167 & 41,629 \\
\hline Average Trip Length (mile) & 10.98 & 11.73 & 12.30 & 12.51 & 12.68 & 11.77 \\
\hline VMT & 561,948 & 581,713 & 562,466 & 562,906 & 551,411 & 497,005 \\
\hline Total delay (hour) & 2,222 & 1,260 & 1,148 & 1,155 & 835 & 222 \\
\hline Wgted speed & 57 & 63 & 64 & 64 & 67 & 74 \\
\hline $\begin{array}{l}\text { Wgted avg. travel time/veh } \\
\text { (min) }\end{array}$ & 18.92 & 17.32 & 16.91 & 16.92 & 16.19 & 14.60 \\
\hline
\end{tabular}




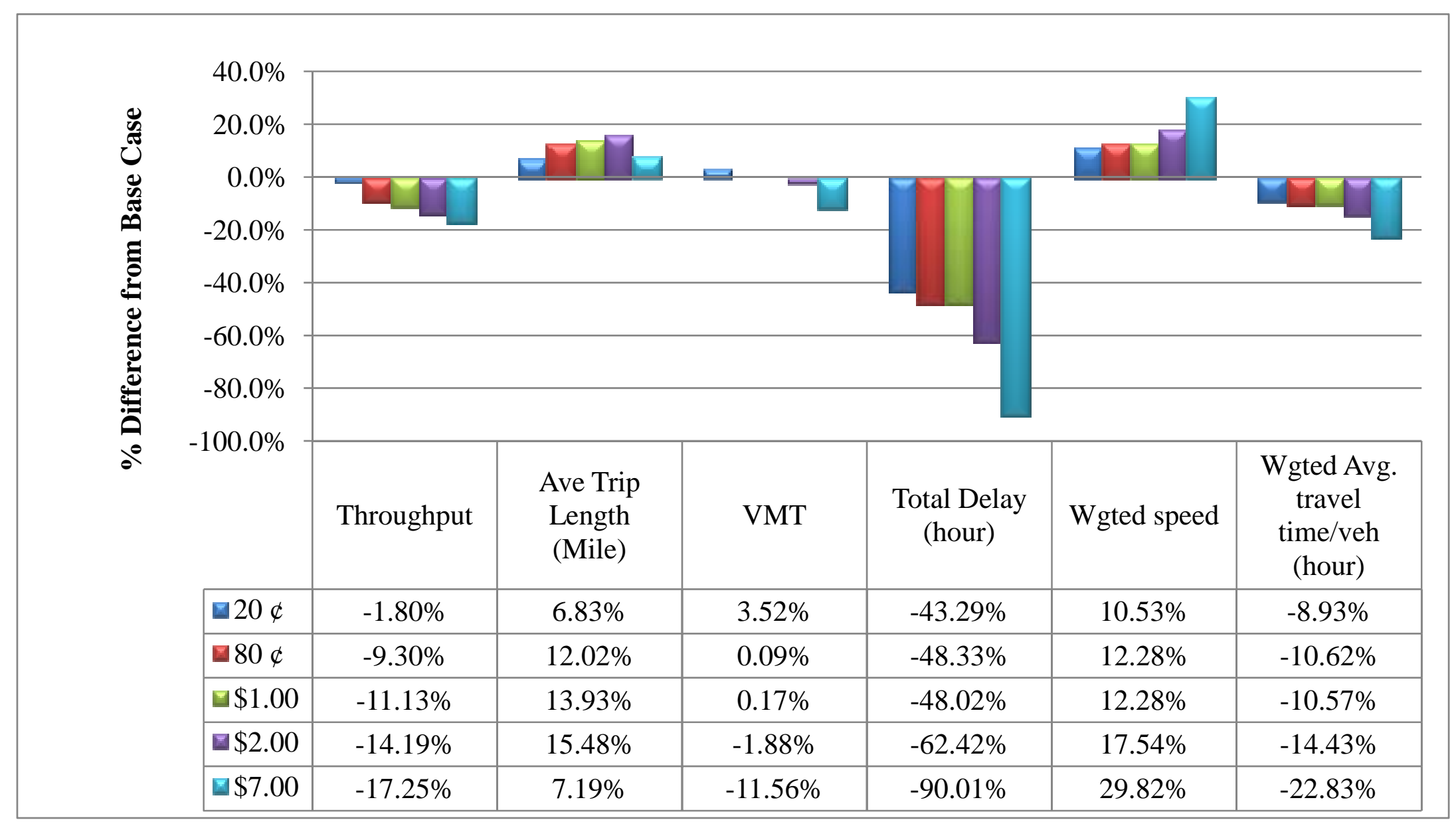

Figure 5.14 Toll-Induced Differences in Traffic Operations on I-95 SB (46 Links). 4:00 am - 10:00 am, Wednesday, May 7, 2008

(\% Difference from the No-Toll Scenario) 
The simulated impacts of five congestion pricing scenarios on the entire I-95 study area are summarized in Table 5.10. These impacts were simulated by taking into account the traffic diversions as a result of the toll. Again, these impacts are only pertinent to travel on the 2,182 nodes and 3,387 links that are within the study area boundary. On average, a 20\$ toll could improve the average speed in the study area by $7 \%$-- an increase from $43 \mathrm{mph}$ when there is no toll to $46 \mathrm{mph}$ with a $20 \$$ toll. However, this improvement in speed is at the expense of a slight increase in trip length - from 10.19 miles without toll to 10.26 miles with a $20 \$$ toll. This finding suggests that one is willing to drive a little longer to avoid congestion. Although the total VMT increases, which could lead to other implications such as safety and carbon emissions, the overall delay is reduced by half, which also has counter-balancing safety and environmental impacts. In summary, the simulation results strongly indicate that congestion pricing has a great impact on reducing delay (Figure 5.15).

The impacts of various toll scenarios on the tolled system (I-95 SB), on the network off the tolled system and on the entire network, are summarized in Table 5.11. The simulation results strongly indicated that congestion pricing implemented on I-95 could not only improve operations on the tolled facilities but also the operations on the network adjacent to the tolled facilities as well as on the entire network (Table 5.11 and Figure 5.16). However, the magnitude of the improvements is sensitive to the amount of toll imposed. As the toll increases, the improvements begin to level off and/or diminish. The challenge is to determine a pricing strategy that optimizes key traffic operations parameters, not only on the tolled links but also on the adjacent parts of the system. 
Table 5.10 Congestion Pricing Impacts on the Entire I-95 Study Network 4:00 am - 10:00 am, Wednesday, May 7, 2008

(Only Pertinent to Travel Characteristics on Links within the Study Area)

\begin{tabular}{|l|c|c|c|c|c|}
\hline & & & & & \\
\hline
\end{tabular}




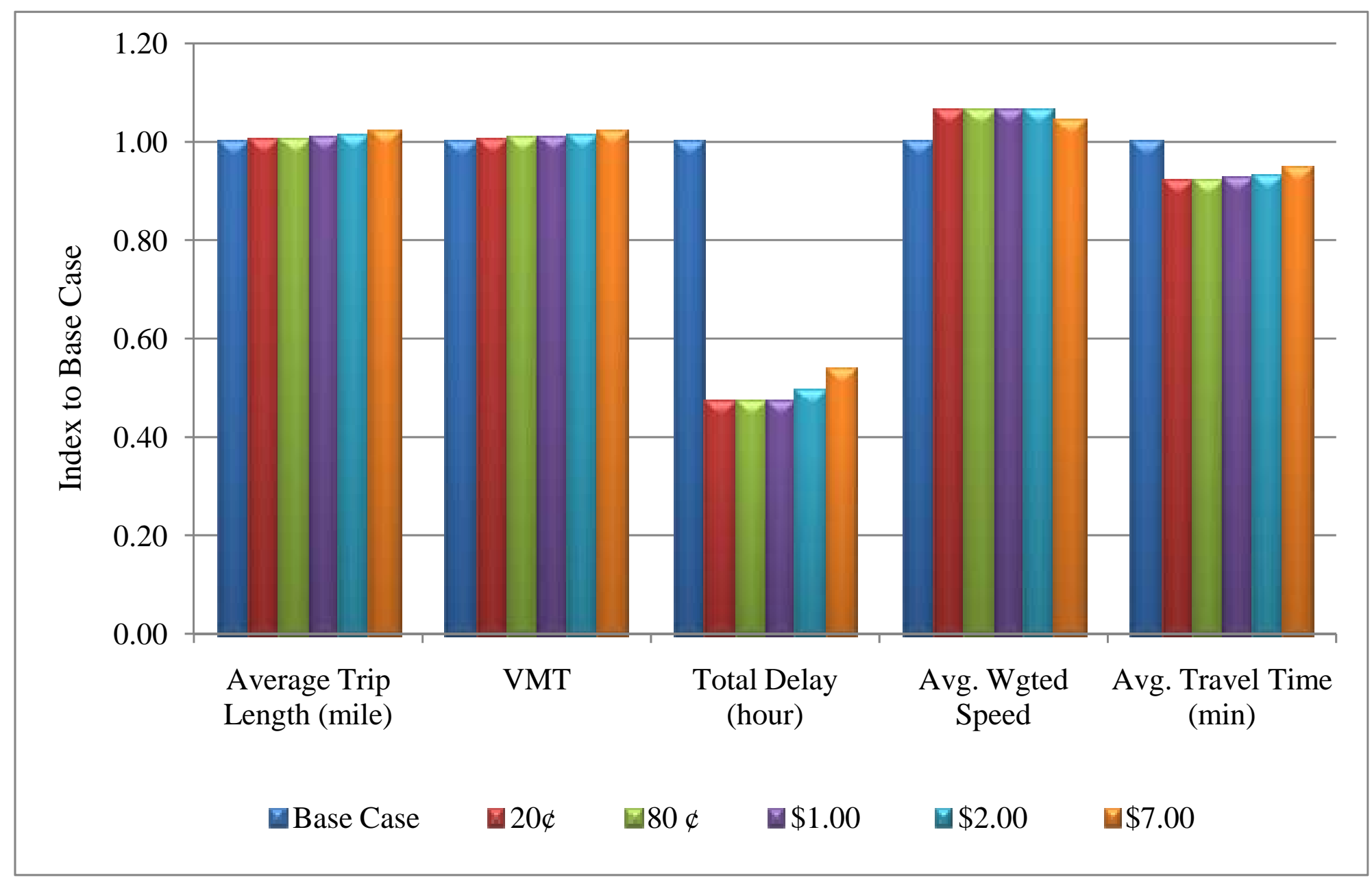

Figure 5.15 Impacts on the entire network when tolls are imposed on I-95 study corridor. 4:00 am - 10:00 am, Wednesday, May 7, 2008

(Only Pertinent to Traffic on Links within the Study Network) 
Table 5.11 Percent Different Due to Toll, by Toll Scenario and Location

4:00 am - 10:00 am, Wednesday, May 7, 2008

(Only Pertinent to Traffic on Links within the Study Network)

\begin{tabular}{|c|c|c|c|c|c|}
\hline & $20 \pitchfork$ & $80 \pitchfork$ & $\$ 1.00$ & $\$ 2.00$ & $\$ 7.00$ \\
\hline \multicolumn{6}{|l|}{ On I-95 SB (46 Links) } \\
\hline Throughput & $-1.80 \%$ & $-9.30 \%$ & $-11.13 \%$ & $-14.19 \%$ & $-17.25 \%$ \\
\hline Ave Trip Length (Mile) & $6.83 \%$ & $12.02 \%$ & $13.93 \%$ & $15.48 \%$ & $7.19 \%$ \\
\hline VMT & $3.52 \%$ & $0.09 \%$ & $0.17 \%$ & $-1.88 \%$ & $-11.56 \%$ \\
\hline Total Delay (hour) & $-43.29 \%$ & $-48.33 \%$ & $-48.02 \%$ & $-62.42 \%$ & $-90.01 \%$ \\
\hline Weighted speed & $10.53 \%$ & $12.28 \%$ & $12.28 \%$ & $17.54 \%$ & $29.82 \%$ \\
\hline Weighted Avg. travel time/vehicle (hour) & $-8.93 \%$ & $-10.62 \%$ & $-10.57 \%$ & $-14.43 \%$ & $-22.83 \%$ \\
\hline \multicolumn{6}{|l|}{ Off I-95 SB (3,341 Links) } \\
\hline Throughput & $-0.01 \%$ & $-0.02 \%$ & $0.00 \%$ & $0.00 \%$ & $0.02 \%$ \\
\hline Ave Trip Length (Mile) & $0.12 \%$ & $0.96 \%$ & $1.21 \%$ & $2.04 \%$ & $4.80 \%$ \\
\hline VMT & $0.18 \%$ & $1.02 \%$ & $1.23 \%$ & $2.13 \%$ & $4.92 \%$ \\
\hline Total Delay (hour) & $-54.12 \%$ & $-54.05 \%$ & $-53.90 \%$ & $-50.02 \%$ & $-41.96 \%$ \\
\hline Weighted speed & $9.76 \%$ & $9.76 \%$ & $9.76 \%$ & $7.32 \%$ & $7.32 \%$ \\
\hline Weighted Avg. travel time/vehicle (hour) & $-8.93 \%$ & $-8.64 \%$ & $-8.53 \%$ & $-7.88 \%$ & $-6.03 \%$ \\
\hline \multicolumn{6}{|l|}{ Entire Network (3,387 Links) } \\
\hline Throughput* & NA & NA & NA & NA & NA \\
\hline Ave Trip Length (mile) & $0.69 \%$ & $0.79 \%$ & $0.88 \%$ & $1.37 \%$ & $2.16 \%$ \\
\hline VMT & $0.70 \%$ & $0.85 \%$ & $0.97 \%$ & $1.42 \%$ & $2.15 \%$ \\
\hline Total Delay (hour) & $-52.19 \%$ & $-52.58 \%$ & $-52.58 \%$ & $-50.18 \%$ & $-45.75 \%$ \\
\hline Weighted speed & $6.98 \%$ & $6.98 \%$ & $6.98 \%$ & $6.98 \%$ & $4.65 \%$ \\
\hline Weighted Avg. travel time/vehicle (minute) & $-7.45 \%$ & $-7.22 \%$ & $-7.08 \%$ & $-6.60 \%$ & $-4.81 \%$ \\
\hline
\end{tabular}

* The total throughput remains the same within the network. 

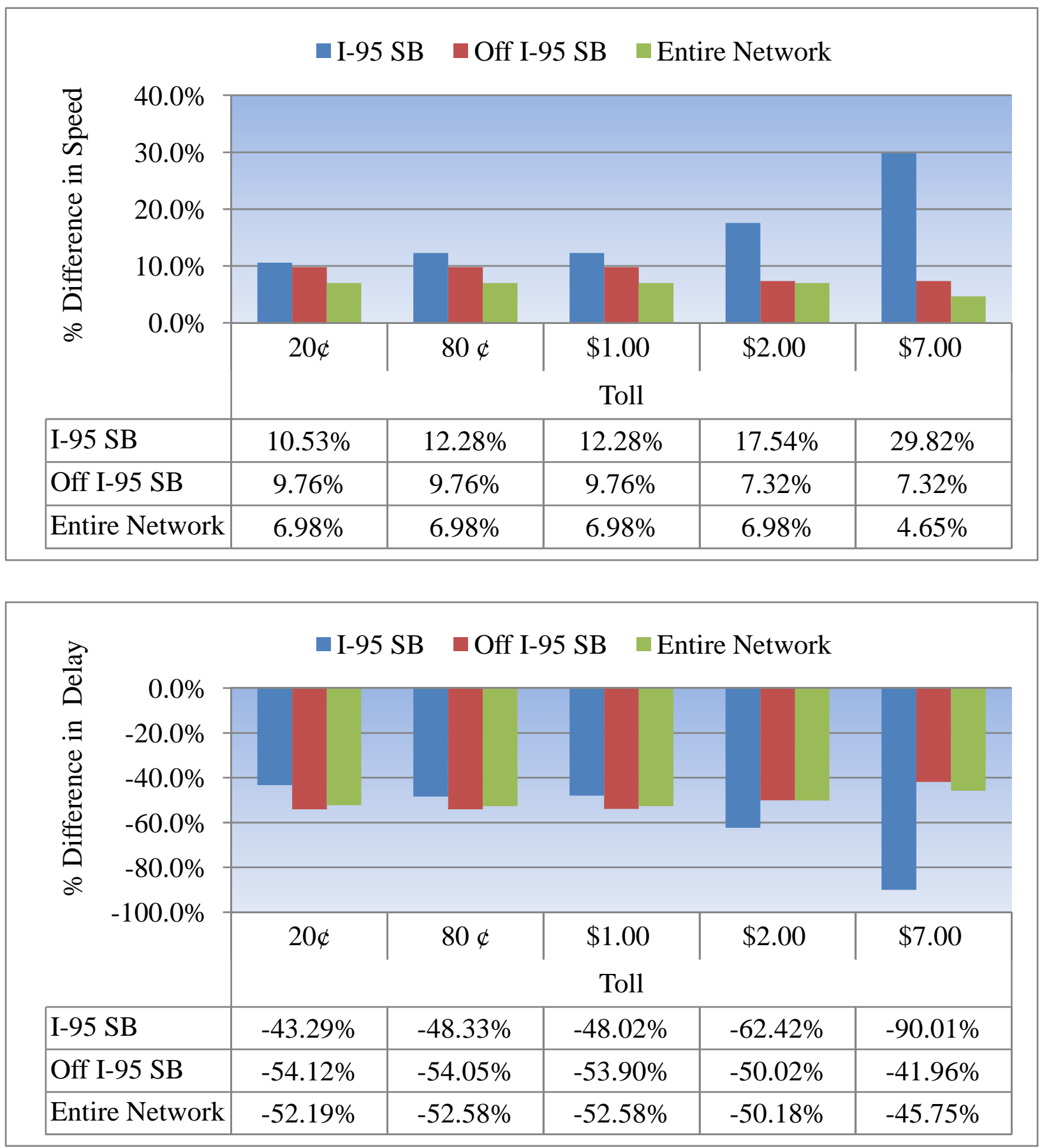

Figure 5.16 Congestion pricing impacts on travel speed and total delay, on the tolled system, the adjacent network, and the entire network.

(\% Difference from the No-Toll Scenario) 
Impacts of Congestion Pricing

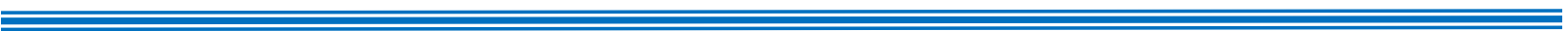

$5-32$ 


\section{CONCLUDING DISCUSSIONS}

The Texas Transportation Institute report ${ }^{1}$ that although traffic congestion improved in 2007 over the previous year, the associated fuel wasted and productivity lost amounted to \$87 billion, which translates to more than $\$ 750$ for every U.S. traveler. The total amount of fuel wasted increased to 2.8 billion gallons and the amount of time wasted totaled 4.2 billion hours, averaging nearly one full work week (or vacation week) for every traveler. Congestion pricing is one of the congestion mitigation strategies with a goal to dynamically match demand with available capacity. The notion is based on the idea that motorists should pay for the additional congestion they create when entering a congested road.

Although many transportation professionals theorize that congestion pricing holds promise for significantly improving traffic flow and reducing levels of congestion, evidence of the effectiveness of congestion pricing on improving traffic flow (i.e. throughput) and reducing congestion has been based on results of a limited set of pricing projects. As more agencies begin to consider congestion pricing as a strategy to reduce their traffic congestion, it is critical that technically-sound information and credible analytical methods are available and accessible upon which to help "make the case" to decision-makers and to the public that congestion pricing will be beneficial in reducing congestion.

To this end, the objectives of this project were to:

- Better understand and quantify the impacts of congestion pricing strategies on traffic operations through the study of actual projects, and

- Better understand and quantify the impacts of congestion pricing strategies on traffic operations through the use of modeling and other analytical methods.

Specifically, the project was to identify credible analytical procedures that FHWA or other agencies can use to quantify the impacts of various congestion pricing strategies on traffic flow (throughput) and congestion.

\footnotetext{
${ }^{1}$ http://mobility.tamu.edu/ums/media_information/press_release.stm
} 


\subsection{Impacts of Congestion Pricing}

Two areas were used to analyze the impacts of congestion pricing: (1) MnPASS on I-394 and (2) I-95 corridor from I-695 (Baltimore) to I-495 (Washington DC). The MnPASS on I-394 was selected because of its comprehenseive archive of the traffic condition data and the maturity of its pricing program. The I-95 corridor was selected because of:

- its traffic gridlock,

a network that was already geocoded, and

- OD flow data that were already compiled.

Although there are many existing traffic simulation models, two were selected for this study: VISSIM and DynusT. VISSIM was selected due to its widespread user base, and DynusT was selected because: (1) it has been tested using the I-95 data ${ }^{2}$, and (2) it was one of the affordable models that is capable of simulating congestion pricing and traffic diversion. In the I394 case, VISSIM was used to simulate traffic conditions prior to the HOT lane implementation (i.e., the "before" scenario). In the I-95 case, since no congesting pricing was actually implemented on the I-95 study corridor at the time of the analysis, the traffic simulation models were used to simulate traffic conditions in the presence of congestion pricing strategies (i.e., the "after" scenarios). Although VISSIM was used in the I-95 study, VISSIM was subsequently eliminated from consideration after extensive testing. Results from the tests suggest that VISSIM assigns a small number of vehicles in toll lanes even when the toll is as high as \$100. In order to use VISSIM to model traffic conditions under the toll scenarios, code modifications are needed ${ }^{3}$.

\section{Impacts on I-394 MnPASS}

From the perspective of speed, the benefits of the HOT lanes were obvious. In general, HOT lanes permit traffic to breakdown later, maintain higher speeds even during the slowdown in speed, and recover sooner than when there is no HOT lane. For example, without the HOT

\footnotetext{
${ }^{2}$ http://www.trb-freewayops.org/5.\%20Value\%20Pricing\%20with\%20DynusT\%20TRB08.pdf

3 "Simulation on Customized Dynamic Tolling Strategies for HOT Land Operations." Y. Wang, University of Washington. TRB $89^{\text {th }}$ Annual Meeting. January 10, 2010, Washington, DC.
} 
lands, the speed in the general purpose lanes started to break down at Xenia Avenue at 6:45 am and only began to recover around 10:30 am (Figure 6.1). With the HOT lanes, speed was maintained above 50 mph until a half-hour later at 7:15 am and began to recover almost an entire hour earlier than when there were no HOT lanes. Even during the slowdown in speed (i.e., between 7:45 am and 9:15 am), the existence of the HOT lanes helped move the flows on the general-purpose lanes at a higher speed than when there were no HOT lanes. Although the impacts of congestion pricing vary from one facility to the next, the trends are indicative in that HOT lanes facilitate moving traffic at a higher speed.

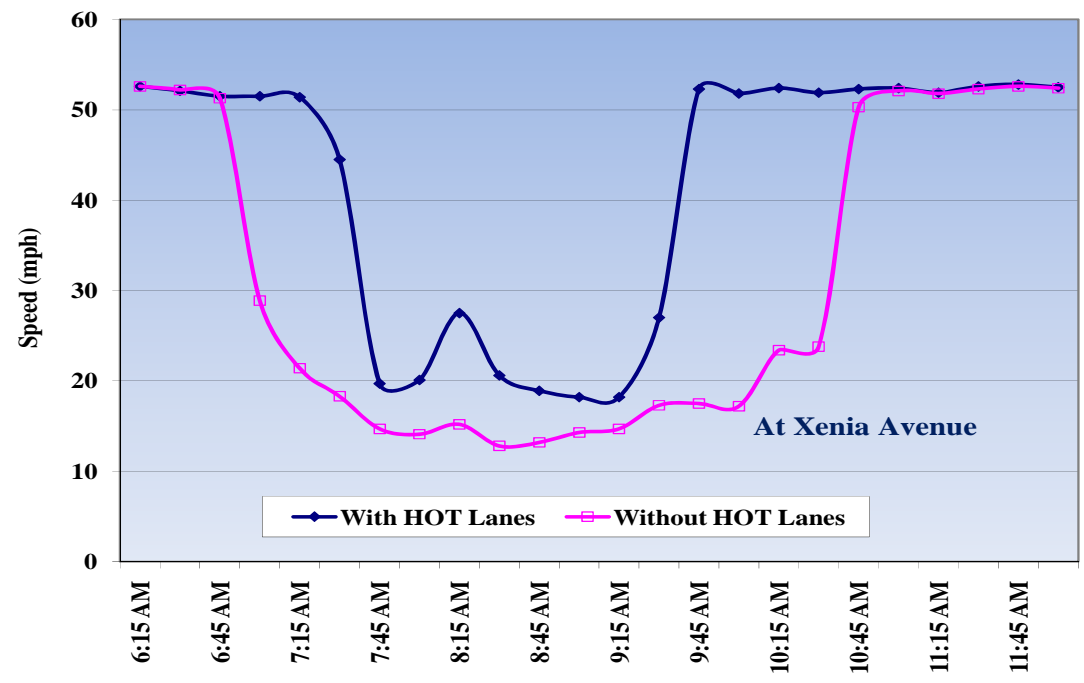

Figure 6.1 Speed profiles at the general-purpose lanes at Xenia Avenue.

HOT lanes significantly mitigate the bottleneck from Xenia Avenue to Wirth Parkway, which includes the on-ramp to $\mathrm{TH}$ 100. In this specific facility, the HOT lanes improve the speed of traffic flow by more than $22 \%$ and reduce total delay by $40 \%$. The difference in the overall VMT is negligible. 
Table 6.1 I-394 Bottleneck Statistics With and Without HOT Lanes From Xenia Avenue to Wirth Parkway during the Study Period

\begin{tabular}{lccc}
\hline & $\begin{array}{c}\text { Before } \\
\text { (without HOT Lanes) }\end{array}$ & $\begin{array}{c}\text { After } \\
\text { (with HOT Lanes) }\end{array}$ & \% Change \\
\hline Throughput & 20,088 & 21,396 & $6.51 \%$ \\
VMT & 32,442 & 32,514 & $0.22 \%$ \\
Total Delay (hour) & 772 & 461 & $-40.37 \%$ \\
Average Speed (MPH) & 30.9 & 23.9 & $-22.65 \%$ \\
\hline
\end{tabular}

\section{Results on I-95 Corridor and Study Area}

Since no congestion pricing was actually implemented on I-95 at the time of the analysis, the toll scenarios were set incrementally at $20 \nsubseteq, 80 \nsubseteq, \$ 1.00, \$ 2.00$, and $\$ 7.00$ so as to test the sensitivity of different pricing levels on the impact metrics. The analysis on I-95 focuses not only on speed and throughput changes at individual facilities but also on traffic diversion due to various pricing strategies. Similar to the findings on I-394, simulation results indicate that pricing improves the speed of traffic flow at the toll facilities. Figure 6.2 compares speed data collected from CHART, the speed profile simulated by DynusT when no toll is imposed, and the simulated speed when a $20 \$$ toll is imposed.

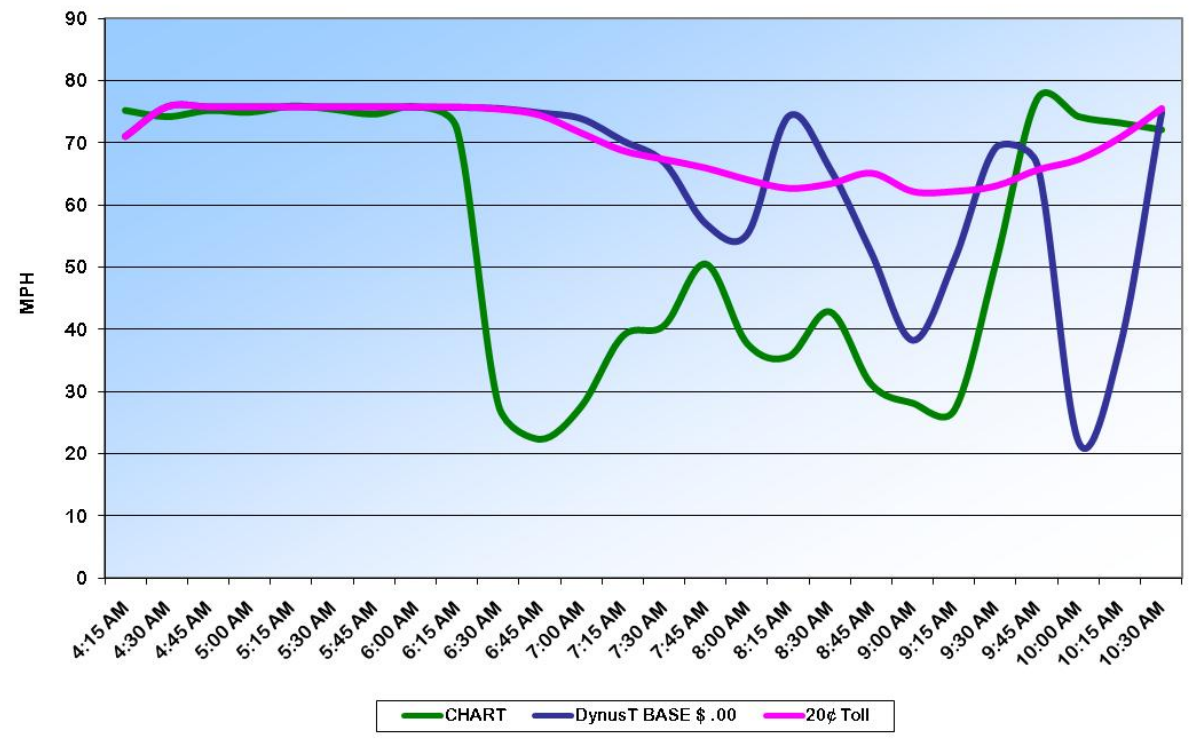

Figure 6.2 Comparison of speed profiles at Cherry Hill on I-95 SB. 
The differences in throughput between the "no toll” and the " $20 \$$ toll” scenarios range widely, from fewer than 1,000 vehicles to more than 1,000 vehicles for a 15 -minute interval. The fluctuation makes it difficult to gauge the overall impacts of pricing on throughput. Alternatively, the differences at 15-minuate intervals were accumulated over the entire study

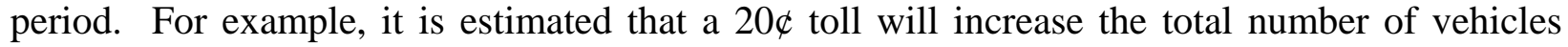
travelling through Cherry Hill by 4,000 vehicles (Figure 6.3), or roughly one-fifth of the typical hourly throughput at Cherry Hill when no toll is imposed.

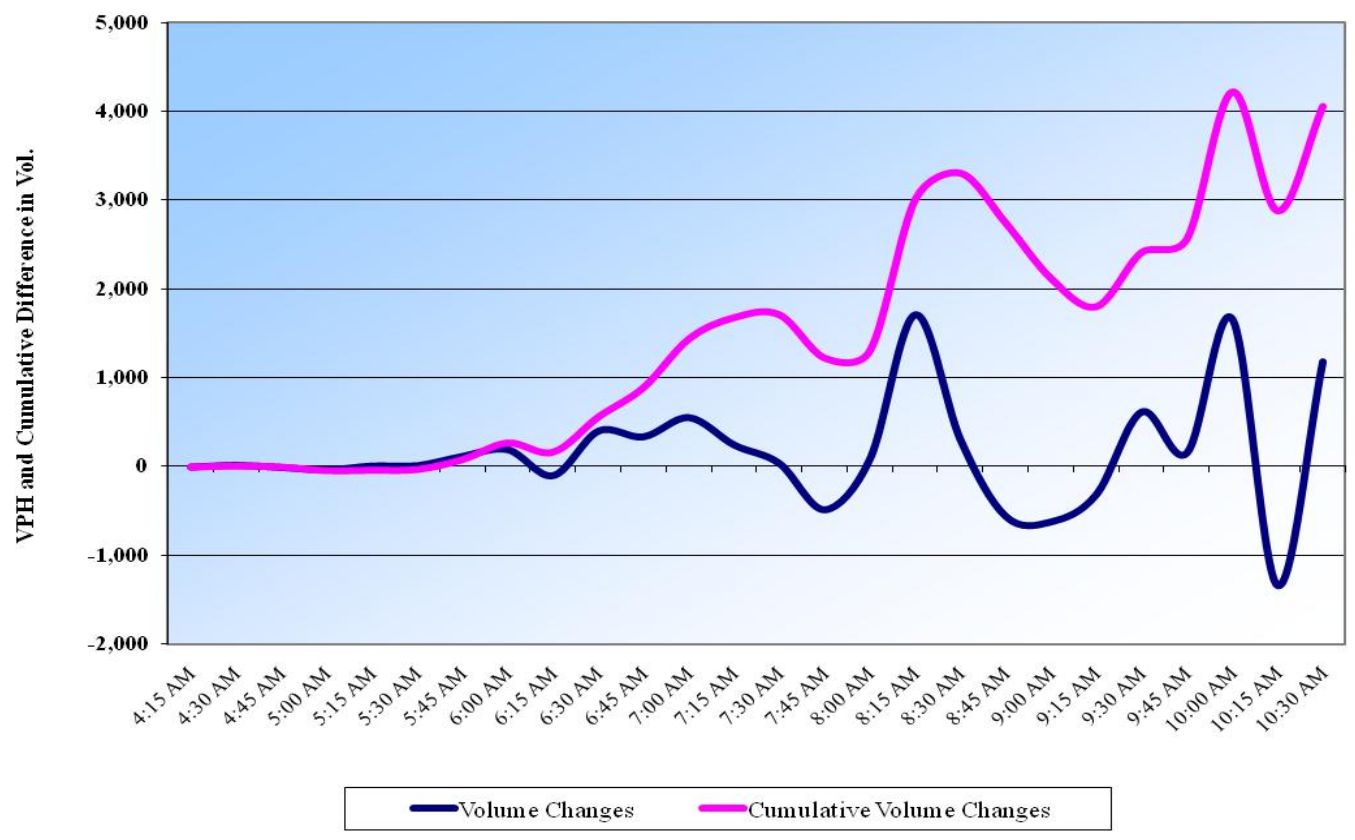

Figure 6.3 Differences in throughput and cumulative throughput between toll and no-toll scenarios at Cherry Hill.

The simulated results at an individual facility suggest that increases in toll could eventually level or reduce the impacts of pricing at a given facility, primarily due to the fact that traffic will begin to divert away from the facility when the toll increases to a certain level. (That is, as tolls increase, less congestion remains to be reduced.) This finding also confirms that the impacts of congestion pricing should be analyzed at the system level to fully consider the effects of diversion to other links, instead of simply at the facility/link level. 
Based on the simulated vehicle trajectories of each of the 351,688 vehicles in the I-95 study area, we were able to categorize these vehicles/drivers into four route-choice groups:

1 Indifferent to the toll. Drivers who continue to travel on I-95 SB without any route changes.

2 Somewhat indifferent to the toll. Drivers who continue to travel on I-95 SB but with some route changes away from I-95 SB.

3 Unwilling and/or unable to pay. Drivers who used to travel on, but who completely bypass, I-95 SB when a toll is imposed.

4 Eager to pay. Newcomers who never travel on I-95 SB when there is no toll, but who begin to travel on I-95 SB when a toll is imposed.

The percentage of drivers who bypassed the I-95 study corridor increases from 19.4\% when a $20 \mathbb{4}$ toll is imposed to $30.3 \%$ when there is a $\$ 7.00$ toll (Figure 6.4). As expected, the extent of diversion increases as the toll increases.

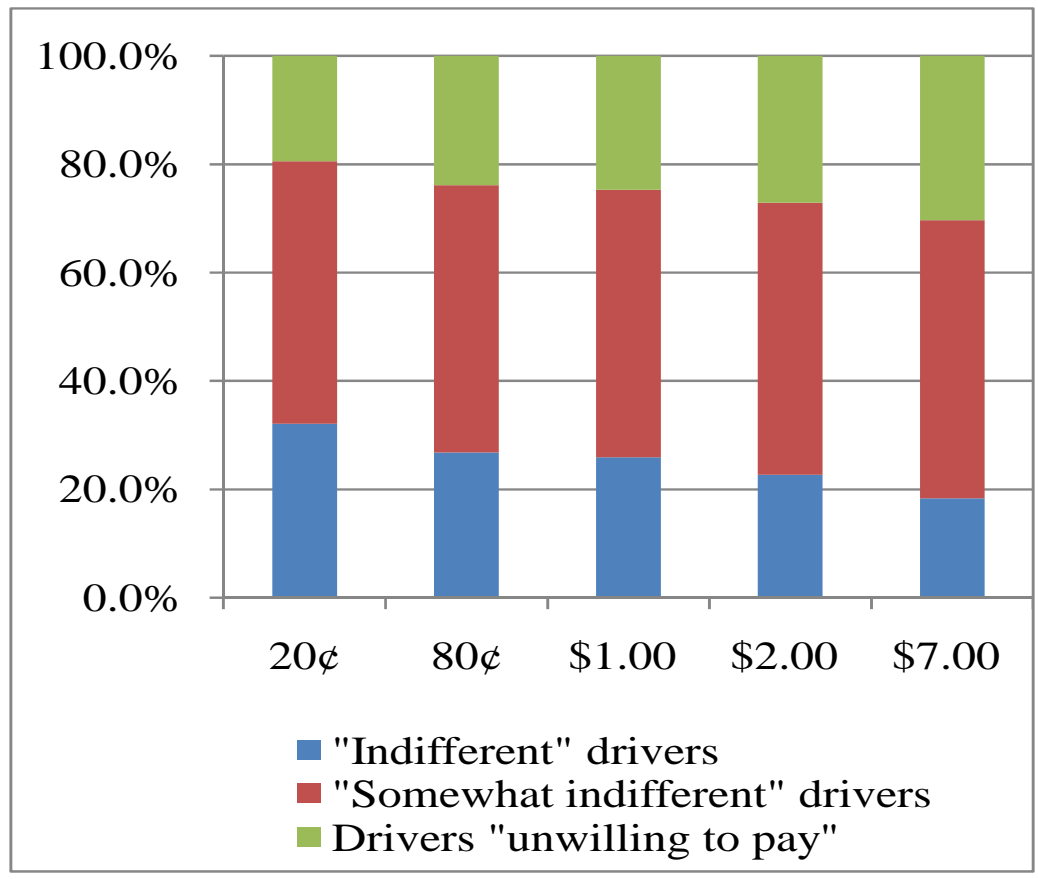

Figure 6.4 Distribution of drivers categorized by their route choice decisions, when various tolls are imposed 
The tolls on I-95 SB divert traffic, thereby reducing throughput and improving traveling speed and total delay (Figure 6.5). The sensitivity to the amount of toll became apparent - for example, when the toll reached $80 \$$, the throughput on I-95 SB dropped by almost $10 \%$, resulting in an increase in traveling speed of 12\%. Almost one-quarter of the traffic on I-95 SB diverted as a result of an $80 \notin$ toll (Table 5.7).

Would the diverted traffic from I-95 SB clog up the adjacent streets? The simulation results indicate otherwise. Congestion pricing improves the speed of traffic flow by 7 to $9 \%$, and decreases the average travel time by 6 to 9\% in areas off I-95 SB. The greatest benefit of congestion pricing is the large reduction in the total number of hours delayed, which ranged from as much as a $54 \%$ reduction with a $20 \$$ toll to a $40 \%$ reduction with a $\$ 7$ toll.

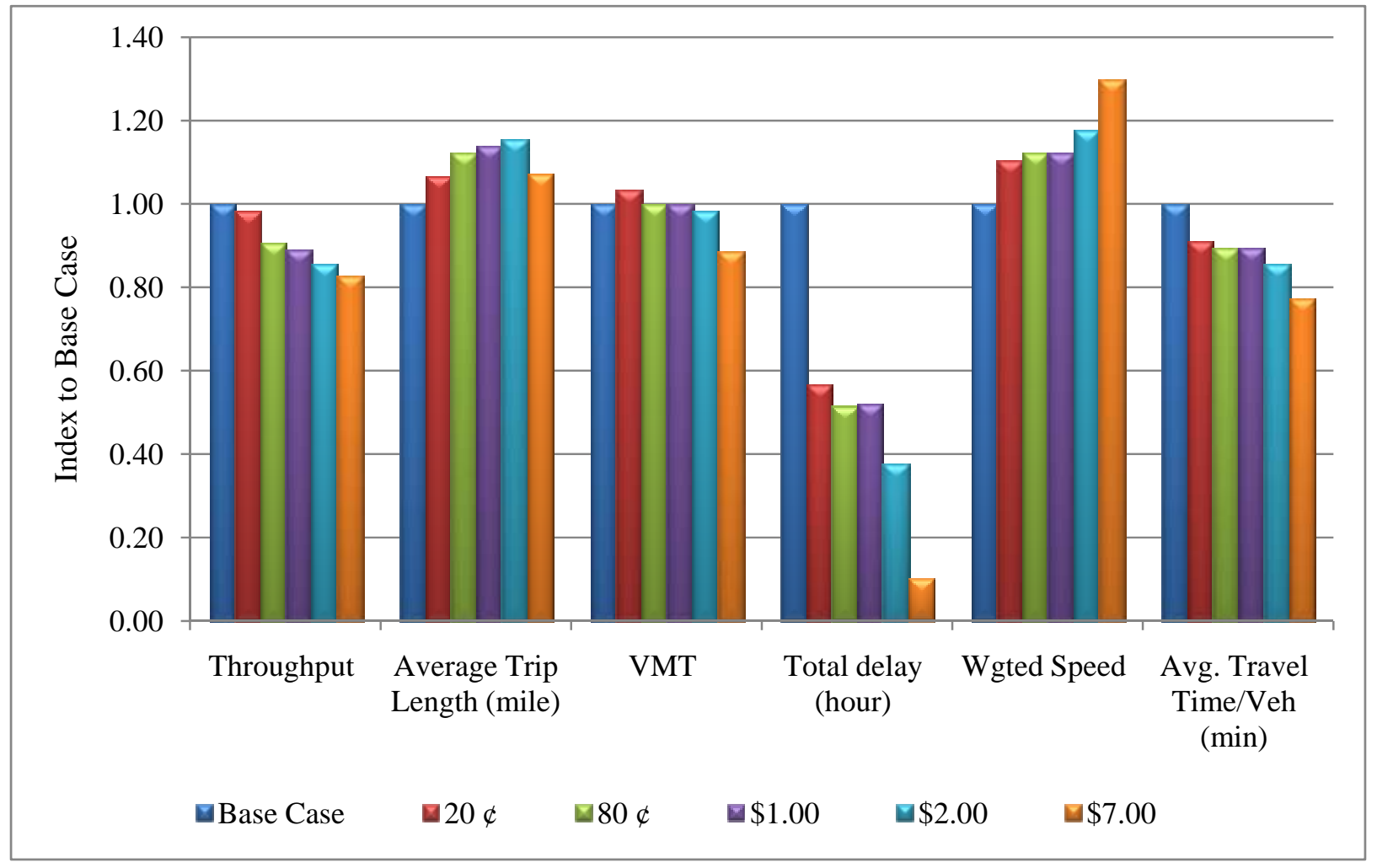

Figure 6.5 Comparison of impacts on I-95 SB 4:00 am - 10:00 am, Wednesday, May 7, 2008

(Only Pertinent to Traffic on Links within the Study Network) 
The simulation results on I-95 also strongly indicated that congestion pricing implemented on I-95 not only improves operations on the tolled facilities but also the operations on the network adjacent to the tolled facilities as well as the entire network (Figure 6.6). However, the magnitude of the improvements is sensitive to the amount of toll imposed. As the toll increases, the improvements begin to level off and/or diminish due to traffic diversion, which then begins to increase congestion on the alternative routes. For example, the total delay on links off I-95 increased from 9,557 hours with a $20 \$$ toll to 10,422 hours with a $\$ 2.00$ toll (Table 5.8).

\subsection{Lessons Learned and Recommended Future Activities}

Although this study is able to use existing traffic simulation models to estimate the benefits of congestion pricing on traffic operations, a number of areas in the analysis need improvement:

1. Since no congestion pricing was actually implemented on I-95 SB at the time of the analysis, tolls were set somewhat arbitrarily in this study. Additional analysis could help make a more realistic case for congestion pricing if more realistic pricing strategies are simulated. The pricing structure should be specific to the links, time of day, and distances travelled.

2. The analysis was conducted based on traffic data on a single day. Thus, the simulation results are indicative but not comprehensive. Calibrating the traffic simulation model with more and updated traffic data would improve the results.

3. Additional sensitivity analysis of pricing would strengthen the results. For example, results from the I-95 analysis show that a $\$ 1$ toll will divert $24.7 \%$ of the traffic while a $\$ 7$ toll will divert $30.3 \%$ of the traffic (Table 5.7). The extent of traffic diversion seems out of proportion to the amount of the toll.

4. More analysis would be useful to assess the extent and nature of route alternation and traffic diversion.

The study concludes that only a very limited number of credible analytical tools are available to quantify the impacts of congestion pricing strategies on traffic operations. However, the learning curve to use these models is extremely steep; and the model calibration is 
challenging, time consuming, and difficult. Even with an existing model, the consensus among analysts is that the calibration step alone demands almost one-third of the resources required to model the congestion pricing impacts ${ }^{4}$. A few suggestions are offered here to facilitate further research on making a greater case for congestion pricing:

1. Improve the transparency and user-friendliness of traffic simulation models:

Explore the feasibility of an more automated approach to calibrate; and

Develop guidelines on how to:

- Determine locale-specific pricing structure;

- Compile and calibrate the model with OD data;

- Check for the quality of calibration data before analysis;

- Geocode the network;

- Determine the reasonableness of the calibration (i.e., how close is close enough?); and

- Diagnose simulation results and modify model and/or data accordingly.

2. Reach a consensus on the definition of the impact metrics. For example, where should the speed be measured -- at the beginning of the link, average across all lanes, or some other way? Consistent definitions will facilitate comparisons across potential pricing strategies and projects.

${ }^{4}$ The Workshop on “Modeling Congestion Pricing Impacts.” TRB 89 $9^{\text {th }}$ Annual Meeting, January 10, 2010. Washington, DC. 


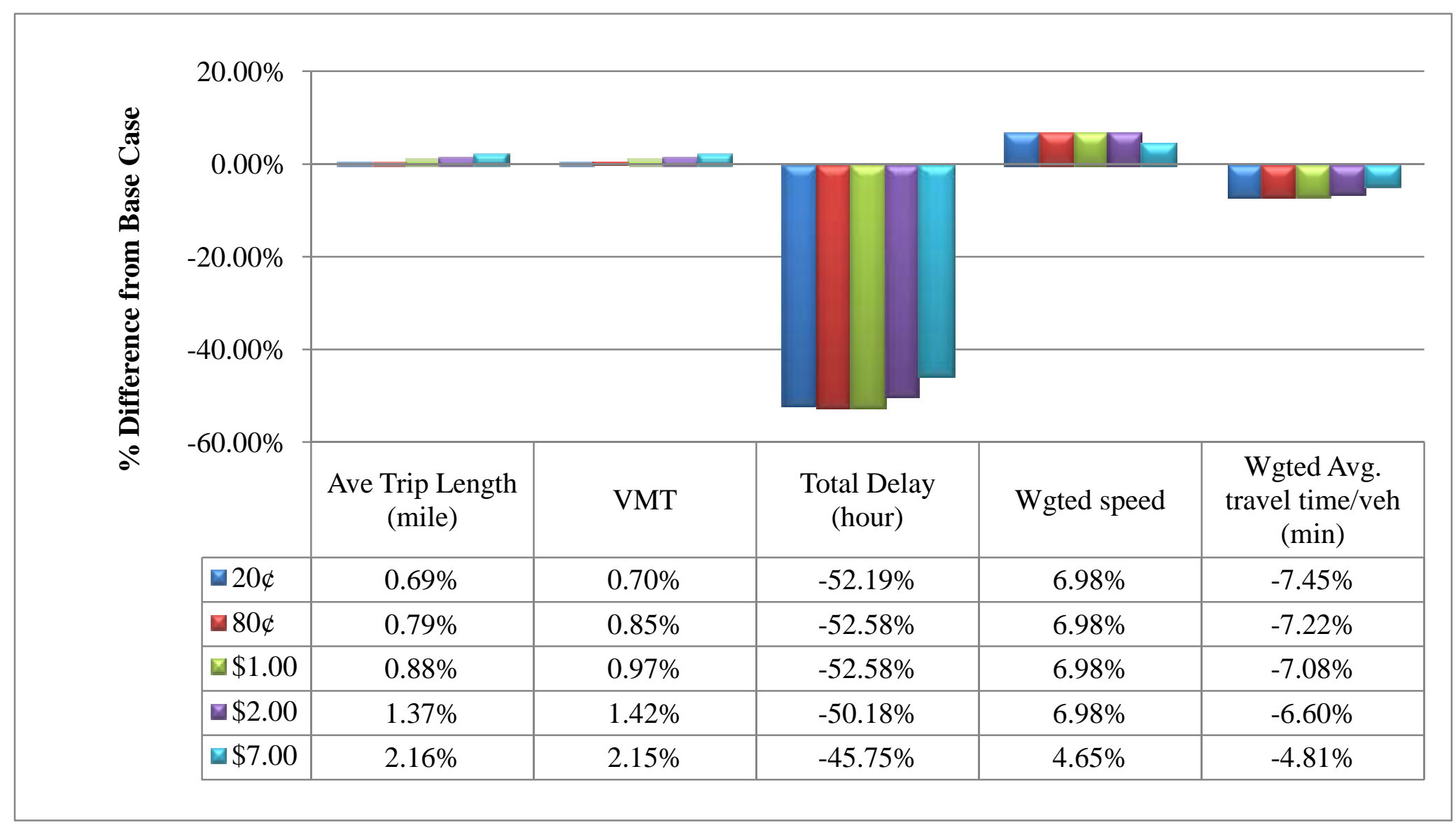

Figure 6.6 Percent difference on the entire network.

4:00 am - 10:00 am, Wednesday, May 7, 2008

(Only Pertinent to Traffic on Links within the Study Network 